Roberto Batista de Lima

\title{
ESTUDO DA ELETROOXIDAÇÃO DE ETILENO GLICOL E DE SEUS PRODUTOS DE OXIDAÇÃO PARCIAL EM ELETRODOS DE Pt E PtRu
}

Tese apresentada ao Instituto de Química de São Carlos, da Universidade de São Paulo, para obtenção do título de Doutor em Ciências Físico-Químicas.

Orientadora: Profa. Dra. Teresa Iwasita 


\section{DEDICATÓRIA}

A D. Eunice e Seu Josué, que sempre me orientaram a buscar o melhor, não importando o sacrifício e nem a distância. A minha adorada esposa Valéria por me amar e cuidar de mim. 


\section{AGRADECIMENTOS}

A Deus que proporcionou conforto e paz a minha alma.

À Professora Dr. ${ }^{\text {a }}$ Teresa Iwasita e ao Professor Wolf Vielstich pelas idéias e sugestões que ajudaram durante a realização deste trabalho.

Ao Prof. Dr. Francisco Carlos Nart (in memoriam) por auxiliar na conclusão deste trabalho.

Às minhas queridas irmãs, Vera e Lúcia, que deram todo o apoio para os meus estudos, ao meu cunhado Américo pelas conversas na sala do computador e ao Tino pelo relógio.

Ao Giuseppe por me ensinar a ter paciência.

Aos técnicos Janete, Jonas e Valdecir que sempre ajudaram no que puderam.

A Silvia e Andréa pela atenção e ajuda dispensadas.

Aos colegas de laboratório Bruno, Luis Gustavo, Daniela, Fábio Henrique, Camilo, Glauco, Eduardo, Érica, Márcia, Janildo, Hilton, as Janaínas (Garcia e Fernandes), os Flávios, Luciano, Elke pelos diferentes temas de conversa abordados na hora do café.

A FAPESP pela bolsa concedida.

Aos professores Edson Antônio Ticianelli, Germano Tremiliose Filho, Arthur de Jesus Moteo e Ernesto Rafael Gonzalez pelo conhecimento compartilhado nesses anos de pós-graduação.

Ao assessor da FAPESP pela leitura atenta dos relatórios. 


\section{RESUMO}

A eletrooxidação de etileno glicol e de seus produtos parciais de oxidação foram estudadas em eletrodos de Pt e eletrodos binários de PtRu, utilizando-se técnicas eletroquímicas fundamentais, espectroscopia de infravermelho por reflexão externa e cromatografia líquida de alta eficiência. Os resultados evidenciam um efeito catalítico na oxidação de etileno glicol com a quantidade de Ru no eletrodo até um máximo de corrente de $11 \mathrm{~mA} \mathrm{~cm}^{-2}$ entre $30 \%$ a $40 \%$ em Ru. Experimentos de espectroscopia de infravermelho in situ detectaram espécies adsorvidas, como o CO, e espécies residuais contendo dois átomos de carbono. Os produtos solúveis foram glicolaldeído, ácido glicólico e $\mathrm{CO}_{2}$. Bandas bipolares de $\mathrm{CO}$ indicam que o etileno glicol já está totalmente dissociado no potencial de referência $(0,05 \mathrm{~V}$ vs. RHE). Espécies contendo o grupo carbonila como o glicolaldeído também são observadas no potencial de referência $(0,05 \mathrm{~V}$ vs $\mathrm{RHE})$. A formação de $\mathrm{CO}_{2}$ é influenciada não só pela concentração do álcool em solução como também pela quantidade superficial de Ru no eletrodo. A eletrooxidação de ácido glicólico mostra a formação de $\mathrm{CO}_{2}$ a baixos potenciais (0,20 vs. RHE) e $\mathrm{CO}$ adsorvido a um potencial de $0,40 \mathrm{~V}$. 


\section{ABSTRACT}

The eletrooxidation of ethylene glycol and its partial oxidation products, glycolic acid and glycolaldehyde was studied on Pt and PtRu electrodes. Cyclic voltammetry and chronoamperometry were used for the electrochemical characterization. The nature of the reaction products and intermediates was studied by in situ Fourier transform infrared spectroscopy and high performance liquid chromatography.

The oxidation reaction is catalyzed by PtRu; the maximum current density observed was $11 \mu \mathrm{A} \mathrm{cm}^{-2}$ for a ruthenium content between $30 \%$ and $40 \%$. Adsorbed $\mathrm{CO}$ and residual species containing two carbon atoms as well as $\mathrm{CO}_{2}$ glycolaldehide and glycolic acid were detected by FTIR spectroscopy. Although the quantitative determination of glycolaldehyde was not possible, the results allowed an indirect estimation of this product, which starts to be formed already at $0.05 \mathrm{~V}$. It was found that glycolaldehyde is the main reaction product.

PtRu favors the scission of the C-C bond. Thus, much higher CO coverage was found at the alloy than at pure Pt. An increase in the amount of glycolaldehyde at PtRu indicates that this material also catalyzes the scission of the $\mathrm{C}-\mathrm{H}$ bond. This effect is probably due to an electronic modification of Pt caused by the presence of ruthenium, since pure Ru is not active for adsorbing or oxidizing ethylene glycol and much less Pt sites are available at PtRu. 


\section{LISTA DE FIGURAS}

Pág.

Figura 1 - Desenho esquemático mostrando a célula utilizada para os experimentos de espectroscopia de infravermelho...

Figura 2 - Célula eletroquímica com sistema de troca de solução, utilizada para estudar as espécies fortemente adsorvidas do etileno glicol.

Figura 3 - Célula eletroquímica utilizada para preparar as amostras a serem analisadas por cromatografia líquida.

Figura 4 - Voltamograma cíclico a $0,05 \mathrm{Vs}^{-1}$ para $0,1 \mathrm{M} \mathrm{C}_{2} \mathrm{H}_{6} \mathrm{O}_{2}+0,5 \mathrm{M}$ $\mathrm{H}_{2} \mathrm{SO}_{4}$ Pt. $A_{\text {real }}=2,0 \mathrm{~cm}^{2} . \mathrm{E}_{\mathrm{ad}}=0,05 \mathrm{~V} . \mathrm{T}=25^{\circ} \mathrm{C}$.

Figura 5 - Espectros de infravermelho para a oxidação de $0,1 \mathrm{M} \mathrm{C}_{2} \mathrm{H}_{6} \mathrm{O}_{2}+0,1$ $\mathrm{M} \mathrm{HClO}_{4}$ em Pt. $E_{\mathrm{ad}}=0,05 \mathrm{~V}$. Resolução: $8,0 \mathrm{~cm}^{-1}$. T=25 ํ․ Referência: 0,05 $\mathrm{V}$......

Figura 6 - Espectros de infravermelho para a oxidação de $0,1 \quad \mathrm{M} \mathrm{C}_{2} \mathrm{H}_{6} \mathrm{O}_{2}$ em $0,1 \mathrm{M} \mathrm{HClO}_{4}$. Eletrodo de Pt. Solvente $\mathrm{D}_{2} \mathrm{O} . \mathrm{E}_{\mathrm{ad}}=0,05 \mathrm{~V}$. Resolução: $8,0 \mathrm{~cm}^{-}$ 1. $\mathrm{T}=25^{\circ} \mathrm{C}$.

Figura 7 - Curvas potenciodinâmicas para a oxidação dos adsorbatos presentes na superfície do eletrodo de Pt. (a) 1aㅡ ciclo; (b) 2 ${ }^{\mathrm{a}}$ ciclo. $\mathrm{V}=10$ $\mathrm{mVs}^{-1} . \mathrm{E}_{\mathrm{as}}=0,05 \mathrm{~V}$. $\mathrm{T}=25^{\circ} \mathrm{C}$.

Figura 8 - Espectros de infravermelho para a oxidação dos adsorbatos em Pt após a adsorção de 0,02 M de EG e troca de solução com $\mathrm{HClO}_{4}$ 0,1 M (a) e (b) Intensidade das bandas de $\mathrm{CO}_{\mathrm{L}}$ e $\mathrm{CO}_{2} . \mathrm{E}_{\mathrm{ad}}=0,05 \mathrm{~V}$. $\mathrm{T}=25^{\circ} \mathrm{C}$. Espectro de referência $\mathrm{E}=0,05 \mathrm{~V}$.......

Figura 9 - Espectros de infravermelho para a oxidação dos adsorbatos do etileno glicol a 0,65 V; 0,95 V e 1,40 V. Eletrólito: 0,1 $\mathrm{M} \mathrm{HClO}_{4} \mathrm{E}_{\mathrm{ad}}=0,05 \mathrm{~V}$. $\mathrm{T}=25 \stackrel{\circ}{ } \mathrm{C}$. Resolução : $8 \mathrm{~cm}^{-1}$.

Figura 10 - Espectros de infravermelho para a oxidação dos adsorbatos em $\mathrm{Pt}$ após a adsorção de $0,02 \mathrm{M}$ de $E \mathrm{G}$ e troca de solução com $\mathrm{HClO}_{4} 0,1 \mathrm{M}$. $\mathrm{E}_{\mathrm{ad}}=$ $0,35 \mathrm{~V} . \mathrm{T}=25 \stackrel{\circ}{\circ} \mathrm{C}$. Resolução: $8,0 \mathrm{~cm}^{-1}$.

Figura 11 - Adsorbato proposto para a adsorção não dissociativa do etileno 
glicol em eletrodos de Pt policristalina.

Figura 12 - Adsorbato proposto para a adsorção não dissociativa do etileno glicol em eletrodos de Pt policristalina.

Figura 13 - Voltamogramas cíclicos nas ligas de PtRu em solução $0,1 \mathrm{M}$ $\mathrm{HClO}_{4} . \mathrm{V}=50 \mathrm{mVs}^{-1} . \mathrm{T}=25^{\circ} \mathrm{C}( \pm 1)$. Composição das ligas: (a) 80:20; (b) 70:30; (c) 60:40.

Figura 14 - Curvas de corrente-tempo para as ligas de PtRu como indicado. Solução $1,0 \mathrm{M} \mathrm{C}_{2} \mathrm{H}_{6} \mathrm{O}_{2}+0,5 \mathrm{M} \mathrm{H}_{2} \mathrm{SO}_{4} . \mathrm{E}=0,50 \mathrm{~V} . \mathrm{T}=25^{\circ} \mathrm{C}( \pm 1)$.

Figura 15 - Espectros de infravermelho em diferentes potenciais para eletrooxidação de etileno glicol na liga de Pt:Ru (70:30) e comparação da banda de $\mathrm{CO}_{\mathrm{L}}$ a $0,50 \mathrm{~V}$ vs $\mathrm{RHE}$ em ligas de $\mathrm{PtRu}$ de diferente composição. Solução: $1,0 \mathrm{M} \mathrm{C} \mathrm{C}_{6} \mathrm{H}_{2}+0,1 \mathrm{M} \mathrm{HClO}$. $\mathrm{E}_{\mathrm{ad}}=0,05 \mathrm{~V}$. $\mathrm{T}=25^{\circ}( \pm 1)$. Espectro de referência medido em $0,05 \mathrm{~V}$.

Figura 16 - Intensidade das bandas de $\mathrm{CO}$ e $\mathrm{CO}_{2}$ vs potencial para as ligas de PtRu. Solução: $1,0 \mathrm{M} \quad \mathrm{C}_{2} \mathrm{H}_{6} \mathrm{O}_{2}+0,1 \mathrm{M} \mathrm{HClO}_{4}$. $\mathrm{E}_{\mathrm{ad}}=0,05 \mathrm{~V}$. $\mathrm{T}=25^{\circ}( \pm 1)$.

Figura 17 - Intensidade normalizada da banda de $\mathrm{CO}_{2}$ vs tempo. Solução: $1,0 \mathrm{M} \mathrm{C}_{2} \mathrm{H}_{6} \mathrm{O}_{2}+0,1 \mathrm{M} \mathrm{HClO}_{4}$. $\mathrm{E}=0,50 \mathrm{~V}$.

Figura 18 - Espectros de infravermelho para PtRu (70:30). Solução: 1,0M $\mathrm{C}_{2} \mathrm{H}_{6} \mathrm{O}_{2}+0,1 \mathrm{M} \mathrm{HClO}_{4}$ em $\mathrm{D}_{2} \mathrm{O} . \mathrm{E}_{\mathrm{ad} .}=0,05 \mathrm{~V} . \mathrm{T}=25^{\circ}( \pm 1) . \mathrm{E}_{\text {ref. }}=0,05 \mathrm{~V}$.

Figura 19 - Espectros de infravermelho para eletrodos de Pt:Ru após 7 min. Solução: 1,0 $\mathrm{M} \mathrm{C}_{2} \mathrm{H}_{6} \mathrm{O}_{2}+0,1 \mathrm{M} \mathrm{HClO}_{4}$. $E=0,50 \mathrm{~V}$. $\mathrm{T}=25^{\circ}( \pm 1) . \mathrm{E}_{\mathrm{ad}}=0,05 \mathrm{~V}$.

Figura 20 - Quantidades em nmol $\mathrm{cm}^{2}$ para $\mathrm{CO}_{2}$ (a) e para o ácido (b) em função da variação da concentração de etileno glicol no eletrodo de $\mathrm{Pt}$ e de PtRu (70:30). $E_{a d}=0,05$ V. T= 5 min

Figura 21 - Dependência da corrente de oxidação de $1,0 \mathrm{~mol} \mathrm{~L}^{-1}+0,5 \mathrm{~mol} \mathrm{~L}^{-1}$ $\mathrm{H}_{2} \mathrm{SO}_{4}$ com a composição do eletrodo. Potencial: $0,5 \mathrm{~V}$. Dados obtidos a 60 $\min$.

Figura 22 - Cromatogramas obtidos para os diferentes produtos de oxidação parcial estudados. Detector: Índice de refração.

Figura 23 - Valores de corrente em função da concentração de $\mathrm{C}_{2} \mathrm{H}_{6} \mathrm{O}_{2}$ após a eletrólise de $20 \mathrm{~min}$. $\mathrm{E}=0,50 \mathrm{~V}$. $\mathrm{T}=25^{\circ} \mathrm{C}$.

Figura 24 - Quantidades em nmol normalizadas por $\mathrm{cm}^{2}$ de área real de Acido glicólico após a eletrólise de 20 min para diferentes concentrações de EG em $1,0 \mathrm{M} \mathrm{HClO}_{4}$ sobre eletrodos de Pt e Pt:Ru. $\mathrm{E}=0,50 \mathrm{~V}$. T=25 $\stackrel{\circ}{\mathrm{C}}$. Erro $<5 \% \ldots$. 
Figura 25 - Esquema proposto para a eletrooxidação de etileno glicol sobre eletrodos de Pt e PtRu.

Figura 26 - Curvas corrente vs tempo para a oxidação do etileno glicol $(0,1 \mathrm{M})$ e dos seus produtos parciais de oxidação $(0,1 \mathrm{M})$. $\mathrm{E}=0,50 \mathrm{~V}$. $\mathrm{T}=25^{\circ} \mathrm{C}$.

Figura 27 - Curva corrente vs potencial a $0,01 \mathrm{Vs}^{-1}$ para $0,1 \mathrm{M} \mathrm{C}_{2} \mathrm{H}_{4} \mathrm{O}_{2}+0,1 \mathrm{M}$ $\mathrm{HClO}_{4}$ em Pt. $E_{a d}=0,05$ V. T=25ㄷ $( \pm 1)$.

Figura 28 - Espectros de infravermelho para a oxidação $0,1 \mathrm{M}$ glicolaldeído em $0,1 \mathrm{M} \mathrm{HClO}_{4}$. Eletrodo de Pt. $\mathrm{E}_{\mathrm{ad}}=0,05 \mathrm{~V}$. Resolução: $8,0 \mathrm{~cm}^{-1} . \mathrm{T}=25^{\circ} \mathrm{C} \ldots$.

Figura 29 - Espectros de infravermelho para a oxidação das espécies adsorvidas de glicolaldeído sobre eletrodo de Pt policristalina. $E_{a d}=0,05 \mathrm{~V}$. Resolução: $8,0 \mathrm{~cm}^{-1}$. T=25 ${ }^{\circ} \mathrm{C}$. $\mathrm{E}_{\text {ref. }}=0,05 \mathrm{~V}$.

Figura 30 - Adsorbatos postulados para a adsorção não dissociativa do glicolaldeído em eletrodos de Pt policristalina.

Figura 31 - Espectros de infravermelho para a eletrooxidação de glicolaldeído em função do potencial na liga de Pt:Ru (80:20). Solução: 0,1 $\mathrm{M} \mathrm{C}_{2} \mathrm{H}_{4} \mathrm{O}_{2}+$ $0,1 \mathrm{M} \mathrm{HClO}_{4}$. $\mathrm{E}_{\mathrm{ad}}=0,05 \mathrm{~V}$. T=25(1). Resolução: $8,0 \mathrm{~cm}^{-1}$.

Figura 32 - Espectros de infravermelho para a eletrooxidação de $\mathrm{C}_{2} \mathrm{H}_{4} \mathrm{O}_{2}$ a 0,80 V para Pt:Ru (70:30).Luz polarizada-p e luz polarizada-s. Resolução: 8,0 $\mathrm{cm}^{-1} \cdot \mathrm{T}=25^{\circ}( \pm 1)$

Figura 33 - Intensidade da banda de $\mathrm{CO}$ (a) e $\mathrm{CO}_{2}$ (b) vs potencial para os eletrodos de Pt e PtRu. Solução: $0,1 \mathrm{M} \mathrm{C}_{2} \mathrm{H}_{4} \mathrm{O}_{2}+0,1 \mathrm{M} \mathrm{HClO}_{4}$. $\mathrm{E}_{\mathrm{ad}}=0,05 \mathrm{~V}$. $\mathrm{T}=25^{\circ}( \pm 1)$

Figura 34 - Curvas corrente versus tempo (a) e cromatogramas (b) obtidos após a eletrooxidação de glicolaldeído $0,10 \mathrm{M} \mathrm{C}_{2} \mathrm{H}_{4} \mathrm{O}_{2}+1,0 \mathrm{M} \mathrm{HClO}{ }_{4}$ em eletrodo de Pt em diferentes potenciais. $\mathrm{E}_{\mathrm{ad}}=0,05 \mathrm{~V}$. $\mathrm{T}=25^{\circ} \mathrm{C}$. Detector: diodo $(220 \mathrm{~nm})$.

Figura 35 - Quantidades em nmol de ácido glicólico e $\mathrm{CO}_{2}$ após a eletrólise de 20 min para $0,1 \mathrm{C}_{2} \mathrm{H}_{4} \mathrm{O}_{2}+1,0 \mathrm{M} \mathrm{HClO}_{4}$ sobre eletrodos de Pt. $\mathrm{T}=25{ }^{\circ} \mathrm{C} \ldots \ldots .$.

Figura 36 - Curvas corrente versus tempo (a) e cromatogramas (b) obtidos após a eletrooxidação de $0,10 \mathrm{M}$ glicolaldeído em $\mathrm{HClO}_{4}(1,0 \mathrm{M})$ em eletrodo de Pt:Ru (72:28). $\mathrm{E}_{\mathrm{ad}}=0,05 \mathrm{~V} . \mathrm{T}=25^{\circ} \mathrm{C}$. Detector: diodo $(220 \mathrm{~nm})$.

Figura 37 - Quantidades normalizadas pela área real em nmol de ácido glicólico e $\mathrm{CO}_{2}$ após a eletrólise de 20 min para $0,1 \mathrm{C}_{2} \mathrm{H}_{4} \mathrm{O}_{2}+1,0 \mathrm{M} \mathrm{HClO}{ }_{4}$ sobre eletrodos de PtRu (72:28) em diferentes potenciais.

Figura 38 - Esquema proposto para a eletrooxidação de glicolaldeído sobre eletrodos de Pt e PtRu..... 
Figura 39 - Voltamograma cíclico para a oxidação de ácido glicólico $(0,1 \mathrm{M})$ em meio de $\mathrm{HClO}_{4}(0,1 \mathrm{M})$ em eletrodo de $\mathrm{Pt} . \mathrm{V}=0,01 \mathrm{Vs}^{-1}$. T=25 ${ }^{\circ} \mathrm{C}$..

Figura 40 - Espectros de infravermelho para a eletrooxidação de ácido glicólico em função do potencial em Pt. Solução: $0,1 \mathrm{M} \mathrm{C}_{2} \mathrm{H}_{4} \mathrm{O}_{3}+0,1 \mathrm{M} \mathrm{HClO}_{4}$. $\mathrm{E}_{\mathrm{ad} .}=0,05 \mathrm{~V} . \mathrm{T}=25^{\circ}( \pm 1)$. Resolução: $8,0 \mathrm{~cm}^{-1}$. $\mathrm{E}_{\mathrm{ref} .}=0,05 \mathrm{~V}$

Figura 41 - Intensidade da banda de $\mathrm{CO}$ e $\mathrm{CO}_{2}$ vs potencial para o eletrodo de Pt. Solução: $0,1 \mathrm{M} \mathrm{C}_{2} \mathrm{H}_{4} \mathrm{O}_{3}+0,1 \mathrm{M} \mathrm{HClO}_{4}$. $\mathrm{E}_{\mathrm{ad}}=0,05 \mathrm{~V}$. $\mathrm{T}=25^{\circ}( \pm 1)$.

Figura 42 - Espectros de infravermelho para eletrooxidação de ácido glicólico em função do potencial em Pt:Ru (80:20). Solução: $1,0 \mathrm{M} \mathrm{C}_{2} \mathrm{H}_{4} \mathrm{O}_{3}+0,1 \mathrm{M}$ $\mathrm{HClO}_{4} . \mathrm{E}_{\mathrm{ad}}=0,05 \mathrm{~V} \cdot \mathrm{T}=25^{\circ}( \pm 1)$. Resolução: $8,0 \mathrm{~cm}^{-1}$

Figura 43 - Curvas corrente versus tempo (a) e cromatogramas (b) obtidos após a eletrooxidação de $0,10 \mathrm{M} \mathrm{C}_{2} \mathrm{H}_{4} \mathrm{O}_{3}+1,0 \mathrm{M} \mathrm{HClO}_{4}$ em eletrodo de Pt:Ru (83:17). $\mathrm{E}_{\mathrm{ad}}=0,05 \mathrm{~V} \cdot \mathrm{T}=25^{\circ} \mathrm{C}$. Detector: diodo $(220 \mathrm{~nm})$

Figura 44 - Esquema proposto para a eletrooxidação de ácido glicólico sobre eletrodos de Pt e Pt:Ru 


\section{LISTA DE TABELAS}

Tabela 1 - Valores de Entalpia e Energia Livre padrões para a reação de combustão dos álcoois e potencial padrão do eletrodo.........

Tabela 2 - Valor de freqüência e coeficiente de absorção molar para $\mathrm{CO}_{2} \mathrm{e}$ ácido glicólico.

Tabela 3 - Atribuição das freqüências para o ácido carboxílico....................... 57

Tabela 4 - Atribuição das freqüências para as bandas dos adsorbatos do glicolaldeído 


\section{LISTA DE ABREVIATURAS}

FTIR - Fourier Transform Infrared Spectroscopy

F - Constante de Faraday

PM - Peso Molecular

$\Delta \mathrm{H}^{\circ} \mathrm{C}-$ Variação da entalpia de combustão padrão

$\Delta \mathrm{G}^{\circ}{ }_{\mathrm{C}}$ - Variação da energia de Gibbs de combustão padrão

ㅌo - Potencial padrão da reação

EDX - Espectroscopia de Dispersiva de Raios-X

CLAE - Cromatografia Líquida de Alta Eficiência 


\section{SUMÁRIO}

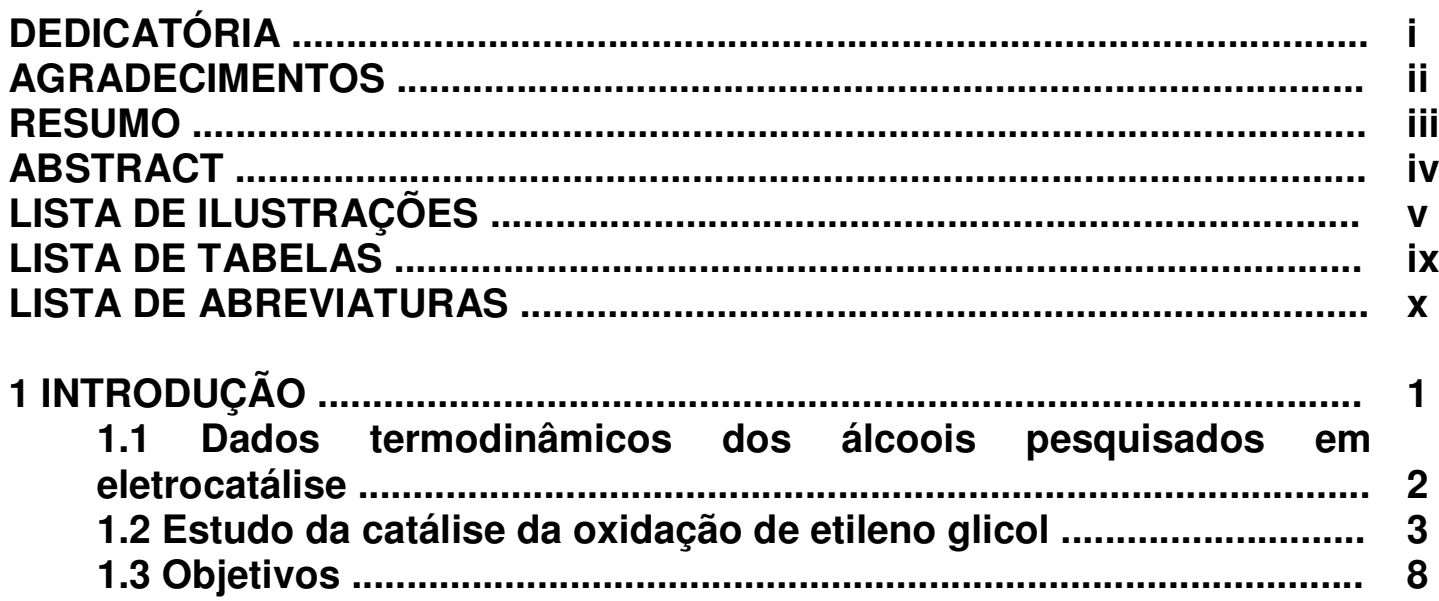

2 PARTE EXPERIMENTAL ….............................................................. 9

2.1 Reagentes utilizados ..................................................................... 9

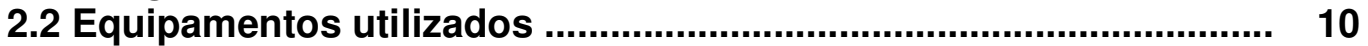

2.3 Eletrodos .................................................................................. 10

2.4 Temperatura ..................................................................... 11

2.5 Procedimentos experimentais ................................................. 11

2.5.1 Preparação dos eletrodos de Pt e PtRu utilizados nas medidas de infravermelho

2.5.2 Preparação dos eletrodepósitos de Pt e PtRu ....................... 12

2.5.3 Método de normalização para as áreas ativas dos eletrodos de trabalho

2.5.4 Medidas de espectroscopia de infravermelho in-situ ...

2.5.5 Medidas de oxidação de resíduos fortemente adsorvidos .........

2.5.6 Medidas de Cromatografia Líquida de Alta Eficiência

\section{1} 2

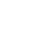

1

11

3 RESULTADOS EXPERIMENTAIS ......................................................... 19

3.1 Eletrooxidação de etileno glicol em eletrodos de $\mathrm{Pt}$..................... 19

3.1.1 Análise dos produtos de oxidação do etileno glicol por espectroscopia de infravermelho .....................................................

3.1.2 Análise dos adsorbatos presentes nos eletrodos de Pt........... 24

3.1.3 Análise dos adsorbatos do etileno glicol por espectroscopia de infravermelho

3.1.4 Possíveis espécies adsorvidas detectadas por espectroscopia de infravermelho

3.2 Catálise da oxidação de etileno glicol em eletrodos de PtRu ........ 32

3.2.1 Análise dos produtos de oxidação de etileno glicol por espectroscopia de infravermelho nas ligas de PtRu

3.2.2 O efeito da concentração de etileno glicol nas vias de reação . 43

3.2.3 O efeito da composição dos eletrodos de PtRu na corrente de oxidação 
3.3 Resumo dos resultados de espectroscopia de infravermelho ...... 3.4 Identificação dos produtos parciais de oxidação por cromatografia líquida de alta eficiência (CLAE) ..................................

3.4.1 Estimativa das porcentagens de glicolaldeído e $\mathrm{CO}_{2}$ formados......

3.5 Provável esquema de reação

3.6 Eletrooxidação dos produtos parciais de oxidação do etileno glicol em eletrodos de Pt e PtRu.

3.6.1 Eletrooxidação de Glicolaldeído em eletrodos de Pt e PtRu .....

3.6.2 Análise dos produtos formados durante a adsorção e oxidação do glicolaldeído

3.6.3 Estudos das espécies fortemente adsorvidas do glicolaldeído..

3.6.4 Estudo das espécies formadas na oxidação de glicolaldeído em eletrodos de PtRu

3.6.5 Análise dos produtos solúveis da oxidação de glicolaldeído em Pt por cromatografia líquida de alta eficiência.

3.6.6 Análise por cromatografia líquida dos produtos formados durante a eletrooxidação do glicolaldeído em eletrodos de PtRu.......

3.6.7 Provável esquema de reação para a oxidação de glicolaldeído

3.7 Eletrooxidação de ácido glicólico em eletrodos de platina policristalina e PtRu

3.7.1 Eletrooxidação de ácido glicólico em eletrodos de $\mathrm{Pt}$

3.7.2 Estudo dos produtos de oxidação do ácido glicólico por espectroscopia de infravermelho....

3.7.3 Estudo dos produtos de oxidação do ácido glicólico por cromatografia líquida

3.7.4 Provável esquema de reação para a oxidação de ácido glicólico em eletrodos de Pt e PtRu 


\section{INTRODUÇÃO}

A eletrooxidação de álcoois de baixo peso molecular tais como metanol, etanol e mais recentemente o etileno glicol tem se tornado alvo de atenção para a eletrocatálise. Tal interesse é justificado pela crescente procura de novos sistemas conversores de energia, mais eficientes e menos poluidores. Mais especificamente, essas substâncias orgânicas são consideradas potencialmente ativas para alimentar células a combustível.

No estudo da eletrooxidação dessas pequenas moléculas orgânicas, utiliza-se platina como principal catalisador, porém, seu uso isolado tem se mostrado pouco eficiente porque intermediários da reação, como o CO, ficam fortemente adsorvidos nos sítios ativos da platina, inibindo assim o prosseguimento da reação. Para que haja a remoção desses adsorbatos, é necessária a participação de espécies oxigenadas na superfície do catalisador. Essas espécies funcionam como doadores de oxigênio para intermediários como o $\mathrm{CO}$, levando assim à produção de $\mathrm{CO}_{2}$. Entretanto, em Pt pura, a formação de tais espécies a partir da água só ocorre em potenciais relativamente altos $(>0,5 \mathrm{~V})$. Um catalisador apropriado para oxidar os resíduos adsorvidos pode ser formado misturando-se a platina com um outro metal, formando-se assim um eletrodo binário. Esse metal adsorveria, a baixos potenciais, espécies oxigenadas, as reagiriam com CO adsorvido na superfície do catalisador, produzindo $\mathrm{CO}_{2}$ como produto final dessa reação. Dentre os metais utilizados para esse fim pode-se citar: Ru, Pd, Rh, Sn [1-4]. 
Além dos adsorbatos, a reação de oxidação de álcoois leva também à formação de intermediários ou produtos solúveis, produzidos através de mecanismos ainda não conhecidos. Também a influência da composição do catalisador nas diferentes vias de reação é um ponto ainda não muito esclarecido na literatura e mereceria mais atenção em estudos futuros.

\subsection{Dados termodinâmicos dos álcoois pesquisados em eletrocatálise}

Nos estudos de eletrocatálise, os álcoois de baixo peso molecular têm sido estudados como uma fonte de energia alternativa. Esses álcoois possuem algumas características importantes: eles podem ser produzidos a partir da biomassa, possuem uma alta densidade elétrica, podem ser manuseados, estocados e transportados [5]. Na Tabela 1 são apresentados os valores de $\Delta \mathrm{H}^{\circ} \mathrm{C}, \Delta \mathrm{G}{ }^{\circ} \mathrm{c}$ para a reação de combustão e $\mathrm{E}^{\circ}$ potencial padrão do eletrodo de alguns álcoois utilizados.

Tabela 1 - Valores de Entalpia e Energia Livre padrões para a reação de combustão dos álcoois e potencial padrão do eletrodo.

\begin{tabular}{|l|c|c|c|}
\hline \multicolumn{1}{|c|}{ Composto } & $\Delta \mathrm{H}^{\circ}{ }^{\circ} \mathrm{C}\left(\mathrm{kJmol}^{-1}\right)$ & $\Delta \mathrm{G}^{\circ}{ }^{\circ}\left(\mathrm{kJmol}^{-1}\right)$ & $\mathrm{E}^{\circ}(\mathrm{mV})$ \\
\hline Metanol $\left(\mathrm{CH}_{3} \mathrm{OH}\right)$ & $-725,65$ & $-701,69$ & 18 \\
\hline Etanol $\left(\mathrm{CH}_{3} \mathrm{CH}_{2} \mathrm{OH}\right)$ & $-1364,5$ & $-1324,09$ & 90 \\
\hline Etileno Glicol $\left(\mathrm{HOCH}_{2} \mathrm{CH}_{2} \mathrm{OH}\right)$ & $-1188,5$ & $-1175,9$ & 10 \\
\hline
\end{tabular}

Mediante a comparação do etileno glicol com os outros álcoois, pode-se observar que os valores de $\Delta \mathrm{H}^{\circ}{ }_{\mathrm{C}}$ e $\Delta \mathrm{G}^{\circ} \mathrm{C}$ são aproximadamente 1,6 vezes maiores que os do metanol e seu potencial padrão é comparável ao do metanol. No entanto, se comparado com o etanol, os valores de $\Delta \mathrm{H}^{\circ}{ }_{\mathrm{C}}$ e $\Delta \mathrm{G}^{\circ}{ }_{\mathrm{C}}$ são da mesma ordem $\mathrm{e}$ 
seu potencial padrão é menor. Assim, considera-se que suas características colocam o etileno glicol em uma posição comparável à dos álcoois candidatos a serem usados em células a combustível.

\subsection{Estudo da catálise da oxidação de etileno glicol}

Uma das maiores dificuldades encontradas até momento no estudo da catálise da oxidação de álcoois de cadeia pequena como o etileno glicol é a ruptura da ligação C-C da molécula. Esse processo é necessário para produzir a oxidação total da molécula do álcool para $\mathrm{CO}_{2}$, o que corresponderia ao rendimento energético máximo.

A reação de oxidação de etileno glicol libera 10 e- por molécula :

$$
\mathrm{C}_{2} \mathrm{H}_{6} \mathrm{O}_{2}+2 \mathrm{H}_{2} \mathrm{O} \longrightarrow 2 \mathrm{CO}_{2}+10 \mathrm{H}^{+}+10 \mathrm{e}^{-}
$$

No entanto, a oxidação do etileno glicol pode ocorrer por vias paralelas de reação, conduzindo a outros produtos, conforme como pode ser visto no seguinte esquema de reações:

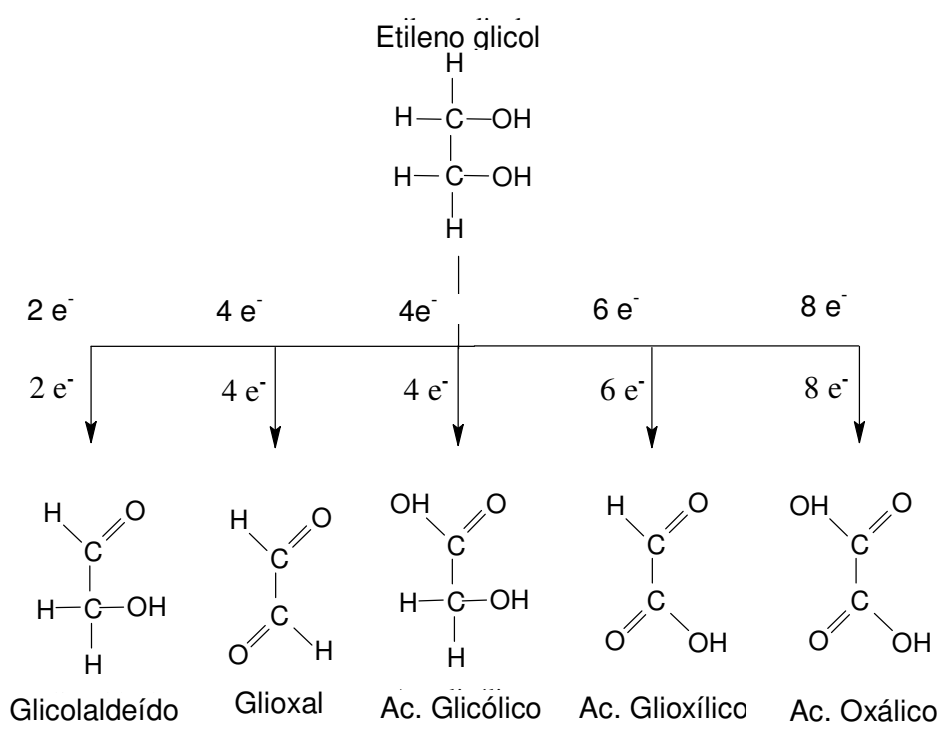


A formação destes produtos de oxidação incompleta diminui a densidade de energia do álcool.

Christensen e Hamnet [6] estudaram a eletrooxidação de etileno glicol tanto em meio ácido como básico, utilizando a técnica de voltametria cíclica em conjunto com a espectroscopia de infravermelho em eletrodos de platina lisa. Os autores sugeriram dois caminhos possíveis para a eletrooxidação do etileno glicol: em meio ácido, a via preferencial daria como produto final $\mathrm{CO}_{2}$, enquanto o produto final da via paralela seria o ácido etileno glicólico; em meio básico, o produto da via preferencial seria $\mathrm{CO}_{3}{ }^{-2}$, enquanto a via paralela daria como produto final o oxalato.

Weaver e colaboradores [7], utilizando a técnica de voltametria cíclica e espectroscopia de infravermelho, estudaram a eletrooxidação de etileno glicol em eletrodos policristalinos de platina, ouro e níquel em meio alcalino. Em ouro, os autores sugeriram a partir dos espectros de infravermelho obtidos a possível formação de glicolato, glioxal, glioxalato e oxalato. Em platina, os referidos autores sugeriram a formação de intermediários como glicolato, oxalato e produtos como o carbonato. A formação de carbonato indicaria a ruptura da ligação $\mathrm{C}-\mathrm{C}$. Os produtos de reação em eletrodos de níquel foram glicolato, glioxal.

Ureta-Zañartu et. al. [8] estudaram a oxidação de etileno glicol em eletrodepósitos de Pt, Pt-Pb e Pt-Ir em substratos de titânio em meio ácido, pela técnica de voltametria cíclica. Os autores observaram baixa atividade em todos os materiais. Contudo, foram observadas diferenças de atividades catalíticas entre os eletrodos. O eletrodo de Pt-Ir apresentou o melhor desempenho na corrente. Os autores atribuíram esta performance à capacidade do irídio de formar espécies oxigenadas. 
Kaleidopolou et al. [9] estudaram a eletrooxidação de etileno glicol em depósitos de Pt-Ru, Pt-Sn e Pt-Ru-Sn dispersos em polianilina sobre substratos de carbono vítreo. Nesse trabalho, observaram-se diferenças na atividade catalítica através das respostas corrente-tempo a um potencial constante de $0,65 \mathrm{~V}$. Os autores obtiveram uma maior estabilidade da corrente no eletrodo de Pt-Sn, pois para esse eletrodo ocorreu uma perda de $23 \%$ na densidade de corrente após 10 min de oxidação, enquanto nos outros eletrodos essa perda chegou a 49\%.

Lebedeva et. al. [10] estudaram o efeito da microestrutura de eletrodos de Pt suportados em grafite na oxidação de etileno glicol em $\mathrm{Na}_{2} \mathrm{SO}_{4}$. Os autores observaram que os eletrodos suportados eram mais estáveis ao envenenamento por espécies adsorvidas e que os efeitos da microestrutura eram mais pronunciados na região compreendida entre os potenciais de $0,3 \mathrm{~V}$ e $0,9 \mathrm{~V}$.

Kardigan et al. [11] estudaram a influência de diferentes metais modificando a superfície de Pt em meio ácido, utilizando a técnica de voltametria cíclica. Foram estudados eletrodos binários com as seguintes composições: Pt-Cd, Pt-Re, Pt-Pb, Pt-Cu, Pt-Bi e Pt-Tl. Observou-se que os eletrodos de Pt-Cd apresentaram um valor de corrente 5 vezes maior do que a Pt pura, enquanto para os eletrodos de Pt-Re a corrente foi 4 vezes maior. Os eletrodos contendo $\mathrm{Pb}$ não tiveram nenhum efeito catalítico sobre a eletrooxidação do etileno glicol, e os eletrodos de Pt-Cu, Pt-Bi e PtTI tiveram um efeito fortemente inibidor.

Em um trabalho utilizando eletrodos monocristalinos de Pt, Weaver et al. [12] estudaram a oxidação de etileno glicol em Pt(111) modificado com átomos de Bi em meio de $\mathrm{HClO}_{4}$ a $0,1 \mathrm{M}$. Os autores observaram que a presença de $\mathrm{Bi}$ na superfície do catalisador deslocava o início da oxidação do álcool cerca de 0,10 V vs SCE para potenciais mais altos quando esse é comparado à $\operatorname{Pt}(111)$ sem modificação. 
Contudo, maiores quantidades de $\mathrm{CO}_{2}$ e menores quantidades de ácido oxálico foram observadas usando a técnica de infravermelho in situ para o eletrodo modificado com Bi.

Além das técnicas eletroquímicas convencionais e da espectroscopia de infravermelho, também a cromatografia foi utilizada no estudo da eletrooxidação de etileno glicol para a identificação dos produtos de reação. Dailey et al [13] estudaram a eletrooxidação de etileno glicol em Pt (111). Após 6 min de eletrólise no eletrodo monocristalino de platina $0,60 \mathrm{~V}$, os autores conseguiram determinar o glicolaldeído via reação com dinitrofenilhidrazina e, por cromatografia líquida, o ácido glicólico como produtos da eletrooxidação do etileno glicol. Em outro trabalho utilizando a técnica de cromatografia, Cherstiouk et al. [14] estudaram os produtos de oxidação do etileno glicol em meio ácido sobre eletrodos de $\mathrm{Pt}$ platinizada. Os autores encontraram como produtos parciais de oxidação tais substâncias: glicolaldeído, ácido glicólico, formaldeído e ácido fórmico.

Mais recentemente, Lima et. al [15] estudaram a influência do conteúdo de Ru em eletrodepósitos de Pt:Ru e em eletrodos de Pt:Ru suportados em carbono na eletrooxidação de etileno glicol. Utilizando técnicas eletroquímicas fundamentais e espectroscopia de infravermelho, observou-se um aumento da corrente com o aumento de conteúdo de $\mathrm{Ru}$ até $\theta_{\mathrm{Ru}}=0,3$ nos eletrodepósitos. Espectros de infravermelho coletados em $500 \mathrm{mV}$ durante $6 \mathrm{~min}$ indicou uma maior quantidade de $\mathrm{CO}_{2}$ em eletrodos com $18 \%$ em $\mathrm{Ru}$ do que no eletrodo com $42 \%$ em $\mathrm{Ru}$. As observações levam a supor que o Ru estaria aumentando a velocidade de reação de uma via paralela que levaria a outros produtos que necessitassem de espécies oxigenadas adsorvidas para se formar, como, por exemplo, o ácido glicólico. A.O. Neto et al. [16] estudaram a eletrooxidação de etileno glicol em eletrodos binários de 
PtRu e PtSn e ternários de PtRuSn suportados em carbono em meio de $\mathrm{H}_{2} \mathrm{SO}_{4}(0,50$ M). Os resultados de varredura linear a $0,010 \mathrm{Vs}^{-1}$ apresentaram como melhor catalisador o eletrodo de PtSn, que exibia uma corrente de oxidação já a potenciais próximos de 0,20 V. Os resultados de cronoamperometria apresentaram uma corrente próxima de $2,5 \mathrm{~A} \mathrm{gPt}^{-1}$.

As vias de reação do etileno glicol foram estudadas utilizando também a espectroscopia eletroquímica de massa diferencial (DEMS). Behm e colaboradores [17] estudaram a formação de $\mathrm{CO}_{2}$ gerada durante a oxidação do etileno glicol em eletrodos de $\mathrm{Pt}, \mathrm{Pt}: \mathrm{Ru}$ e $\mathrm{Pt}_{3} \mathrm{Sn}$ dispersos em carbono em meio ácido. O estudo foi feito pela adsorção do etileno glicol em diferentes potenciais, e os autores observaram uma diminuição do sinal $\mathrm{CO}_{2}(\mathrm{~m} / \mathrm{z}=44)$ a potenciais de $0,36 \mathrm{~V}$ para o eletrodo de $\mathrm{Pt}_{3} \mathrm{Sn}$ eletrodo de Pt. No eletrodo de Pt:Ru a diminuição foi observada a potenciais acima de $0,26 \mathrm{~V}$.

Em estudos em células a combustível, o etileno glicol vem sendo testado como uma alternativa em substituição ao hidrogênio. Peled e colaboradores [18] estudaram a densidade de potência produzida por uma célula unitária usando uma membrana trocadora de prótons nanoporosa (NP-PCM) e eletrodos de Pt:Ru (50:50) E-TEK. Durante a operação da célula, os autores circularam junto com o álcool (1,5

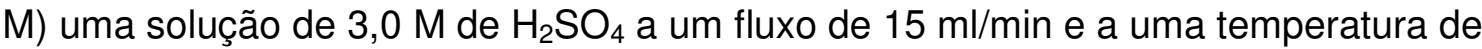
operação de $130 \stackrel{\circ}{\circ}$. Nestas condições experimentais a densidade de potencia obtida foi de $300 \mathrm{~mW} \mathrm{~cm}^{-2}$.

Como pode ser apreendido dos trabalhos citados acima, os dados obtidos na literatura sobre a reação de eletrooxidação de etileno glicol e de seus produtos parciais de oxidação são, por vezes, incompletos e contraditórios. Portanto, não é possível estabelecer com certeza quais seriam os produtos da reação de 
eletrooxidação do álcool ou quais adsorbatos são formados durante a sua dissociação na superfície do catalisador. Assim por meio dessas informações faz-se necessário um estudo sistemático que leve a conclusões mais precisas sobre a eletrooxidação do etileno glicol e de seus produtos de oxidação.

\subsection{Objetivos}

O presente trabalho tem por objetivo estudar a reação de oxidação do etileno glicol e de seus produtos de oxidação parcial em eletrodos de Pt e em ligas e eletrodepósitos PtRu. Utilizando-se a técnica de espectroscopia de infravermelho por refletância externa, pretende-se estabelecer a natureza dos adsorbatos parcialmente dissociados na superfície dos eletrodos, além dos produtos solúveis provenientes de reações paralelas de cada uma das substâncias. A quantificação dos produtos solúveis de reação será realizada por meio da técnica de cromatografia líquida de alta eficiência. A técnica de espectrometria de massa diferencial auxiliará na detecção de produtos voláteis que não possam ser observados nos espectros de infravermelho. 


\section{PARTE EXPERIMENTAL}

\subsection{Reagentes utilizados}

Todas as soluções foram preparadas com água deionizada (milli-Q), exceto quando foi utilizada água deuterada; nesse caso, as soluções foram preparadas com $\mathrm{D}_{2} \mathrm{O}$ Aldrich (99\% D).

Para a preparação das soluções de eletrólito suporte foram usados: ácido perclórico 70\% J. T. Baker PA e, ácido sulfúrico Mallinckrodt PA.

As soluções contendo as substâncias orgânicas foram preparadadas utilizando:

Etileno Glicol (98\%) Mallinckrodt PA-ACS;

Glicolaldeído (98\%) Fluka PA-ACS;

Glioxal Avocado (40\%) PA-ACS;

Ácido glicólico (98\%) e Ácido glioxílico (98\%) Alfa Aesar PA-ACS;

Ácido Oxálico (99\%) Acros PA-ACS.

Para purgar as soluções foi utilizado $\mathrm{N}_{2} 5,0$ ou Ar 5,0 da White Martins. 


\subsection{Equipamentos utilizados}

As medidas eletroquímicas de voltametria cíclica e cronoamperometria foram feitas utilizando um potenciostato Solartron SI 1287.

Para os experimentos de espectroscopia de infravermelho foi utilizado um espectrômetro de infravermelho com transformada de Fourier Nicolet modelo Nexus 670, com um detector MCT (telureto de cádmio e mercúrio). O controle de potencial foi feito utilizando um potenciostato Wenking POS 73 e um gerador de funções Prodis $1 / 161$.

As análises de cromatografia líquida foram feitas em um cromatógrafo Shimadzu LC-10AD VP com uma coluna de troca iônica, HPX-87H, Bio Rad.

\subsection{Eletrodos}

Neste trabalho foram utilizados dois tipos de eletrodos: para as medidas de espectroscopia de infravermelho foram utilizados discos polidos de Pt policristalina lisa com $1,0 \mathrm{~cm}$ de diâmetro e ligas metalúrgicas de $\mathrm{Pt}: \mathrm{Ru}$ com diferentes composições, com 0,6 cm de diâmetro, fornecidas por Johnson Matthey. Para os demais experimentos foram utilizados eletrodepósitos de Pt e PtRu depositados sobre substratos de Au.

Todos os potenciais são referidos ao eletrodo reversível de hidrogênio $(E R H)$, preparado com a mesma solução utilizada como eletrólito suporte. 


\subsection{Temperatura}

Todos os experimentos foram realizados em temperatura ambiente, a qual variou entre 24 e $27^{\circ} \mathrm{C}$.

\subsection{Procedimentos experimentais}

2.5.1 Preparação dos eletrodos de Pt e PtRu utilizados nas medidas de infravermelho

A superfície do eletrodo de Pt foi tratada em chama de hidrogênio por um período de 5,0 min; em seguida, o eletrodo foi resfriado em atmosfera inerte de nitrogênio e hidrogênio. A caracterização da superfície foi realizada utilizando-se a técnica de voltametria cíclica.

As ligas comerciais de PtRu foram preparadas polindo-se a superfície dos eletrodos com pasta de diamante de 1,0 $\mu \mathrm{m}$ por 1,0 min para a remoção de camadas de óxido superficiais, já que esses óxidos podem interferir na adsorção da molécula de etileno glicol. Após o polimento, os resíduos produzidos foram removidos utilizando-se acetona, etanol e água em abundância. Após essa limpeza inicial, os eletrodos foram imersos em uma solução de $\mathrm{HClO}_{4} 0,1 \mathrm{molL}^{-1}$ e levados ao ultrasom por 10 min. Após passar pelo ultrasom, os eletrodos de trabalho foram submetidos a um potencial constante de $-0,30 \mathrm{~V}$ por $30 \mathrm{~min}$ para a redução dos óxidos superficiais residuais. 


\subsubsection{Preparação dos eletrodepósitos de Pt e PtRu}

A deposição eletrolítica foi realizada aplicando-se um potencial constante de $0,2 \mathrm{~V}$ por $5 \mathrm{~min}$ em placas de ouro de $2,0 \mathrm{~cm}^{2}$ de área geométrica. Como os eletrodos de trabalho foram preparados a partir de sais de cloreto, os quais se adsorvem fortemente bloqueando a superfície do eletrodo, foi necessária a remoção desses íons adsorvidos mediante um processo de "limpeza". Este consistiu na aplicação de um potencial de - 0,003 $\mathrm{V}$ por um período de tempo de uma hora em solução $0,1 \mathrm{~mol} \mathrm{~L}^{-1}$ de $\mathrm{HClO}_{4}[19]$.

As composições atômicas dos metais foram determinadas por energia dispersiva de raios-X (EDX), usando um instrumento Zeica Liess/440 com um detector de SiLi.

2.5.3 Método de normalização para as áreas ativas dos eletrodos de trabalho

Com o objetivo de comparar a atividade catalítica dos diferentes eletrodepósitos de PtRu, utilizou-se um método de normalização baseado na adsorção de CO sobre os sítios ativos [20]. A normalização se faz necessária para servir como referência da atividade catalítica em relação à área real dos eletrodos. Os eletrodos de $\mathrm{Pt}$ tiveram sua área normalizada a partir da integração da área de adsorção de hidrogênio.

Nos eletrodos eletrodepositados de PtRu, o gás $\mathrm{CO}$ foi borbulhado por $10 \mathrm{~min}$ em solução $0,5 \mathrm{~mol} \mathrm{~L}^{-1}$ de $\mathrm{H}_{2} \mathrm{SO}_{4}$. Em seguida, a solução foi purgada por $20 \mathrm{~min}$ 
com gás nitrogênio. O potencial de adsorção de $\mathrm{CO}$ foi de $0,05 \mathrm{~V}$. Após a purga foi realizada uma voltametria cíclica a $10 \mathrm{mVs}^{-1}$ no intervalo de $0,05 \mathrm{~V}$ a $0,8 \mathrm{~V}$ para a total remoção da monocamada de $\mathrm{CO}$.

A corrente de oxidação de $\mathrm{CO}$ foi integrada e o cálculo da área real foi feito considerando-se que, para oxidar uma monocamada de CO em $1,0 \mathrm{~cm}^{2}$, é necessária uma carga de 0,420 mC. Deve-se destacar que esta carga está baseada na suposição de que cada molécula de CO está adsorvida em forma linear e ocupa um sítio ativo do catalisador.

A fim de normalizar a banda de $\mathrm{CO}_{2}$ obtida nos espectros de infravermelho usou-se o seguinte procedimento: o $\mathrm{CO}$ foi adsorvido na superfície do eletrodo durante 5 minutos em solução $0,1 \mathrm{~mol} \mathrm{~L}^{-1}$ de $\mathrm{HClO}_{4}$, e após a remoção de $\mathrm{CO}$ em excesso da solução por borbulhamento de $\mathrm{N}_{2}$, aplicou-se um potencial de $0,8 \mathrm{~V}$ para oxidar o CO adsorvido. Durante a oxidação foram obtidos espectros de FTIR (50 varreduras) até se obter o máximo de intensidade da banda de $\mathrm{CO}_{2}\left(2344 \mathrm{~cm}^{-1}\right)$

\subsubsection{Medidas de espectroscopia de infravermelho in-situ}

A célula espectro-eletroquímica utilizada é mostrada na Figura 1 e assemelhase à descrita na literatura [21]. Para a coleta dos espectros, o eletrodo é colocado muito próximo à janela de infravermelho, formando-se entre o eletrodo e a janela

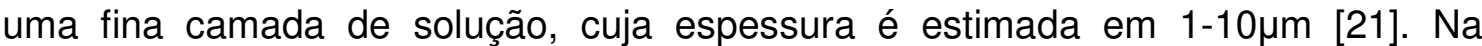
camada fina a difusão está restringida e, portanto, todas as informações obtidas nos espectros referem-se aos processos que ocorrem na superfície do eletrodo e na camada fina de solução. 
Em todos os experimentos de espectroscopia de infravermelho foi utilizada uma janela prismática de $\mathrm{CaF}_{2}$ com ângulos de $60^{\circ}$.

A resolução dos espectros foi de $8 \mathrm{~cm}^{-1}$ e 0 número de interferogramas coletados variou conforme o experimento. Diferentes programas de potencial foram utilizados, dependendo dos objetivos específicos de cada experimento.

Os espectros apresentados foram calculados a partir de espectros obtidos em dois potenciais diferentes [21]:

$$
\frac{\Delta R}{R}=\frac{\left(R-R_{0}\right)}{R_{0}}
$$

onde:

$$
\begin{aligned}
& R_{0}=\text { espectro coletado no potencial de referência; } \\
& R=\text { espectro coletado em outro potencial na mesma seqüência experimental. }
\end{aligned}
$$

Se $R_{0}>R$, observam-se bandas negativas de espécies que foram produzidas no potencial em que $R$ foi coletado. Já, se $R_{0}<R$, são observadas bandas positivas de espécies que foram consumidas no potencial em que $R$ foi coletado. Assim:

- Bandas negativas $\rightarrow$ espécies produzidas;

- Bandas positivas $\rightarrow$ espécies consumidas; 
- Bandas bipolares $\rightarrow$ espécies adsorvidas que estão presentes nos dois potenciais utilizados, e que apresentaram variação de freqüência pela mudança de potencial.

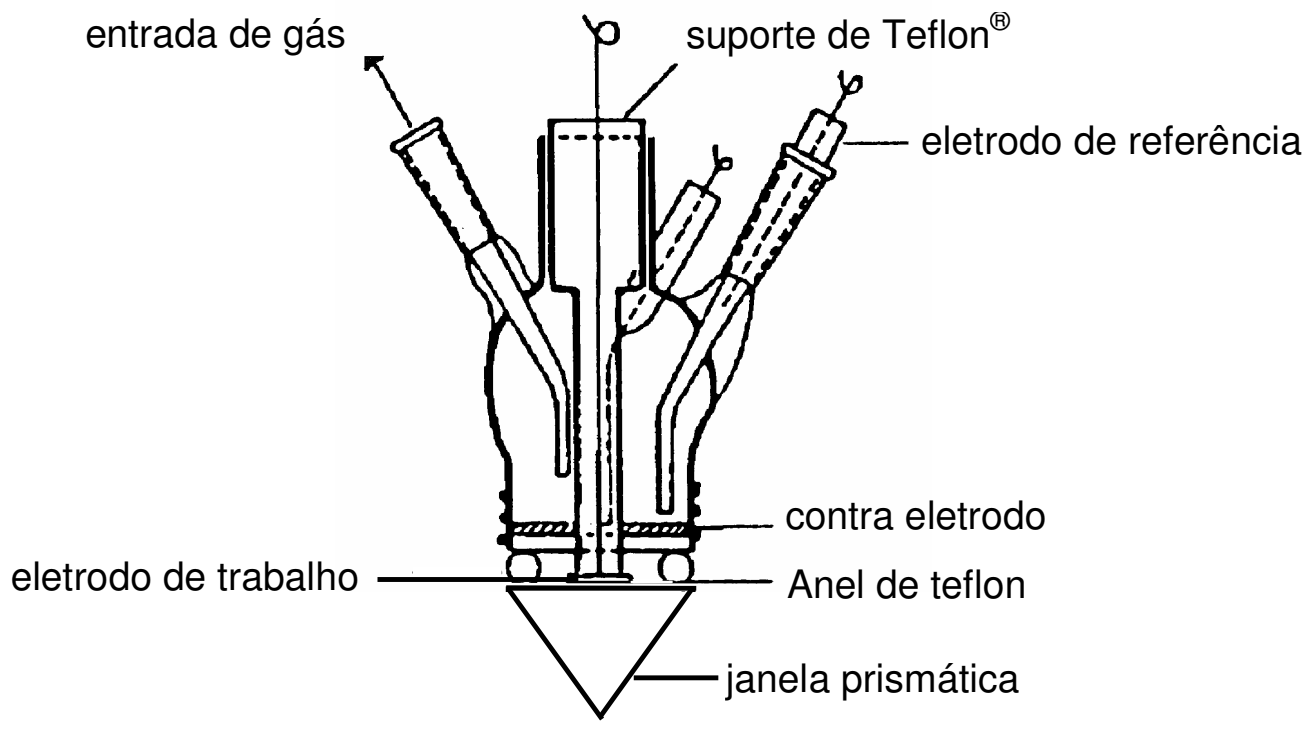

Figura 1 - Desenho esquemático mostrando a célula utilizada para os experimentos de espectroscopia de infravermelho.

2.5.5 Medidas de oxidação de resíduos fortemente adsorvidos

Para estudar os adsorbatos provenientes da adsorção dissociativa do etileno glicol e de seus produtos de oxidação parcial em eletrodos de Pt foi realizado um experimento de troca de solução.

A célula eletroquímica utilizada para esta finalidade é apresentada na Figura 2. No arranjo experimental eram utilizadas duas garrafas de $0,30 \mathrm{~L}$; em uma das garrafas era acondicionada a solução de trabalho contendo o álcool e na outra o eletrólito suporte $\left(0,1 \mathrm{M}\right.$ de $\left.\mathrm{HClO}_{4}\right)$. Um eletrodo de trabalho de $\mathrm{Pt}\left(0,5 \mathrm{~cm}^{2}\right.$ de área 
geométrica), um contra eletrodo de $\mathrm{Pt}\left(1,0 \mathrm{~cm}^{2}\right.$ de área geométrica) e um eletrodo de referência de hidrogênio eram imersos em um pequeno recipiente contendo um volume ca. 2,0 mL. Com o eletrodo polarizado a um potencial de $0,05 \mathrm{~V}$, a solução de trabalho era inserida no pequeno recipiente. Após um tempo de adsorção de 10 mim, a solução de trabalho contida no pequeno recipiente era trocada pela do eletrólito suporte até que toda a solução de trabalho fosse removida. Durante todo o tempo mantinha-se o eletrodo de trabalho sob controle de potencial. Após a troca de solução, uma varredura de potencial a $10 \mathrm{mVs}^{-1}$ era realizada entre $0,05 \mathrm{~V}$ e $1,45 \mathrm{~V}$ para medir a carga devida à oxidação dos adsorbatos.

Um procedimento similar de troca de solução foi realizado na célula de infravermelho, com o intuito de identificar espectroscopicamente as espécies adsorvidas.

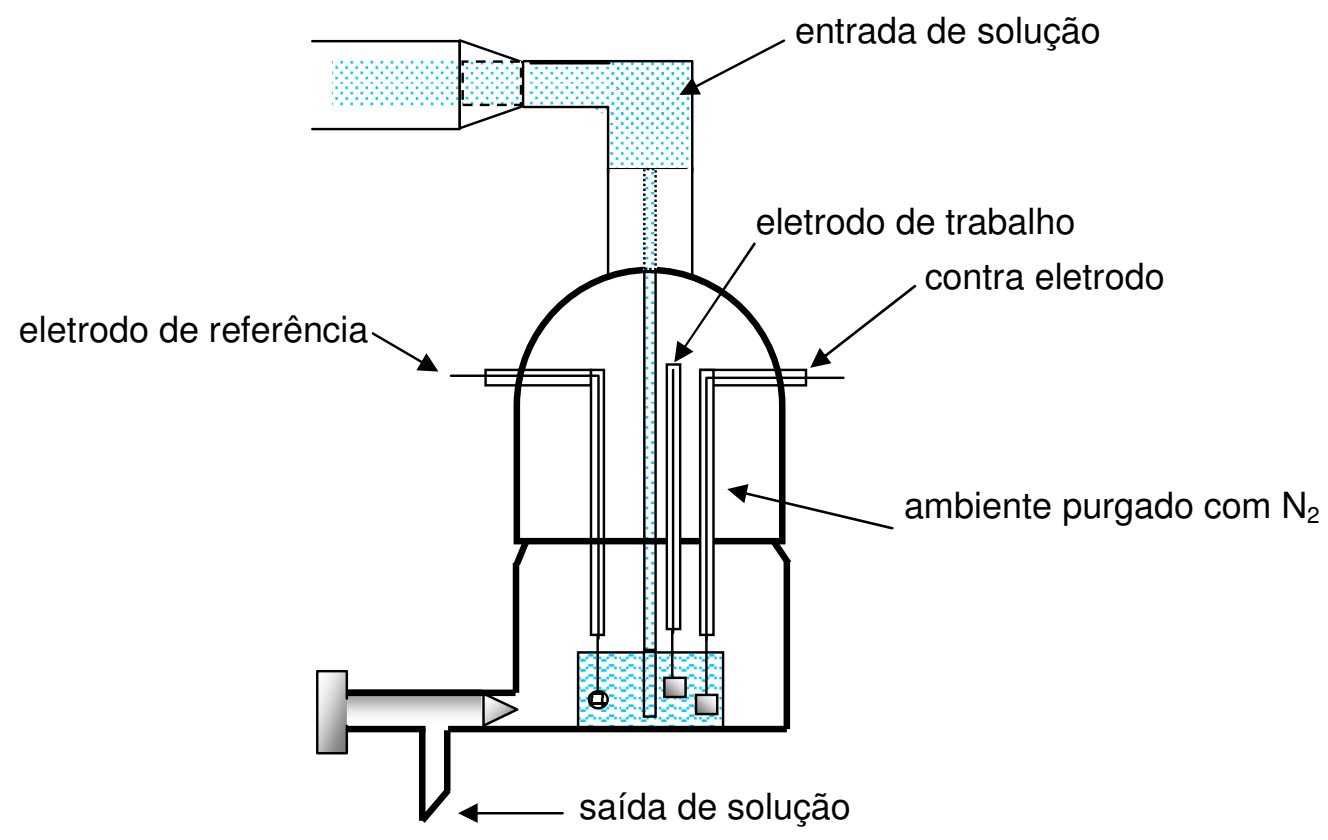

Figura 2 - célula eletroquímica com sistema de troca de solução, utilizada para estudar as espécies fortemente adsorvidas do etileno glicol. 


\subsubsection{Medidas de Cromatografia Líquida de Alta Eficiência}

Para a identificação dos produtos solúveis provenientes da oxidação parcial do etileno glicol nos eletrodos de Pt e PtRu foi utilizada a técnica de cromatografia líquida de alta resolução (CLAE). Para tanto, usou-se um equipamento de cromatografia líquida $\left(\right.$ Shimadzu $\left.{ }^{\circledR}\right)$ com uma coluna HPX-87H (Biorad). O aparelho conta com um detector de diodo (SPD-M10A) $\left(\right.$ Shimadzu $\left.{ }^{\circledR}\right)$. A identificação foi feita por comparação dos tempos de retenção com os das substâncias de referência puras sob as mesmas condições de operação. As concentrações dos produtos foram determinadas por comparação das áreas dos picos com uma curva de calibração previamente preparada, construída na faixa de concentração das amostras.

A eletrólise foi realizada oxidando o etileno glicol a um potencial constante de 0,50 V. Cada amostra foi injetada três vezes (três alíquotas). Os resultados apresentados representam a média das repetições (desvio < 5\%).

A amostra para a análise foi preparada numa célula cujo esquema é ilustrado na Figura 3. Essa célula possui um compartimento separado (tubo de vidro com placa porosa na extremidade inferior) para o eletrodo de trabalho. $O$ tubo para 0 eletrodo de trabalho, além de manter separados cátodo e ânodo, permite a recoleta de produtos num volume de solução pequeno e conhecido $(4,0 \mathrm{~mL})$. É importante realizar a eletrólise num volume pequeno de solução para que a concentração de produtos seja maior. A medida experimental foi realizada polarizando o eletrodo de trabalho a um potencial de $0,05 \mathrm{~V}$ e em seguida realizando-se um salto de potencial a $0,50 \mathrm{~V}$ por um tempo de 20 min. Após esse tempo a reação foi interrompida (aplicando-se um salto de potencial para $0,05 \mathrm{~V}$ ), imediatamente o eletrodo foi 
retirado e a solução do compartimento anódico foi retirada com uma pipeta e transferida num porta-amostra para ser analisada por CLAE.

Durante o tempo em que a reação se processava, a corrente foi registrada. As curvas de corrente em função do tempo foram posteriormente utilizadas para calcular a carga gerada durante a reação.

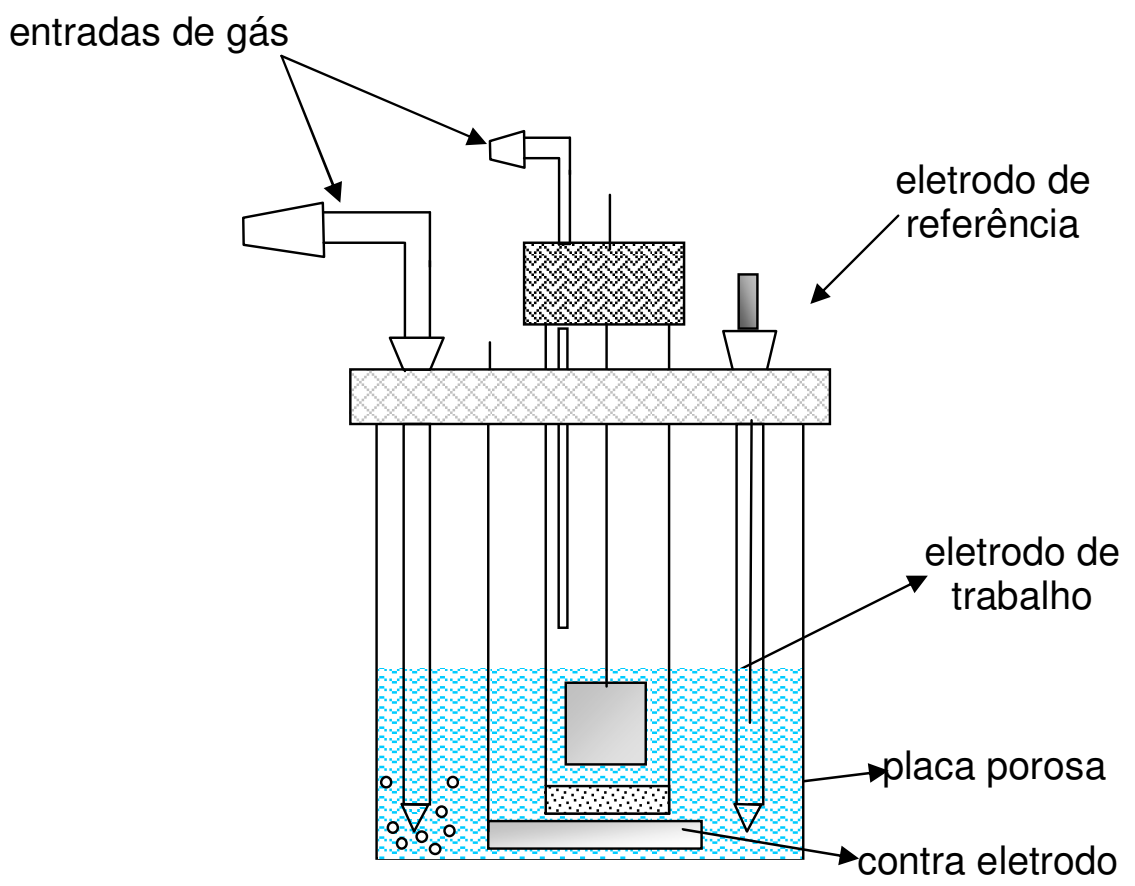

Figura 3 - Célula eletroquímica utilizada para preparar as amostras a serem analisadas por cromatografia líquida. 


\section{RESULTADOS EXPERIMENTAIS}

\subsection{Eletrooxidação de etileno glicol em eletrodos de Pt}

Na Figura 4 é apresentado o típico voltamograma cíclico para a oxidação do etileno glicol sobre um eletrodo de Pt $[8,11,22]$. Observa-se inicialmente que toda a região de hidrogênio $(0,05 \mathrm{~V}-0,35 \mathrm{~V})$ encontra-se totalmente suprimida devido à presença de espécies adsorvidas na superfície. A um potencial próximo de 0,65 V, é observado um aumento de corrente até um máximo a 0,95 V. Esta inibição da reação é devida à formação de óxidos de platina. A corrente passa por um mínimo a $1,1 \mathrm{~V}$ e, em seguida, sobe novamente devido à oxidação de etileno glicol do seio da solução. Na varredura de retorno pode-se observar uma corrente positiva que se inicia a um potencial próximo de $1,0 \mathrm{~V}$ e pode estar relacionada à recuperação da atividade catalítica após a redução dos óxidos de Pt. No entanto, os valores de corrente são menores que os observados no ciclo de ida. 


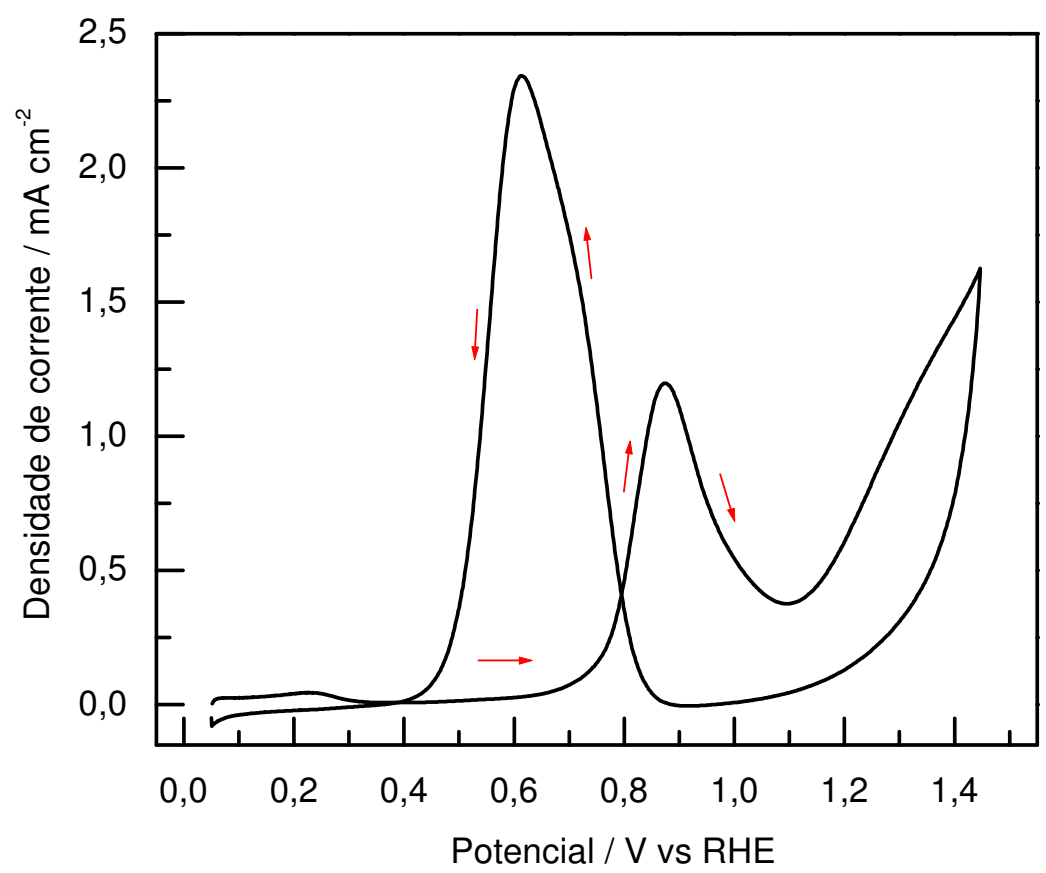

Figura 4 - voltamograma cíclico a $0,05 \mathrm{Vs}^{-1}$ para 0,1 $\mathrm{M} \mathrm{C}_{2} \mathrm{H}_{6} \mathrm{O}_{2}+0,5 \mathrm{M} \mathrm{H}_{2} \mathrm{SO}_{4}$ Pt. $A_{\text {real }}=2,0 \mathrm{~cm}^{2}$. $\mathrm{E}_{\mathrm{ad}}=$ $0,05 \mathrm{~V} . \mathrm{T}=25^{\circ} \mathrm{C}$.

3.1.1 Análise dos produtos de oxidação do etileno glicol por espectroscopia de infravermelho

Para o estudo inicial dos produtos de oxidação parcial da eletrooxidação de etileno glicol nos eletrodos de Pt foi utilizada a técnica de espectroscopia de infravermelho por reflexão externa. Espectros de infravermelho in-situ foram coletados após a aplicação de sucessivos saltos de potencial. O etileno glicol foi adicionado à célula estando o eletrodo polarizado em $0,05 \mathrm{~V}$. O eletrodo foi colocado contra a janela de infravermelho e foi, então, coletado um espectro de feixe simples 
(single beam) nesse potencial. Esse espectro foi usado como referência para calcular os espectros medidos em outros potenciais. Os saltos de potencial foram realizados de $0,05 \mathrm{~V}$ até $0,8 \mathrm{~V}$. Após cada salto, o potencial era mantido fixo enquanto o espectro estava sendo coletado. O número de interferogramas coletados foi 100. Assim, o tempo necessário para coletar cada espectro foi de aproximadamente 40 seg. Os resultados obtidos encontram-se na Figura 5.

Os espectros de infravermelho mostram bandas em diferentes regiões e podem assim ser identificadas: a forte banda na região de $2345 \mathrm{~cm}^{-1}$ é atribuída ao $\mathrm{CO}_{2}$ formado pela oxidação total das espécies adsorvidas; a banda em $2050 \mathrm{~cm}^{-1}$ indica a formação de $\mathrm{CO}_{\mathrm{ad}}$ na forma linear enquanto a pequena banda em $1855 \mathrm{~cm}^{-1}$ é atribuída a $\mathrm{CO}_{\mathrm{ad}}$ na forma ponte $[23,24]$. Um fato a acrescentar é o caráter bipolar da banda de $\mathrm{CO}_{\mathrm{L}}$, o qual indica que a molécula de etileno glicol sofre adsorção dissociativa no potencial de referência $(0,05 \mathrm{~V})$. A intensa banda positiva na região de $1650 \mathrm{~cm}^{-1}$ corresponde à deformação $(\mathrm{O}-\mathrm{H})$ das moléculas de água na camada fina situada entre a janela de infravermelho e o eletrodo de trabalho [25]. As bandas em $1739 \mathrm{~cm}^{-1}$ e $1241 \mathrm{~cm}^{-1}$ indicam a presença de um ácido carboxílico [26]. Trabalhos publicados na literatura $[6,13,26]$ atribuem estas últimas bandas à presença de ácido glicólico ou oxálico.

A banda da água não compensada em $1650 \mathrm{~cm}^{-1}$ interfere nos experimentos, podendo encobrir outras bandas provenientes de adsorbatos ou de outros produtos parciais da oxidação do etileno glicol. Para evitar esta interferência, a solução de trabalho foi preparada com água deuterada $\left(\mathrm{D}_{2} \mathrm{O}\right)$, e neste caso a deformação $\delta(\mathrm{O}-$ D) da água é deslocada para $1200 \mathrm{~cm}^{-1}$. A Figura 6 mostra os espectros obtidos em $\mathrm{D}_{2} \mathrm{O}$ para o eletrodo Pt em função do potencial. 


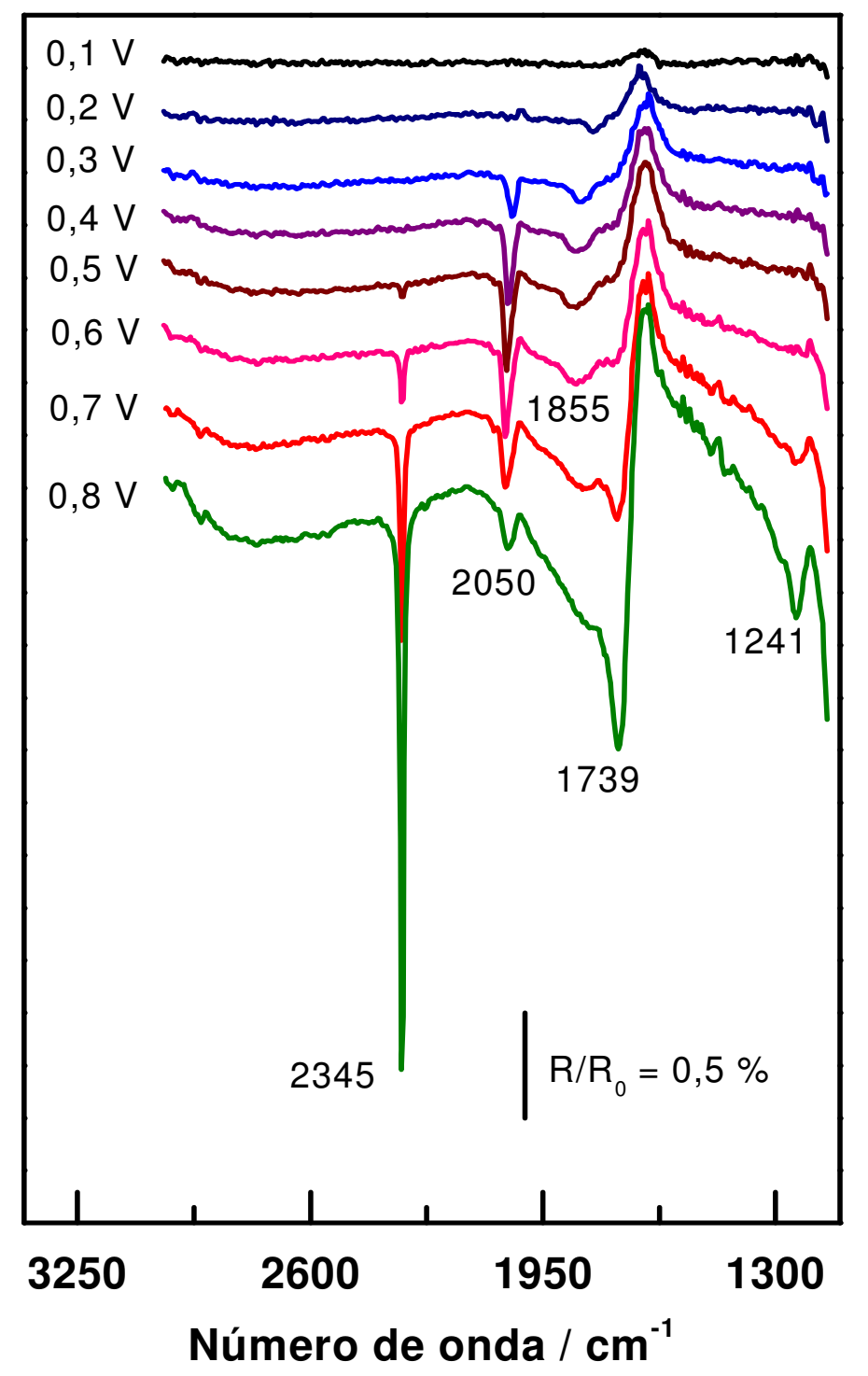

Figura 5 - Espectros de infravermelho para a oxidação de $0,1 \mathrm{M} \mathrm{C}_{2} \mathrm{H}_{6} \mathrm{O}_{2}+0,1 \mathrm{M} \mathrm{HClO}_{4}$ em Pt. $\mathrm{E}_{\mathrm{ad}}=0,05 \mathrm{~V}$. Resolução: $8,0 \mathrm{~cm}^{-1}$. $\mathrm{T}=25^{\circ} \mathrm{C}$. Referência: $0,05 \mathrm{~V}$.

Em $1716 \mathrm{~cm}^{-1}$ ocorre um fenômeno bastante peculiar da banda atribuída ao estiramento $\mathrm{C}=\mathrm{O}$ do grupo carbonila. A banda tem uma forma bipolar, indicando que algum produto ou adsorbato contendo este grupo funcional já está presente no 
potencial de referência. Além disso, como pode ser visto nos espectros da Figura 5, a banda relacionada ao ácido carboxílico $\left(1241 \mathrm{~cm}^{-1}\right)$ proveniente da oxidação parcial do etileno glicol surge a potenciais altos $(0,70 \mathrm{~V})$. O mais provável é que a banda em $1716 \mathrm{~cm}^{-1}$ pertença a um aldeído que no caso do etileno glicol, pode ser o glicolaldeído ou glioxal. No caso de a banda pertencer a um adsorbato carbonilado, esse teria origem em um dos dois aldeídos citados.

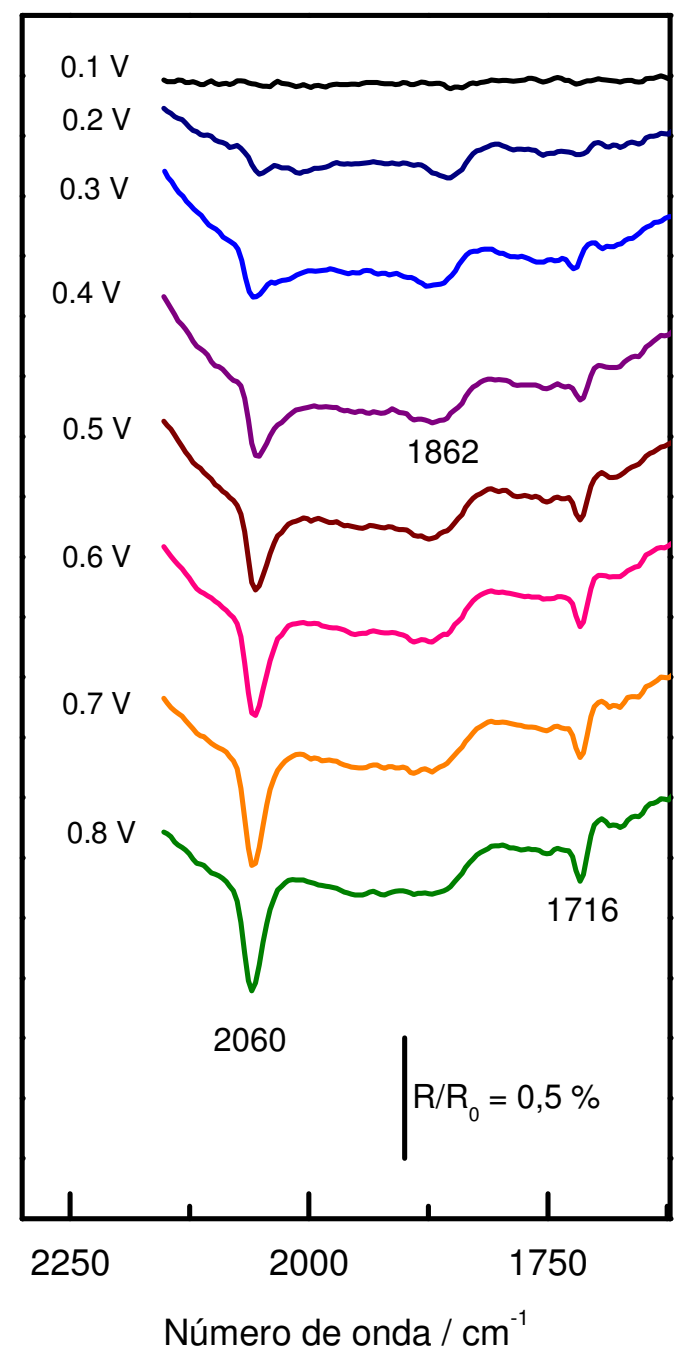

Figura 6 - Espectros de infravermelho para a oxidação de $0,1 \mathrm{M} \mathrm{C}_{2} \mathrm{H}_{6} \mathrm{O}_{2}$ em $0,1 \mathrm{M} \mathrm{HClO}_{4}$. Eletrodo de Pt. Solvente $\mathrm{D}_{2} \mathrm{O}$. $\mathrm{E}_{\mathrm{ad}}=0,05 \mathrm{~V}$. Resolução: 8,0 $\mathrm{cm}^{-1}$. $\mathrm{T}=25 \stackrel{\circ}{\circ} \mathrm{C}$. 
Os resultados acima descritos para a eletrooxidação de etileno glicol nos eletrodos de Pt demonstram a complexidade do seu mecanismo de reação, exigindo assim um estudo em separado de cada um de seus produtos parciais de oxidação.

3.1.2 Análise dos adsorbatos presentes nos eletrodos de Pt

A dissociação da molécula de um álcool na superfície do catalisador pode gerar espécies fortemente adsorvidas. Estas bloqueiam a superfície, impedindo o progresso da reação por outras vias. Na oxidação de álcoois como metanol e etanol, um dos adsorbatos encontrados é o monóxido de carbono originado na dissociação total da molécula do álcool na superfície do catalisador. Contudo, o monóxido de carbono pode ser oxidado a $\mathrm{CO}_{2}$ com a ajuda de espécies $\mathrm{OH}$ presentes na superfície da Pt a altos potenciais ou adicionando-se outro metal à Pt como, por exemplo, o Ru, para que esta oxidação ocorra a potenciais mais baixos.

Por sua vez, quando a dissociação não é total, podem ser formadas espécies hidrogenadas, cujo processo de oxidação é mais complexo. Segundo a literatura [27], espécies de etóxido $\left(\mathrm{Pt}-\mathrm{OCH}_{2}-\mathrm{CH}_{3}\right)$ seriam formadas pela interação do etanol com a platina a baixos potenciais. Estas espécies são estáveis e de difícil oxidação mesmo a altos potenciais.

Com o intuito de estudar o processo de oxidação das espécies fortemente adsorvidas do etileno glicol foi utilizado um sistema de troca de solução e a célula esquematizada na Figura 2. Após caracterização da superfície utilizando a técnica 
de voltametria cíclica, $25 \mathrm{~mL}$ de uma solução de $0,020 \mathrm{M}$ de etileno glicol foram injetados na célula eletrolítica a um potencial de adsorção de 0,05 V. Após um tempo de adsorção de 10 min a solução contida na célula foi trocada pela do eletrólito suporte mantendo-se o potencial sob controle, até que todo o etileno glicol fosse removido. Em seguida foram realizados dois ciclos voltamétricos a $10 \mathrm{mVs}^{-1}$ entre $0,05 \mathrm{~V}$ e $1,45 \mathrm{~V}$ para a total oxidação dos adsorbatos presentes na superfície do catalisador. O resultado deste experimento é apresentado na Figura 7.

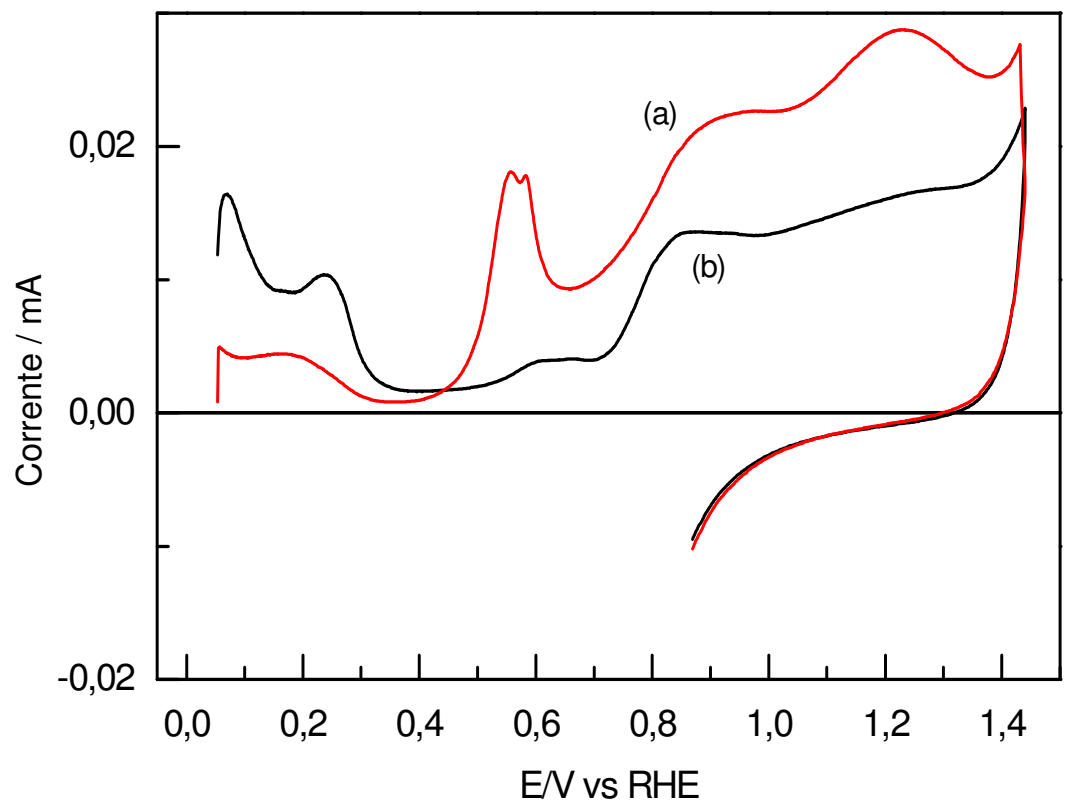

Figura 7 - Curvas potenciodinâmicas para a oxidação dos adsorbatos presentes na superfície do eletrodo de Pt. (a) 1ª ciclo; (b) $2^{\mathrm{a}}$ ciclo. $\mathrm{V}=10 \mathrm{mVs}^{-1} . \mathrm{E}_{\mathrm{as}}=0,05 \mathrm{~V}$. $\mathrm{T}=25^{\circ} \mathrm{C}$.

Pode-se observar a presença de três regiões de oxidação distintas: A primeira região (I), entre $0,40 \mathrm{~V}$ e $0,70 \mathrm{~V}$. As duas outras regiões encontram-se em faixas de potencial relativamente altas. A segunda abrange a região entre $0,70 \vee$ e 1,15 $\mathrm{V}$ (II) e a terceira entre $1,15 \mathrm{~V}$ e $1,35 \mathrm{~V}$ (III). As respectivas cargas obtidas pela 
deconvolução dos picos da curva-(a) após a subtração da curva-(b) indica que 17\% da carga total de oxidação encontra-se na primeira região, as outras duas regiões, localizadas a altos potenciais, correspondem respectivamente a $36 \%$ e $47 \%$ da carga total. Os valores calculados indicam que a maior parte da carga de oxidação (83\%) está relacionada a adsorbatos oxidáveis em potenciais acima de $0,70 \mathrm{~V}$. Estas espécies inibem a adsorção de outras moléculas de etileno glicol, impedindo assim o prosseguimento da reação.

O grau de recobrimento por adsorbatos foi calculado utilizando a carga obtida na região de adsorção de hidrogênio para ambos os voltamogramas. O resultado obtido indicou que $75 \%$ da superfície do catalisador estaria recoberta por adsorbatos. Este valor está próximo ao de $80 \%$ encontrado por Weaver et al. [28] para a adsorção dissociativa do etileno glicol em eletrodos de Pt policristalina.

3.1.3 Análise dos adsorbatos do etileno glicol por espectroscopia de infravermelho

Para identificar as espécies adsorvidas foi utilizada a técnica de espectroscopia de infravermelho por reflexão externa. O procedimento adotado para a adsorção e troca de solução foi o mesmo utilizado no experimento anterior. Após a adsorção e posterior troca de solução, o eletrodo de trabalho foi posto em contato com a janela prismática e em seguida foram realizados saltos de potencial de $0,05 \mathrm{~V}$ entre $0,05 \mathrm{~V}$ e 1,40 V para oxidar os adsorbatos presentes na superfície do eletrodo. Os resultados obtidos podem ser observados na Figura 8. 


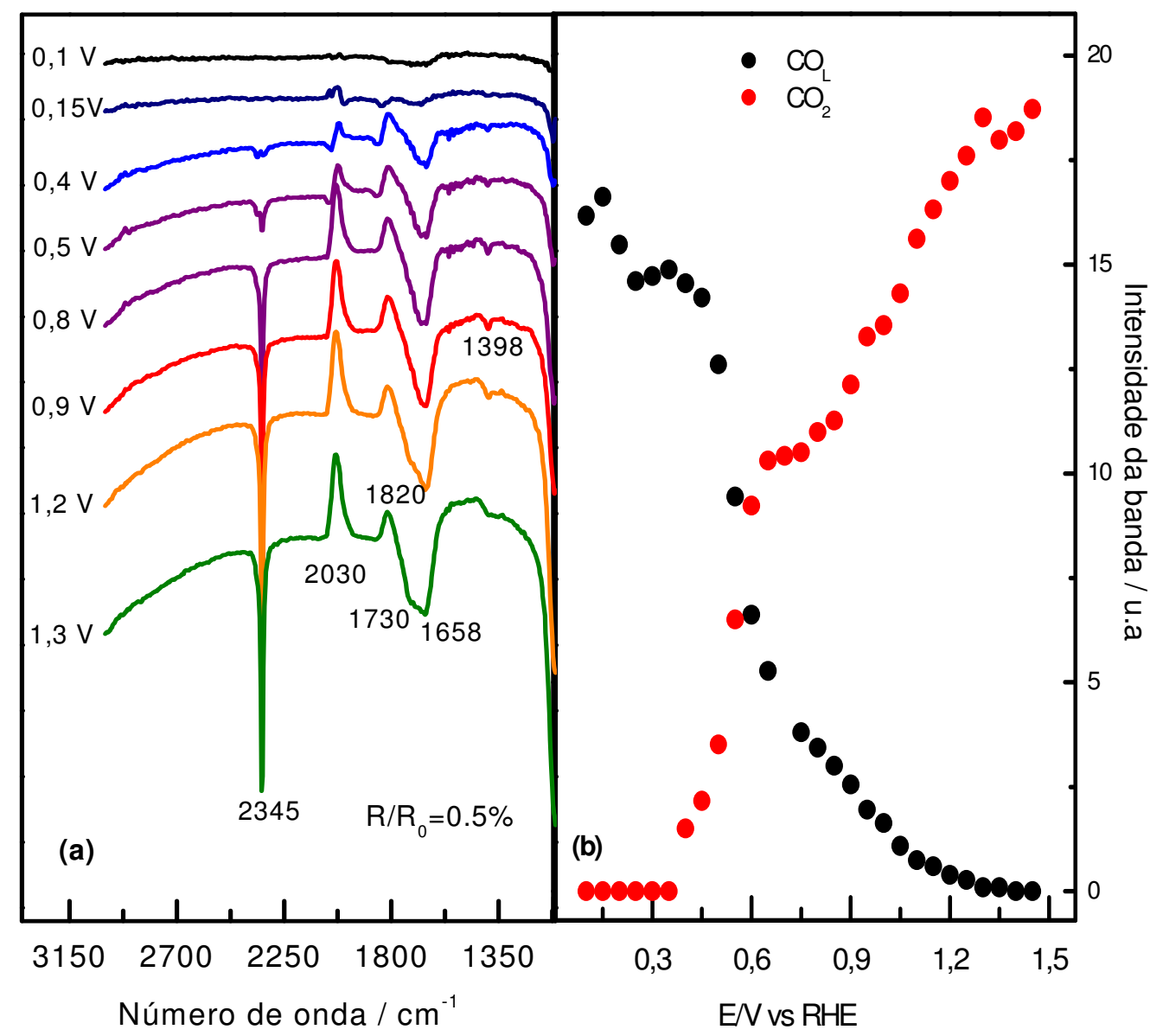

Figura 8 - Espectros de infravermelho para a oxidação dos adsorbatos em Pt após a adsorção de 0,02 M de EG e troca de solução com $\mathrm{HClO}_{4}$ 0,1 M (a) e (b) Intensidade das bandas de $\mathrm{CO}_{\mathrm{L}}$ e $\mathrm{CO}_{2}$. $\mathrm{E}_{\mathrm{ad}}=0,05 \mathrm{~V}$. $\mathrm{T}=25^{\circ} \mathrm{C}$. Espectro de referência $\mathrm{E}=0,05 \mathrm{~V}$.

As bandas observadas nas diferentes regiões do espectro podem assim ser identificadas: A intensa banda em $2345 \mathrm{~cm}^{-1}$ é atribuída à formação de $\mathrm{CO}_{2}$, enquanto as bandas em $2030 \mathrm{~cm}^{-1}$ e $1820 \mathrm{~cm}^{-1}$ referem-se, respectivamente, a $\mathrm{CO}_{\mathrm{ad}}$ na forma linear e ao $\mathrm{CO}_{\mathrm{ad}}$ na forma ponte. A banda do $\mathrm{CO}_{\mathrm{ad}}$ na forma ponte geralmente encontra-se na região de $1840 \mathrm{~cm}^{-1}-1860 \mathrm{~cm}^{-1}$, porém, um baixo recobrimento desse adsorbato pode deslocar o centro da banda para regiões de 
menor número de onda [29]. A banda localizada em $1658 \mathrm{~cm}^{-1}$ corresponde à deformação $\delta(\mathrm{O}-\mathrm{H})$ da água não compensada na camada fina.

Além dessas, duas outras bandas estão presentes: a primeira delas surge a um potencial de $0,50 \mathrm{~V}$ e situa-se em $1398 \mathrm{~cm}^{-1}$, enquanto a outra surge a um potencial próxímo de $1,20 \mathrm{~V}$ e está localizada em $1730 \mathrm{~cm}^{-1}$. Estas bandas podem estar associadas à formação de um ácido carboxílico como também à formação de um novo adsorbato. Para remover a dúvida sobre se a espécie está adsorvida ou em solução, foram realizados experimentos utilizando luz polarizada-s. A luz polarizadas tem seu vetor de campo elétrico perpendicular ao plano de incidência e, de acordo com a regra de seleção superficial, só espécies contendo uma componente do vetor de campo eletrico paralela ao plano de incidencia são detectáveis. Por isso, as espécies adsorvidas não podem ser detectadas pela luz polarizada-s. O resultado experimental não indicou nenhuma banda situada na região de $1398 \mathrm{~cm}^{-1}$ confirmando que a banda observada pertence a uma espécie adsorvida na superfície do catalisador.

Ampliando-se a região espectral compreendida entre $3000 \mathrm{~cm}^{-1}$ e $2700 \mathrm{~cm}^{-1}$ dos espectros mostrados na Figura 8, podem ser observadas duas pequenas bandas de baixa intensidade (Figura 9). Essas bandas correspondem aos estiramentos simétrico e assimetrico do grupo $\mathrm{CH}_{2}[6,26,27]$. 


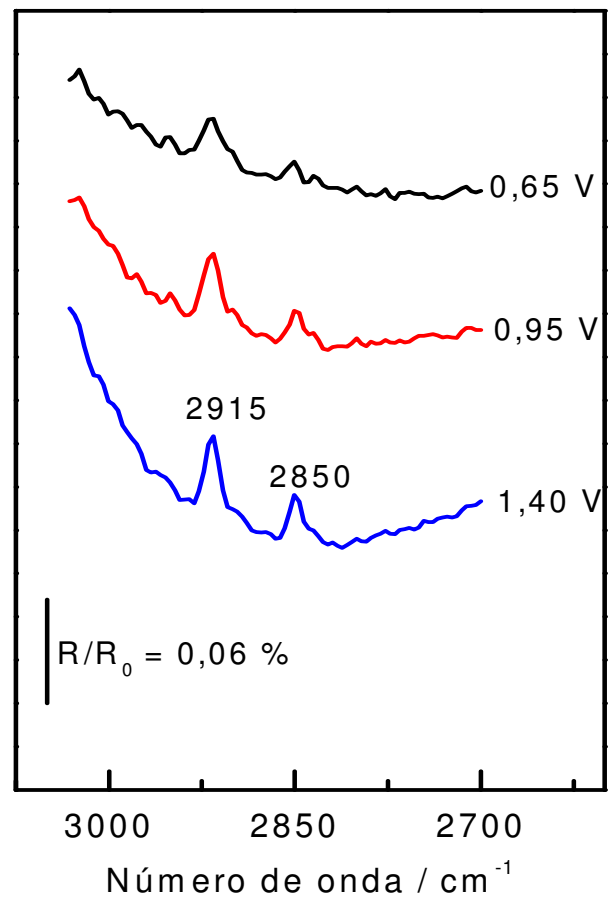

Figura 9 - Espectros de infravermelho para a oxidação dos adsorbatos do etileno glicol a 0,65 V; 0,95 V e 1,40 V. Eletrólito: 0,1 $\mathrm{M} \mathrm{HClO}_{4} \mathrm{E}_{\mathrm{ad}}=0,05 \mathrm{~V}$. $\mathrm{T}=25 \stackrel{\circ}{\circ}$. Resolução : $8 \mathrm{~cm}^{-1}$.

Embora a molécula de etileno glicol já esteja dissociada ao potencial de referência $(0,05 \mathrm{~V})$, os átomos de hidrogênio presentes podem bloquear a superfície dos sítios catalíticos impedindo a adsorção da molécula ou reduzindo-a outros produtos. Para estudar o efeito do potencial de adsorção, o álcool foi adsorvido a 0,35 V, sendo o recobrimento com $\mathrm{H}$ desprezível neste potencial. Neste caso, para minimizar os efeitos da interferência da banda da água não compensada, os espectros foram coletados com apenas 100 varreduras e realizados somente três saltos de potencial a $0,65 \mathrm{~V}, 0,95 \mathrm{~V}$ e $1,25 \mathrm{~V}$ para oxidar os adsorbatos. Os resultados são apresentados na Figura 10. 


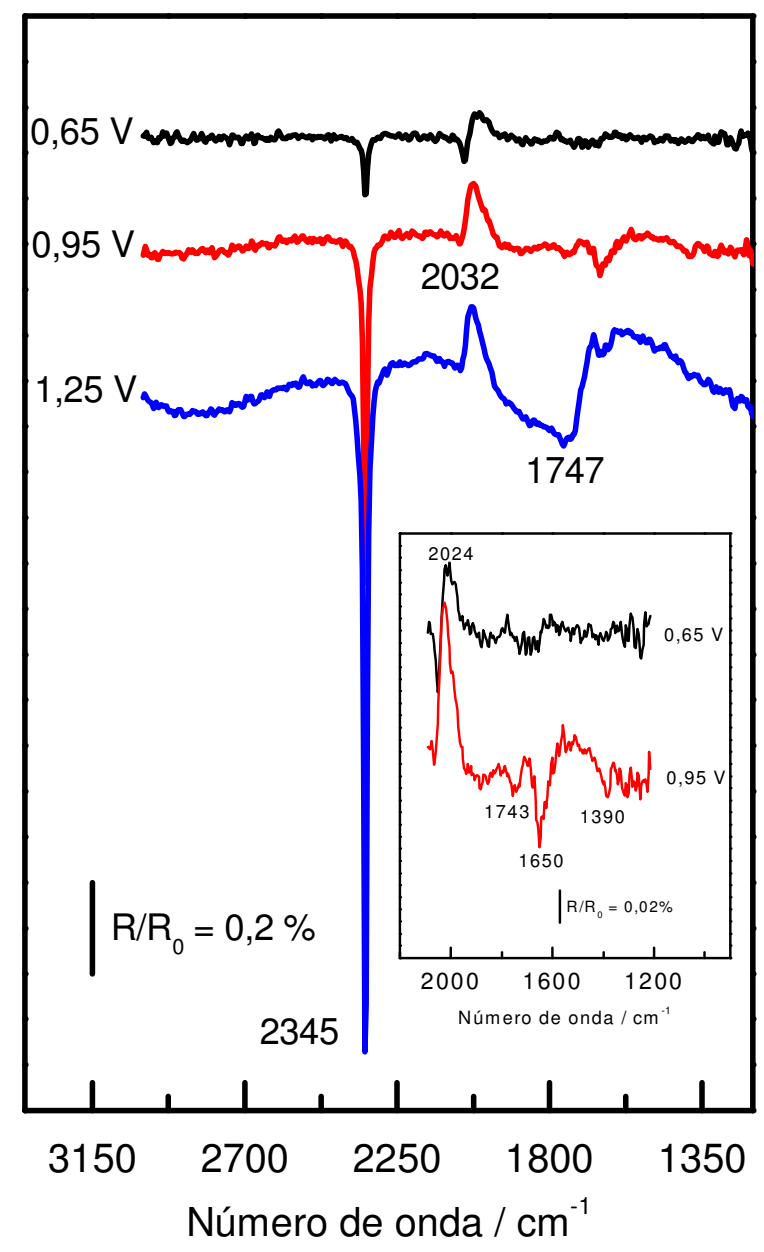

Figura 10 - Espectros de infravermelho para a oxidação dos adsorbatos em Pt após a adsorção de $0,02 \mathrm{M}$ de $\mathrm{EG}$ e troca de solução com $\mathrm{HClO}_{4} 0,1 \mathrm{M}$. $\mathrm{E}_{\mathrm{ad}}=0,35 \mathrm{~V}$. $\mathrm{T}=25 \stackrel{\circ}{\circ} \mathrm{C}$. Resolução: $8,0 \mathrm{~cm}^{-1}$.

Os espectros apresentam a banda intensa atribuída à produção de $\mathrm{CO}_{2}$ em 2345 $\mathrm{cm}^{-1}$ e a banda de $\mathrm{CO}_{\mathrm{ad}}$ na forma linear em $2032 \mathrm{~cm}^{-1}$. Nenhuma evidência da formação de $\mathrm{CO}_{\mathrm{ad}}$ na forma ponte $\left(1840 \mathrm{~cm}^{-1}\right)$ é observada. Na região compreendida entre $1800 \mathrm{~cm}^{-1}$ e $1200 \mathrm{~cm}^{-1}$ percebem-se com maior clareza as bandas situadas em $1743 \mathrm{~cm}^{-1}$ e $1390 \mathrm{~cm}^{-1}$ atribuídas à formação de um produto carbonilado, possivelmente um ácido carboxílico. Os resultados obtidos demonstram que, mesmo 
mudando o potencial de adsorção para valores mais positivos a fim de facilitar a dissociação da molécula do álcool, a formação de outros produtos de reações paralelas ainda é evidente.

3.1.4 Possíveis espécies adsorvidas detectadas por espectroscopia de infravermelho

De acordo com os princípios da regra de seleção superficial [21] já mencionada, podem ser propostos os seguintes adsorbatos para a dissociação parcial da molécula de etileno glicol ( $\mathrm{C}-\mathrm{H}$ detectável): o primeiro deles teria a forma $\mathrm{Pt}-\mathrm{CHOH}-\mathrm{CH}_{2} \mathrm{OH}$. Na Figura 11 é mostrado um desenho esquemático do adsorbato proposto.

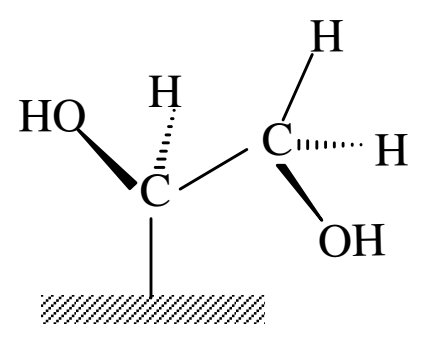

Figura 11 - Adsorbato proposto para a adsorção não dissociativa do etileno glicol em eletrodos de Pt policristalina.

Esse adsorbato tem, provavelmente, uma rotação livre na ligação $C-C$ que dá ao grupo $\mathrm{CH}_{2}$ uma posição favorável para exibir ambos os estiramentos simétrico e assimétrico da ligação $\mathrm{C}-\mathrm{H}$. Ao contrário, nos adsorbatos contendo somente um carbono, como por exemplo $\mathrm{Pt}-\mathrm{CH}_{2} \mathrm{OH}$ ou $\mathrm{Pt}-\mathrm{CH}_{2}$, o modo vibracional assimétrico é 
inativo ao feixe de infravermelho e por isso seria inativo [27]. O adsorbato da Figura 11 também pode ser precursor para a formação de CO linear:

$$
\mathrm{Pt}-\mathrm{CHOH}-\mathrm{CH}_{2} \mathrm{OH} \rightarrow \mathrm{Pt}-\mathrm{CO}+\mathrm{Pt}-\mathrm{CO}+5 \mathrm{H}^{+}+5 \mathrm{e}^{-}
$$

No entanto, este caminho dependerá da disponibilidade de sítios livres do catalisador para que ocorra a dissociação. O segundo adsorbato cuja ligação C-H pode ser detectada pela luz infravermelha teria a forma $=\mathrm{COH}-\mathrm{CH}_{2} \mathrm{OH}$ e é originado a partir da desprotonação de dois átomos de hidrogênio da molécula do etileno glicol. Abaixo segue um desenho esquemático do adsorbato proposto.

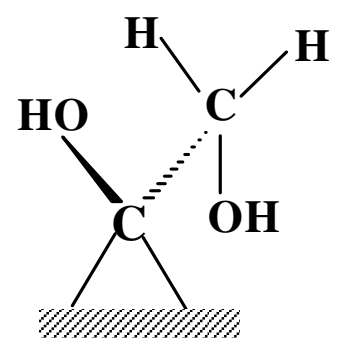

Figura 12 - Adsorbato proposto para a adsorção não dissociativa do etileno glicol em eletrodos de Pt policristalina.

\subsection{Catálise da oxidação de etileno glicol em eletrodos de PtRu.}

Nos estudos eletroquímicos da catálise de álcoois de cadeia pequena, a Platina tem sido utilizada como principal catalisador. Contudo, o seu uso isolado tem se mostrado pouco eficiente, isto porque a superfície do catalisador sofre um forte recobrimento de espécies oriundas da dissociação do álcool, o que impede o 
prosseguimento da reação. Uma forma de desbloquear a superfície do catalisador é utilizar espécies oxigenadas adsorvidas, oriundas da dissociação da molécula de água, para oxidar esses adsorbatos. Todavia, a formação destas espécies oxigenadas na superfície da platina a velocidade apropriada só ocorre a potenciais acima de ca. 0,60 V. Em busca de facilitar a oxidação das espécies adsorvidas a potenciais mais baixos, outros metais têm sido utilizados em associação com a Pt. Na catálise da oxidação do metanol e etanol têm sido obtidos bons resultados com a combinação de Pt e Ru [31-34]. A promoção da reação pelo rutênio pode ser explicada por um mecanismo bifuncional [34], segundo o qual a platina adsorve e dissocia o álcool e o rutênio dissocia a água formando $\mathrm{Ru}(\mathrm{OH})$, que por sua vez atua como doador de oxigênio.

$$
\mathrm{Pt}(\mathrm{CO})+\mathrm{Ru}(\mathrm{OH}) \rightarrow \mathrm{CO}_{2}+\mathrm{H}^{+}+\mathrm{e}^{-}+\mathrm{Pt}+\mathrm{Ru}
$$

$\mathrm{Na}$ catálise da oxidação do etileno glicol os eletrodos de PtRu tem sido utilizados [15-19], mas o efeito do Ru na distribuição dos produtos formados ainda não foi estudado. Nesta etapa do trabalho foram utilizados como eletrodos de trabalho ligas metalúrgicas polidas e eletrodepósitos de PtRu.

Após o tratamento de limpeza descrito na parte experimental deste trabalho, as ligas de Pt:Ru foram caracterizadas por voltametria cíclica em $\mathrm{HClO}_{4} \quad 0,1 \mathrm{M}$. A Figura 13 apresenta os voltamogramas obtidos em meio ácido semelhante aos encontrados na literatura. Neste tipo de eletrodo, os picos de corrente na região de hidrogênio não estão definidos e a região de dupla camada possui um valor de carga maior se comparado a eletrodos de Pt policristalina. Esse aumento na carga elétrica 
na região de dupla camada está associado à adsorção de espécies oxigenadas sobre os átomos de Ru, essas oriundas da dissociação de moléculas de água [34].

$$
\mathrm{Ru}+\mathrm{H}_{2} \mathrm{O} \rightarrow \mathrm{Ru}(\mathrm{OH})+\mathrm{H}^{+}+\mathrm{e}^{-}
$$

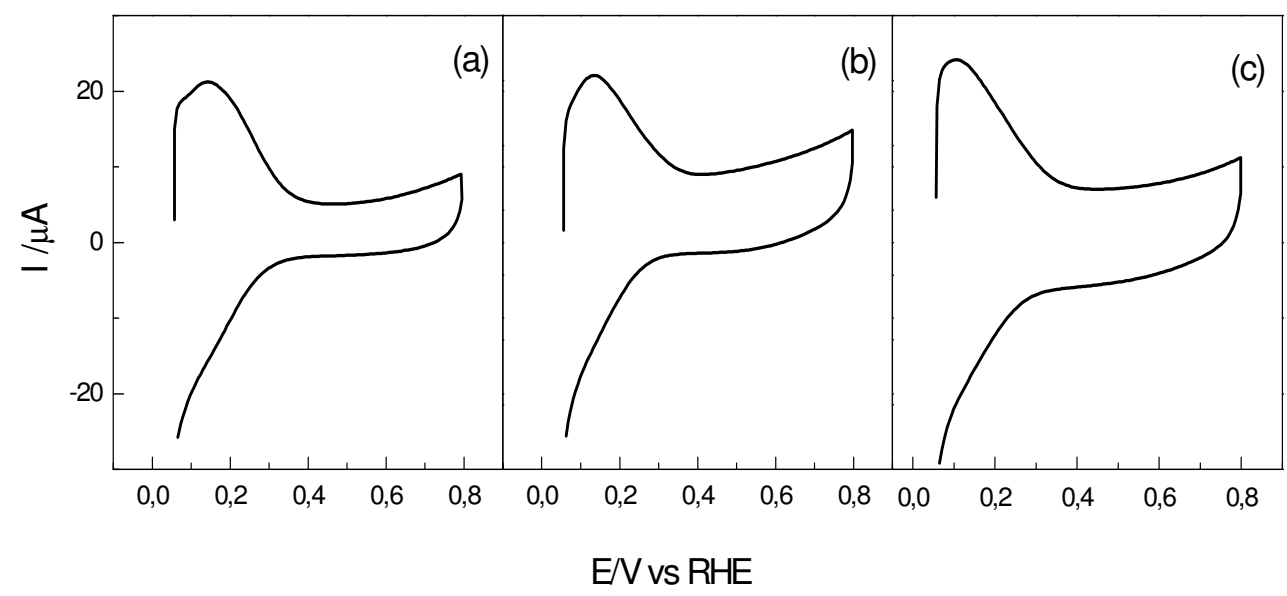

Figura 13 - Voltamogramas cíclicos nas ligas de PtRu em solução $0,1 \mathrm{M}$ $\mathrm{HClO}_{4} . \mathrm{V}=50 \mathrm{mVs}^{-1} . \mathrm{T}=25^{\circ} \mathrm{C}( \pm 1)$. Composição das ligas: (a) 80:20; (b) 70:30; (c) 60:40

Para comparar a atividade catalítica das ligas, foram realizadas medidas de cronoamperometria. $\mathrm{O}$ eletrodo foi posicionado em configuração de menisco e o etileno glicol foi adsorvido a um potencial de adsorção de 0,05 V. Em seguida, foi realizado um salto de potencial a $0,50 \mathrm{~V}$ e a corrente foi monitorada. Os resultados obtidos são apresentados na Figura 14. Observam-se diferenças na corrente com a quantidade de Ru no eletrodo. Os maiores valores de corrente foram observados com o eletrodo contendo $30 \%$ em Ru. Os menores valores foram obtidos com o eletrodo de $20 \%$ em Ru, ficando o eletrodo com $40 \%$ em Ru com valores de corrente intermediários. A discussão deste comportamento é feita na página 44 onde são 
apresentados os resultados da oxidação de etileno glicol em eletrodepósitos de PtRu.

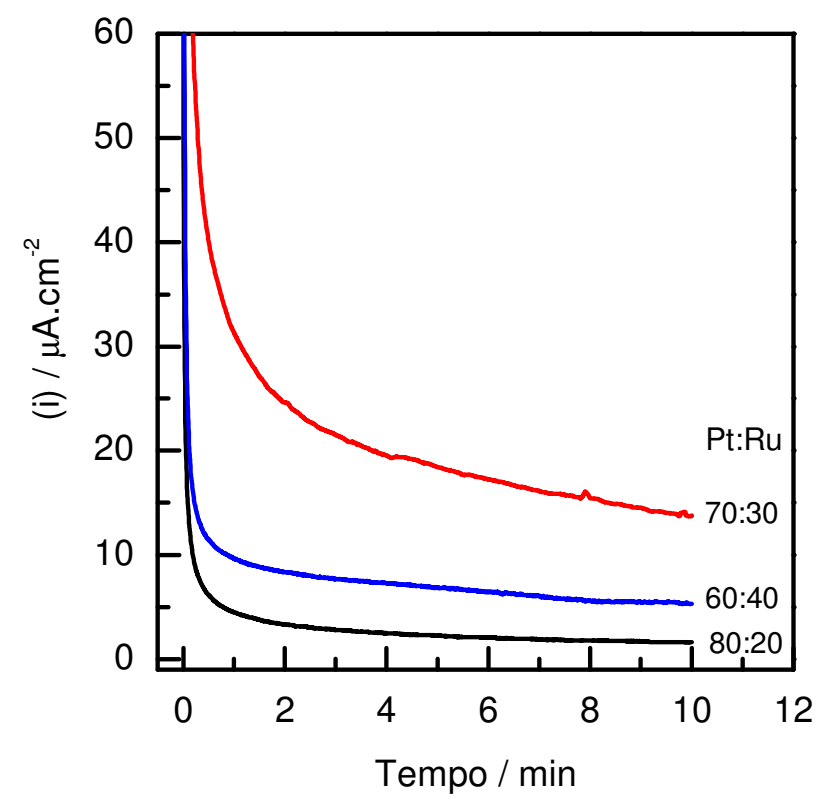

Figura 14 - Curvas de corrente-tempo para as ligas de PtRu como indicado. Solução $1,0 \mathrm{M} \mathrm{C}_{2} \mathrm{H}_{6} \mathrm{O}_{2}+$ $0,5 \mathrm{M} \mathrm{H}_{2} \mathrm{SO}_{4} . \mathrm{E}=0,50 \mathrm{~V} . \mathrm{T}=25^{\circ} \mathrm{C}( \pm 1)$.

Assim como nos eletrodos de Pt, a técnica de espectroscopia de infravermelho foi utilizada para identificar os adsorbatos e produtos formados durante a eletrooxidação do etileno glicol nos eletrodos binários de PtRu.

3.2.1 Análise dos produtos de oxidação de etileno glicol por espectroscopia de infravermelho nas ligas de PtRu

A Figura 15 traz um conjunto de espectros obtidos para a eletrooxidação de etileno glicol a diferentes potenciais na liga de PtRu (70:30) e o aspecto da banda de 
$\mathrm{CO}_{\mathrm{L}}$ a $0,50 \mathrm{~V}$ para todas as ligas de PtRu. A um potencial de $0,40 \mathrm{~V}$ pode ser observada uma banda centrada em $2345 \mathrm{~cm}^{-1}$, atribuída à formação de $\mathrm{CO}_{2}$ produzido durante a oxidação. A banda em $2050 \mathrm{~cm}^{-1}$ é atribuída à formação de CO na forma linear. O aspecto bipolar da banda de $\mathrm{CO}$ indica que, ao potencial de referência $(0,05 \mathrm{~V})$, a molécula de etileno glicol já se encontra dissociada na superfície de todos os eletrodos de PtRu utilizados. Embora este efeito possa ser observado nos eletrodos de Pt (Figura 5), a sua intensidade é bem maior nos eletrodos de PtRu. Este efeito pode estar sendo causado pela presença do Ru no eletrodo, já que dados na literatura indicam que o rutênio produz efeitos sinérgicos na catálise [35] e mudanças nas propriedades eletrônicas da platina [36].

Em estudos da eletrooxidação de metanol em eletrodos de PtRu, Krausa e Vielstich [35] observaram que a adsorção do metanol sobre eletrodos de PtRu é deslocada para potenciais abaixo dos observados com Pt pura. Os mesmos autores mostraram que o Ru puro não adsorve e, conseqüentemente, não oxida o metanol. Sendo assim, assume-se que um efeito combinado de átomos vizinhos de Pt e de Ru favorece a formação dos adsorbatos. Esse tipo de efeito não pode ser explicado pelo mecanismo bifuncional. Assim, os autores sugerem que há um efeito catalítico adicional, devido a interações eletrônicas entre os átomos vizinhos de Pt e Ru [35]. Com base em resultados de absorção de raios-X in-situ, McBreen e Mukerjee [36] propõem que a formação de ligas com Ru diminui a energia de adsorção de hidrogênio sobre a Pt. $O$ hidrogênio pode funcionar como um bloqueador da superfície em potenciais baixos, inibindo a adsorção do metanol. Essa proposta de McBreen e Mukerjee pode, portanto, ser uma explicação para o fato de a formação de adsorbatos da molécula do etileno ser deslocada para potenciais mais baixos nas ligas de PtRu. 


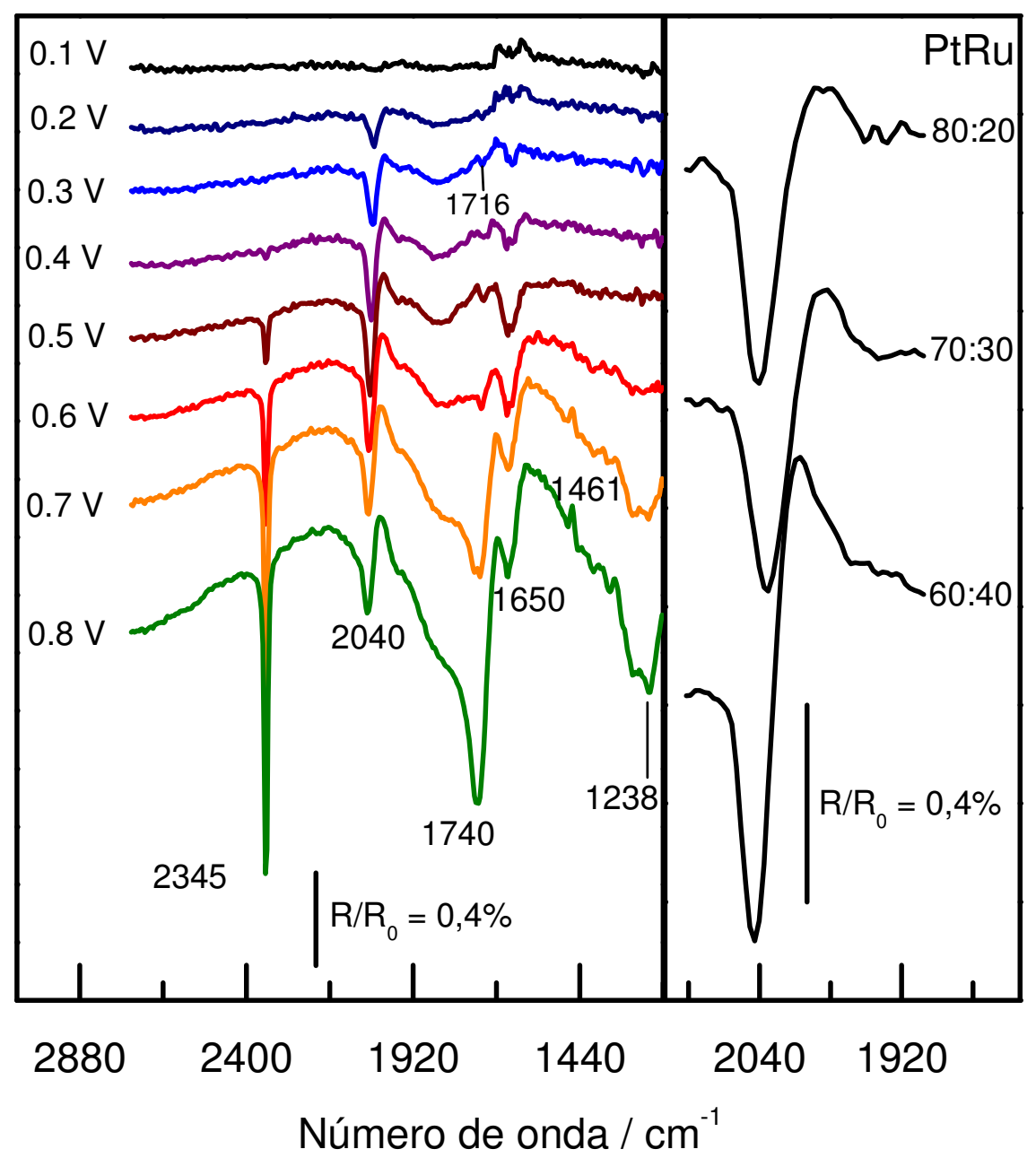

Figura 15 - Espectros de infravermelho em diferentes potenciais para eletrooxidação de etileno glicol na liga de Pt:Ru (70:30) e comparação da banda de $\mathrm{CO}_{\mathrm{L}}$ a $0,50 \mathrm{~V}$ vs $\mathrm{RHE}$ em ligas de PtRu de diferente composição. Solução: $1,0 \mathrm{M} \quad \mathrm{C}_{2} \mathrm{H}_{6} \mathrm{O}_{2}+0,1 \mathrm{M} \mathrm{HClO}_{4} \cdot \mathrm{E}_{\mathrm{ad}}=0,05 \mathrm{~V}$. $\mathrm{T}=25^{\circ}( \pm 1)$. Espectro de referência medido em $0,05 \mathrm{~V}$.

Observa-se uma banda centrada em $1740 \mathrm{~cm}^{-1}$ atribuída ao estiramento $\mathrm{C}=\mathrm{O}$ de um grupo carbonila. Em $1461 \mathrm{~cm}^{-1}$ observa-se uma banda positiva atribuída à deformação $\mathrm{C}-\mathrm{H}$ do etileno glicol consumido na oxidação. A banda em $1238 \mathrm{~cm}^{-1}$ pode ser atribuída ao estiramento $\mathrm{C}-\mathrm{OH}$ de um grupo carboxila [37-39]. Nota-se, no entanto, que a banda do ácido carboxílico formado surge a potenciais acima de 0,60V. Ainda na Figura 15, observa-se que nas três ligas utilizadas o caráter bipolar 
da banda de CO não desaparece, indicando que aparentemente a dissociação de etileno glicol não é afetada mesmo com quantidade de Ru superior a $30 \%$.

Para se estudar o comportamento do $\mathrm{CO}$ sobre as ligas de PtRu foi necessário recalcular os espectros usando um espectro de referência medido num potencial no qual o recobrimento por $\mathrm{CO}$ fosse zero, pois em tal caso espera-se obter bandas absolutas de CO. Para esta finalidade, utilizou-se como referência um espectro medido a um potencial de 1,20 V. Neste potencial, todo o CO adsorvido no eletrodo é oxidado a $\mathrm{CO}_{2}$. A Figura 16 exibe as intensidades de banda de $\mathrm{CO}$ para as ligas de PtRu, bem como a intensidade normalizada da banda de $\mathrm{CO}_{2}$ a diferentes potenciais. A normalização realizou-se dividindo os valores de intensidade de banda de $\mathrm{CO}_{2}$ obtida por oxidação de uma monocamada de $\mathrm{CO}$.

Para todas as ligas utilizadas o recobrimento máximo de CO ocorre a um potencial próximo de $0,35 \mathrm{~V}$, mas, podem ser observadas algumas diferenças: os maiores valores de intensidade para a banda de $\mathrm{CO}_{\llcorner}$são observados para as ligas contendo $20 \%$ e $30 \%$ em $\mathrm{Ru}$. O recobrimento por CO é menor na liga de $40 \%$ e ainda decresce mais na platina pura. Evidentemente, a presença de Ru favorece a adsorção dissociativa do etileno glicol, sendo este efeito maior nas ligas com $20 \%$ e $30 \%$ em Ru. Por outro lado, sabe-se que a dissociação do álcool acontece preferencialmente nos sítios de Pt, já que o Ru puro não tem atividade catalítica para oxidar o etileno glicol ${ }^{1}$. Portanto, o aumento do grau de recobrimento por CO pode ser atribuído a alguma mudança na estrutura eletrônica do substrato que favoreceria a quebra da ligação $\mathrm{C}-\mathrm{C}$, e tal efeito decresce quando a concentração de Ru é de $40 \%$. 


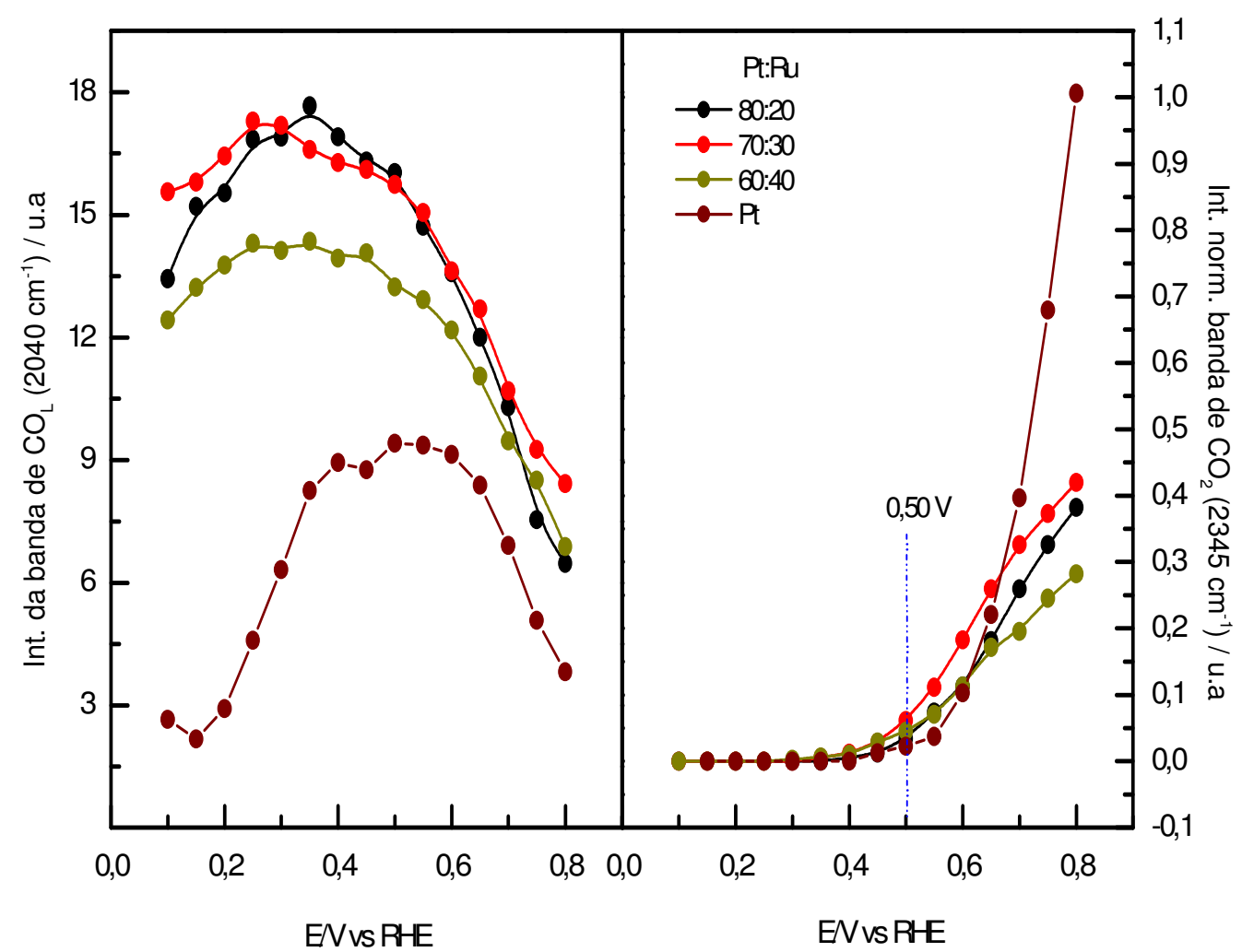

Figura 16 - Intensidade das bandas de $\mathrm{CO}$ e $\mathrm{CO}_{2}$ vs potencial para as ligas de PtRu. Solução: 1,0M C $\mathrm{H}_{6} \mathrm{O}_{2}+0,1 \mathrm{M} \mathrm{HClO}_{4}$. $\mathrm{E}_{\mathrm{ad} .}=0,05 \mathrm{~V}$. T=25(1)

No que respeita à formação de $\mathrm{CO}_{2}$, observa-se na Figura 16 que, para potenciais menores que $0,60 \mathrm{~V}$, a liga de $\mathrm{Pt}: \mathrm{Ru}(70: 30)$ produz as maiores quantidades de $\mathrm{CO}_{2}$. No entanto, a $0,50 \mathrm{~V}$ não se observa uma diferença significativa na intensidade da banda para justificar os valores de corrente apresentados na Figura 14. Em outro experimento foi analisada a formação de $\mathrm{CO}_{2}$ ao longo do tempo. Neste caso, o etileno glicol foi adsorvido a um potencial de $0,05 \mathrm{~V}$ por um período de 5 min e, em seguida, realizado um salto de potencial a $0,50 \mathrm{~V}$. O tempo da coleta de espectros foi limitado em 10 min para minimizar os efeitos da difusão do $\mathrm{CO}_{2}$ para fora da camada fina. A intensidade da banda de $\mathrm{CO}_{2}$ foi 
integrada e normalizada segundo o método descrito na parte experimental deste trabalho. Os resultados são apresentados na Figura 17.

A formação de $\mathrm{CO}_{2}$ é mais pronunciada para o eletrodo contendo $30 \%$ em $\mathrm{Ru}$, permanecendo as ligas com $20 \%$ e $40 \%$ com valores de intensidade mais baixos. Assim, este experimento mostra que sob condições quase-estacionárias a readsorção do etileno glicol e a oxidação para $\mathrm{CO}_{2}$ são mais efetivas na liga com $30 \%$ em Ru.

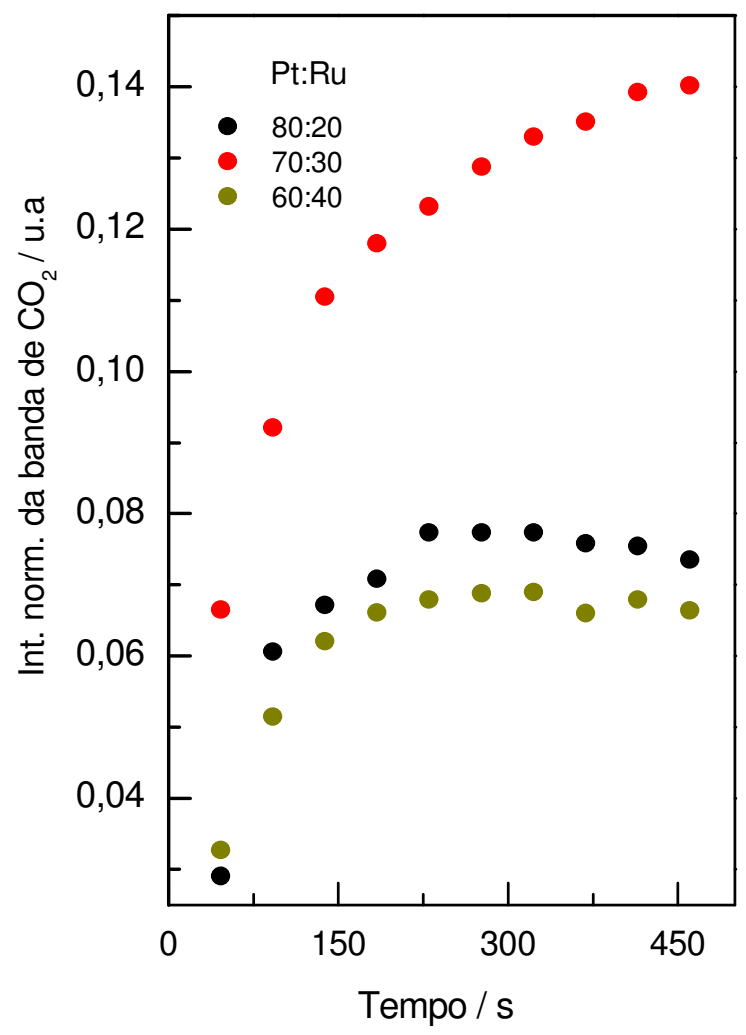

Figura 17 - Intensidade normalizada da banda de $\mathrm{CO}_{2}$ vs tempo. Solução: $1,0 \mathrm{M} \mathrm{C}_{2} \mathrm{H}_{6} \mathrm{O}_{2}+0,1 \mathrm{M} \mathrm{HClO}_{4}$. $\mathrm{E}=0,50 \mathrm{~V}$.

Apesar dos efeitos positivos do Ru quanto à corrente e à produção de $\mathrm{CO}_{2}$, os valores fracionários da intensidade de banda normalizada para todos os eletrodos 
indicam que a formação de $\mathrm{CO}_{2}$ é pequena, e sugerem que outras reações paralelas podem estar ocorrendo.

Baseando-se nos resultados obtidos para a formação de $\mathrm{CO}$ e $\mathrm{CO}_{2}$ nas ligas de PtRu, fez-se necessário estudar os possíveis produtos formados nas reações paralelas e a influência da quantidade de Ru nessas reações. As bandas dos diferentes produtos formados durante a oxidação de etileno glicol estão localizadas na região compreendida entre $1200 \mathrm{~cm}^{-1}$ e $1700 \mathrm{~cm}^{-1}$. Porém, nesta região ocorre a deformação $\delta(\mathrm{O}-\mathrm{H})$ da água em $1650 \mathrm{~cm}^{-1}$, e a banda da água não compensada poderia interferir com as dos outros produtos de reação. A Figura 18 apresenta os espectros obtidos para o eletrodo Pt:Ru (70:30) em função do potencial. A banda bipolar em $2040 \mathrm{~cm}^{-1}$ é atribuída ao estiramento do CO linear adsorvido. A banda na região de $1716 \mathrm{~cm}^{-1}$ é atribuída ao estiramento $\mathrm{C}=\mathrm{O}$ do grupo carbonila. Essa banda tem uma forma bipolar, indicando que algum produto ou adsorbato contendo esse grupo funcional já está presente ao potencial de referência $(0,05 \mathrm{~V})$. A banda situada próxima à região de $1460 \mathrm{~cm}^{-1}$ é atribuída à deformação $\mathrm{C}-\mathrm{H}$. A banda em $1403 \mathrm{~cm}$

${ }^{1}$ é atribuída à deformação $-\mathrm{OH}$ mais o estiramento $\mathrm{C}-\mathrm{OH}$ de um ácido carboxílico. 


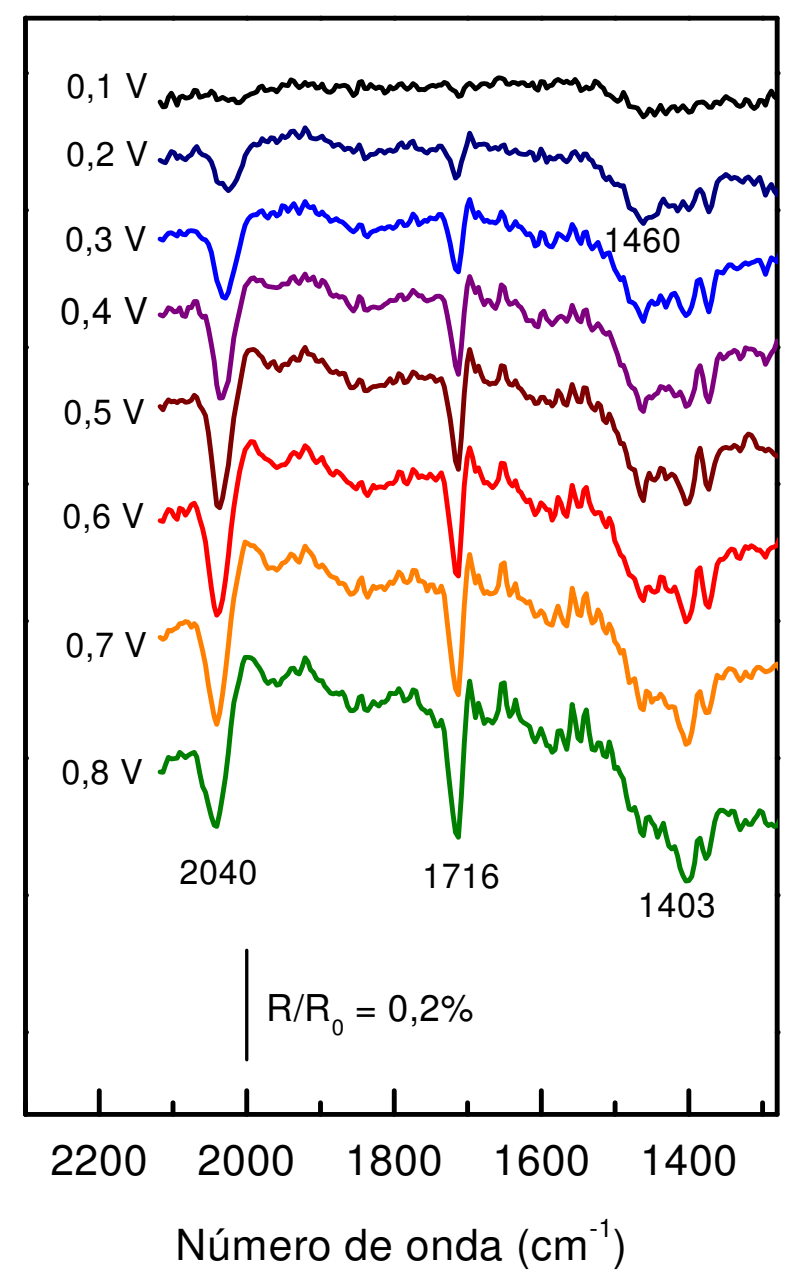

Figura 18 - Espectros de infravermelho para PtRu (70:30). Solução: 1,0M C $\mathrm{H}_{6} \mathrm{O}_{2}+0,1 \mathrm{M} \mathrm{HClO}$ em $\mathrm{D}_{2} \mathrm{O} . \mathrm{E}_{\mathrm{ad} .}=0,05 \mathrm{~V} . \mathrm{T}=25^{\circ}( \pm 1) . \mathrm{E}_{\mathrm{ref} .}=0,05 \mathrm{~V}$.

A partir da análise dos espectros de infravermelho após 7 min de oxidação a um potencial constante de 0,50V para as diferentes ligas de PtRu, nota-se que a concentração de Ru no eletrodo também tem influência na formação dos produtos das reações paralelas (Figura 19). A intensidade das bandas do ácido $\left(1716 \mathrm{~cm}^{-1} \mathrm{e}\right.$ $1400 \mathrm{~cm}^{-1}$ ) aumentam quando o conteúdo de Ru aumenta de $20 \%$ para $30 \%$ em $\mathrm{Ru}$. 


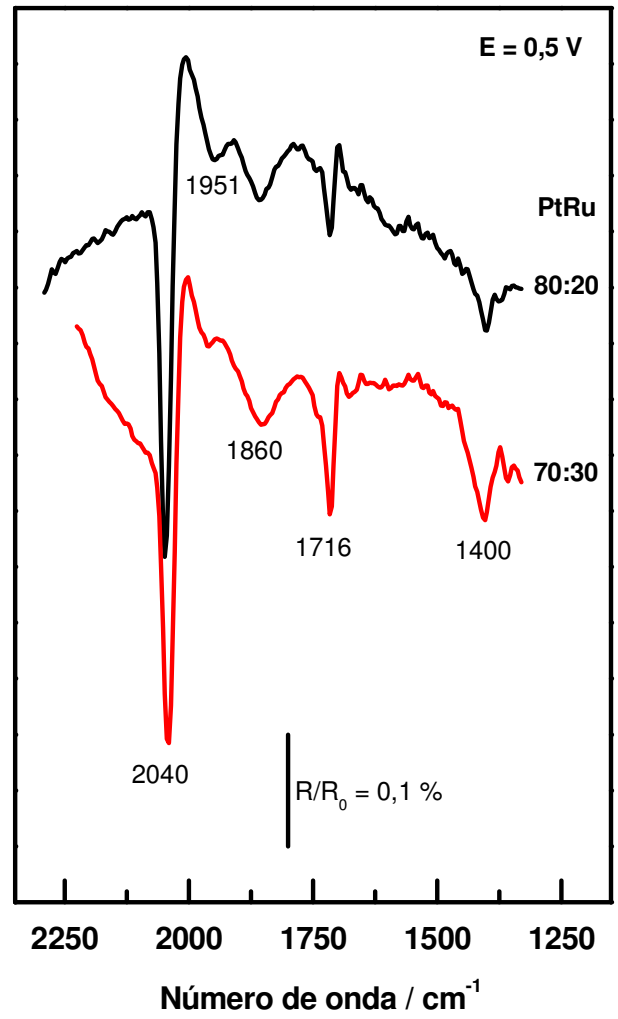

Figura 19 - Espectros de infravermelho para eletrodos de Pt:Ru após 7 min. Solução: 1,0 M $\mathrm{C}_{2} \mathrm{H}_{6} \mathrm{O}_{2}+0,1 \mathrm{M} \mathrm{HClO}_{4} . \quad \mathrm{E}=0,50 \mathrm{~V}$. $\mathrm{T}=25^{\circ}( \pm 1)$. $\mathrm{E}_{\mathrm{ad}}=0,05 \mathrm{~V}$.

Além da banda bipolar na região de $1716 \mathrm{~cm}^{-1}$, outras bandas podem ser observadas nas regiões de $2040 \mathrm{~cm}^{-1}, 1860 \mathrm{~cm}^{-1}$ e $1950 \mathrm{~cm}^{-1}$, atribuídas respectivamente ao $\mathrm{CO}_{\mathrm{ad}}$ na forma linear e ponte e ao $\mathrm{CO}_{\mathrm{ad}}$ nos sítios de $\mathrm{Ru}$ [40].

3.2.2 O efeito da concentração de etileno glicol nas vias de reação

O efeito da concentração de etileno glicol nas vias de reação também foi estudada utilizando a técnica de espectroscopia de infravermelho. No experimento, 
o eletrodo foi polarizado a $0,05 \mathrm{~V}$, realizando em seguida um salto de potencial a $0,50 \mathrm{~V}$. As banda de $\mathrm{CO}_{2}$ e do ácido carboxílico foram monitoradas durante 5 min. Estas bandas foram transformadas em absorbância, A, integradas e divididas pelos seus respectivos coeficientes de absorção molar, $€$ [41]. Este cálculo tem como resultado a quantidade de produtos formados em $\mathrm{mol} \mathrm{cm}^{-2}$ :

$$
\mathrm{Q}=\frac{\mathrm{A}}{\varepsilon}
$$

Apesar da incerteza a respeito da natureza do ácido formado, foi assumido para este cálculo esse é o ácido glicólico. Esta postulação foi logo confirmada por medidas de cromatografia de alta eficiência. Os valores utilizados estão na tabela 2 [41]:

Tabela 2- Valor de freqüência e coeficiente de absorção molar para $\mathrm{CO}_{2}$ e ácido glicólico.

\begin{tabular}{ccc}
\multicolumn{1}{c}{ Espécie } & $v\left(\mathrm{~cm}^{-1}\right)$ & $\epsilon\left(\mathrm{mol}^{-1} \mathrm{~cm}^{-2}\right)$ \\
$\mathrm{CO}_{2}$ & 2345 & $3,5 \times 10^{7}$ \\
$\mathrm{HOH}_{2} \mathrm{C}-\mathrm{COOH}$ & 1242 & $1,0 \times 10^{6}$
\end{tabular}

Os resultados obtidos são apresentados na Figura 20. Note-se que ambos os produtos possuem o mesmo perfil, e as quantidades do ácido carboxílico aumentam até valores de concentração de etileno glicol de 0,30-0,40 M. Por sua vez, o $\mathrm{CO}_{2}$ apresenta um máximo ao redor de $0,10 \mathrm{M}$ e tende a se tornar constante a concentrações acima de 0,6 M de etileno glicol. Além disso, verifica-se que a presença do Ru produz um aumento máximo de 10 vezes na quantidade de ácido. 
Entretanto, a quantidade de $\mathrm{CO}_{2}$ aumenta somente 5 vezes. Em PtRu o ácido carboxílico tende a decrescer à medida que a concentração de etileno glicol aumenta.

O perfil das duas curvas permitiria postular que os processos que levam à formação de ambos os produtos seguem um mecanismo de Langmuir-Hinshelwood. Nesse mecanismo, espera-se que a velocidade da reação passe por um máximo com o recobrimento de uma das espécies reagentes [42, 43].
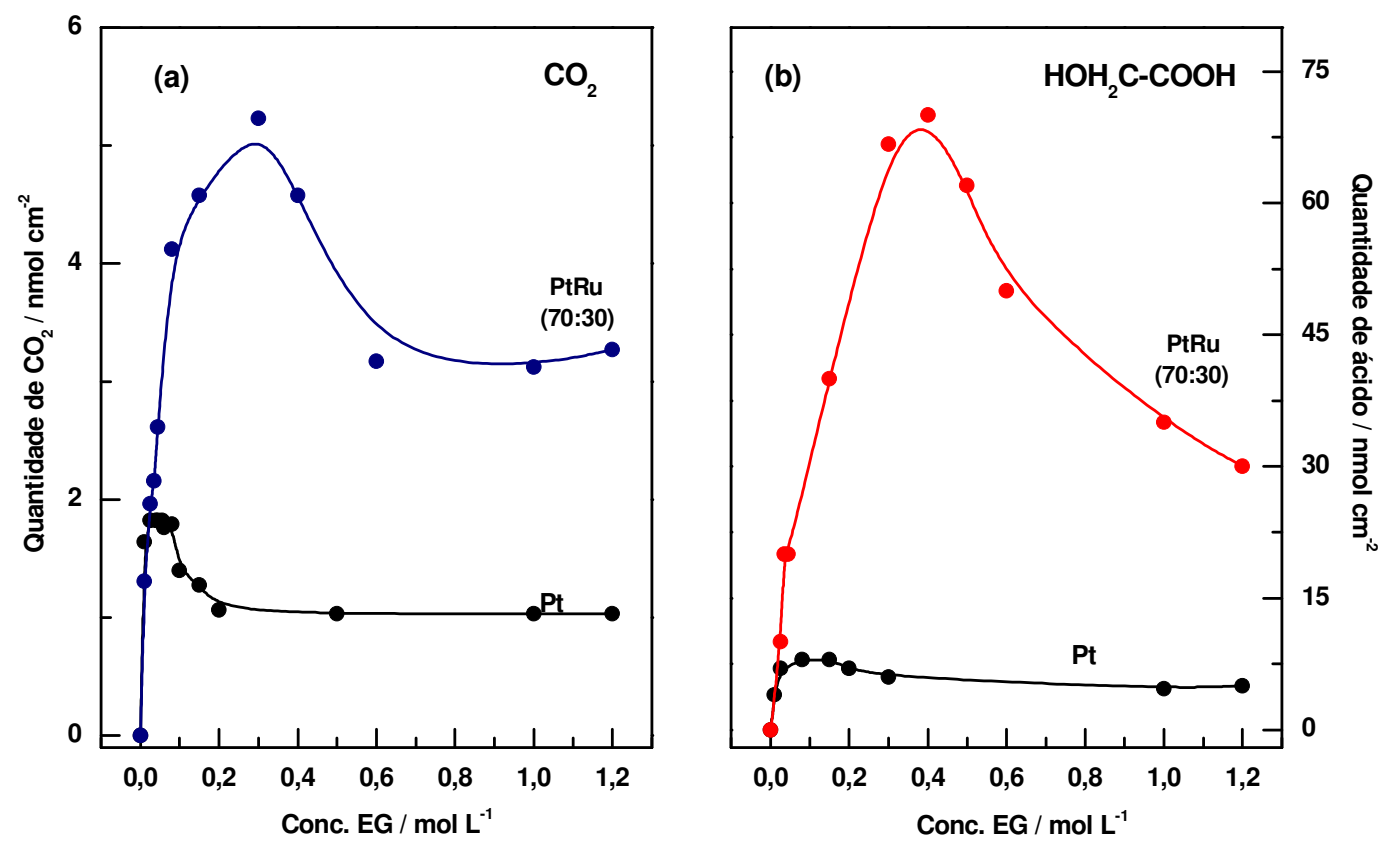

Figura 20 - Quantidades em nmol $\mathrm{cm}^{2}$ para $\mathrm{CO}_{2}$ (a) e para o ácido (b) em função da variação da concentração de etileno glicol no eletrodo de $\mathrm{Pt}$ e de PtRu (70:30). $E_{a d}=0,05$ V. T= 5 min. 
3.2.3 O efeito da composição dos eletrodos de PtRu na corrente de oxidação

Os resultados da atividade catalítica das ligas metalúrgicas de PtRu, mostrando um valor maior de corrente para um conteúdo de Ru de $30 \%$ do que para $20 \%$ ou $40 \%$, indicaram a necessidade de investigar o comportamento de PtRu numa faixa mais ampla de composição. Num trabalho prévio [16], foram apresentados resultados de medidas cronoamperométricas de oxidação de etileno glicol em eletrodepósitos cobrindo a faixa de 0 a $40 \%$ de Ru. Nesse estudo, observou-se um aumento da corrente de 0,2 $\mu \mathrm{A} / \mathrm{cm}^{-2}$ na Pt pura para 11,2 $\mu \mathrm{A} / \mathrm{cm}^{-2}$ em Pt:Ru (60:40) após $60 \mathrm{~min}$ de polarização a 0,50 V. Esses resultados são apresentados na Figura 21 (pontos azuis). No presente trabalho, foram preparados e medidos eletrodepósitos com conteúdos de Ru maiores. Os resultados estão representados na Figura 21 (pontos vermelhos).

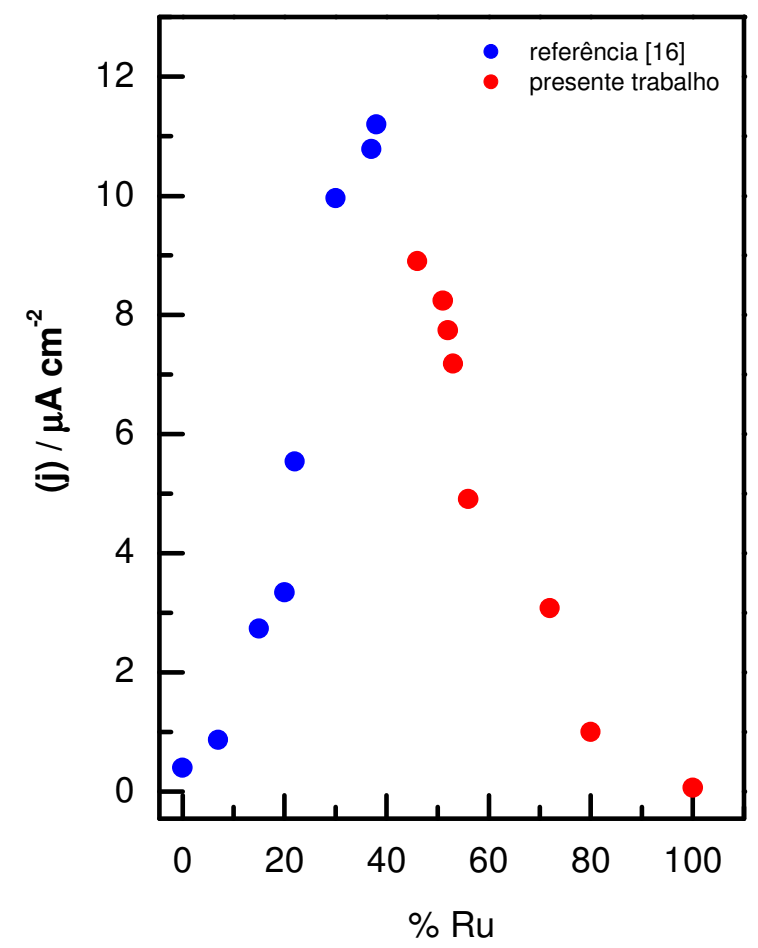

Figura 21 - Dependência da corrente de oxidação de $1,0 \mathrm{~mol} \mathrm{~L}^{-1}+0,5 \mathrm{~mol} \mathrm{~L}^{-1} \mathrm{H}_{2} \mathrm{SO}_{4} \mathrm{com}$ a composição do eletrodo. Potencial: 0,5 V. Dados obtidos a 60 min. 
Observa-se que o efeito catalítico passa por um máximo a cerca de $40 \%$ em Ru. A curva é bastante estreita, o que justificaria a dificuldade de estabelecer exatamente o máximo.

\subsection{Resumo dos resultados de espectroscopia de infravermelho}

A técnica de infravermelho permite estabelecer com segurança no eletrodo de Pt a formação de $\mathrm{CO}_{2}$ como produto solúvel e $\mathrm{CO}_{\mathrm{ad}}$ como intermediário adsorvido. Outros intermediários, contendo 2 átomos de carbono, podem ser postulados devido à presença de bandas de estiramento simétrico e assimétrico do grupo $-\mathrm{CH}_{2}$ (Figura 9), do estiramento $-\mathrm{C}=\mathrm{O}$ da carbonila (Figura 8) e do estiramento simétrico $\mathrm{O}-\mathrm{C}-\mathrm{O}$ do carboxilato (Figura 8).

Outros produtos solúveis seriam o glicolaldeído (carbonila em $1716 \mathrm{~cm}^{-1}$ ) e o ácido glicólico (carbonila em $1747 \mathrm{~cm}^{-1}$ e estiramento $-\mathrm{C}-\mathrm{OH}$ em $1241 \mathrm{~cm}^{-1}$ ).

As maiores quantidades de $\mathrm{CO}_{2}$ e ácido glicólico são formadas no eletrodos de PtRu, e o aumento da quantidade monóxido de carbono indicou uma promoção da dissociação oxidativa do etileno glicol pelo rutênio.

\subsection{Identificação dos produtos parciais de oxidação por cromatografia líquida de alta eficiência (CLAE)}

Com o intuito de identificar e quantificar os produtos de oxidação do etileno glicol nos eletrodos de PtRu, foram realizadas medidas de cromatografia líquida de 
alta eficiência. Inicialmente, amostras contendo as substâncias que pudessem ser geradas durante a oxidação parcial do etileno glicol foram analisadas para observar o tempo de retenção de cada uma na coluna analítica. Os resultados obtidos são apresentados na Figura 22.

Note-se que a primeira substância a ser detectada é o ácido oxálico (7,1 min) seguido pelo ácido glioxílico (11,1 min), depois o glioxal (11,7 min), glicolaldeído (13,5 min) e finalmente o ácido glicólico (14,4 min). Um pequeno sinal é observado próximo a um tempo de retenção de 16 min para todas as substâncias e pode ser atribuído a impurezas contidas no frasco das substâncias.

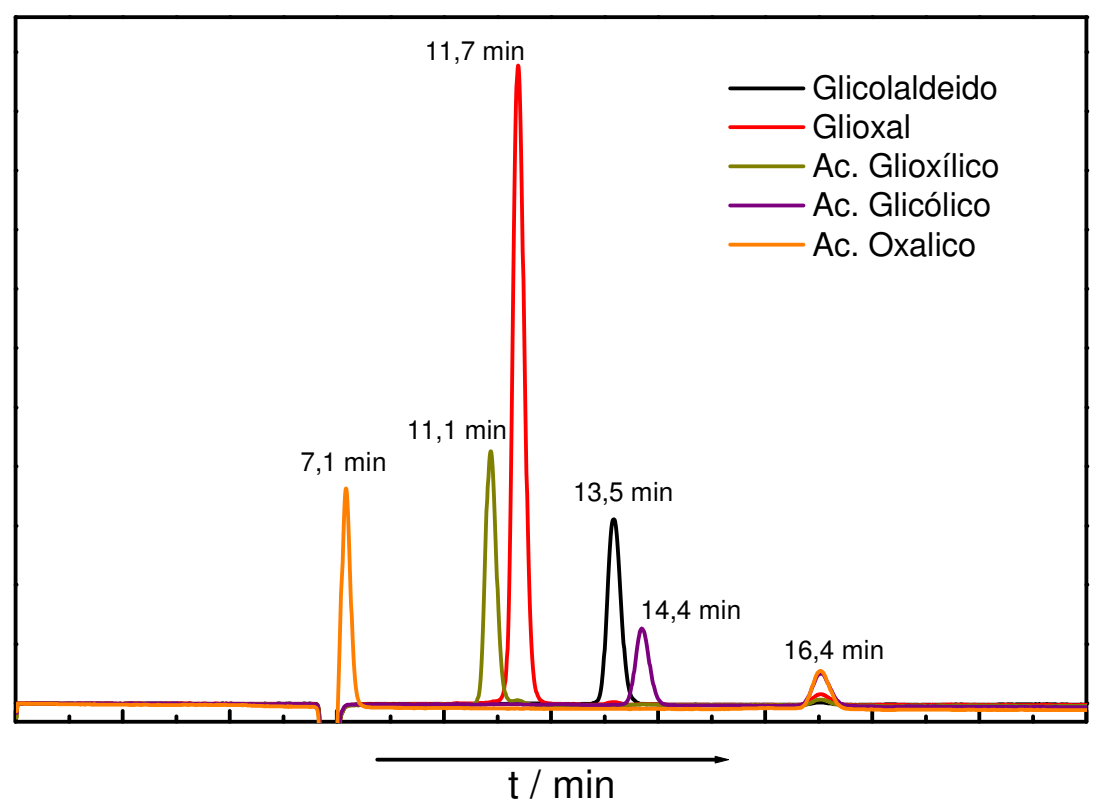

Figura 22 - Cromatogramas obtidos para os diferentes produtos de oxidação parcial estudados. Detector: Índice de refração.

Para a realização da quantificação dos produtos de oxidação do etileno glicol foram preparados três eletrodepósitos: Pt, Pt:Ru (79:21) e Pt:Ru (59:41). A célula utilizada foi descrita na parte experimental deste trabalho (Figura 3). Após adsorção 
do etileno glicol a um potencial de $0,05 \mathrm{~V}$ foi realizado um salto de potencial a $0,50 \mathrm{~V}$ por um período de $20 \mathrm{~min}$.

$\mathrm{Na}$ Figura 23 são apresentados os valores de corrente em função da concentração de etileno glicol após 20 min de eletrólise. Verifica-se que todos os eletrodos possuem um perfil semelhante nos valores de corrente: A corrente aumenta rapidamente com a concentração até valores de $0,5 \mathrm{M}$, quando ocorre uma pequena queda nos valores para 1,0 M, tornando-se estável em seguida. Nota-se que a presença de Ru melhora os níveis obtidos de corrente quando comparado com o eletrodo de Pt.

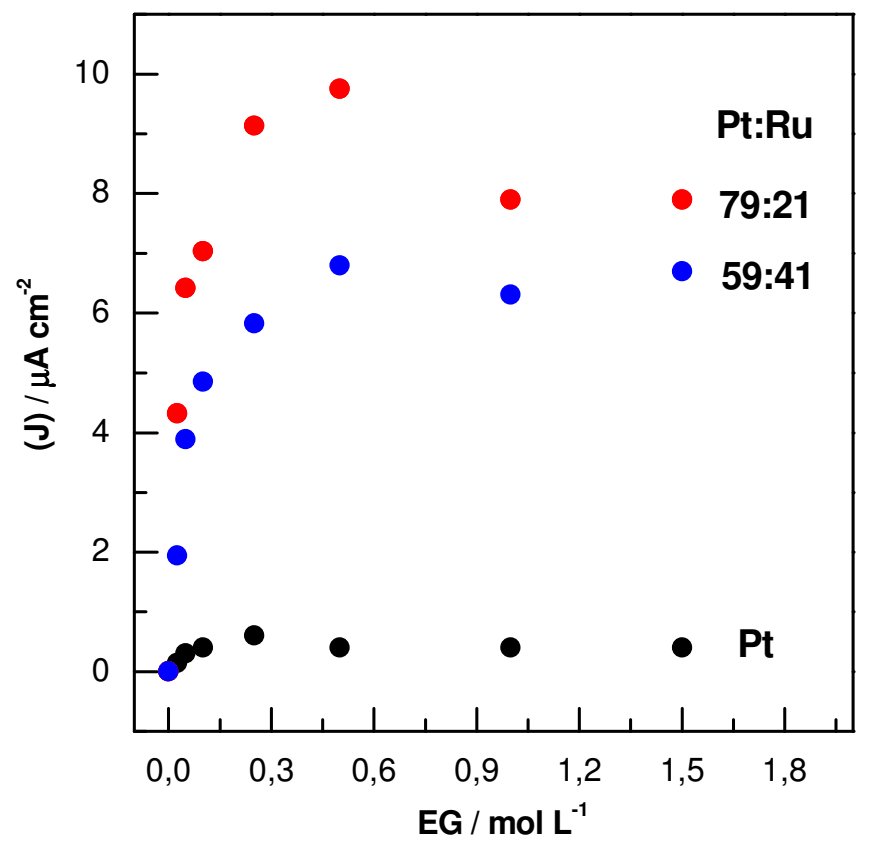

Figura 23 - Valores de corrente em função da concentração de $\mathrm{C}_{2} \mathrm{H}_{6} \mathrm{O}_{2}$ após a eletrólise de $20 \mathrm{~min}$. $\mathrm{E}$ $=0,50 \mathrm{~V} . \mathrm{T}=25^{\circ} \mathrm{C}$.

Após a eletrólise foi coletada uma alíquota para a análise quantitativa dos produtos por cromatografia líquida. Devido ao etileno glicol possuir um pico na mesma posição de tempo de retenção do glicolaldeído no cromatograma, ele não 
pode ser quantificado. Por isso, somente os resultados quantitativos do ácido carboxílico foram levados em consideração. O resultado obtido para as quantidades do ácido glicólico em função da concentração de etileno glicol pode ser observado no gráfico da Figura 24.

Assim, nos eletrodos contendo $\mathrm{Ru}$, as quantidades do ácido oscilam ao redor de 8-15 nmols para o eletrodo contendo $21 \%$ em $\mathrm{Ru}$, mantendo-se aproximadamente em 9 nmols para o eletrodo com 41\%. As quantidades de ácido glicólico no eletrodo de Pt são praticamente desprezíveis a 0,50 V. Os resultados de cromatografia confirmam os dados experimentais obtidos por espectroscopia de infravermelho (Figura 20), os quais indicam que a presença de Ru na superfície do eletrodo favorece a via de reação que leva à formação de ácido glicólico.

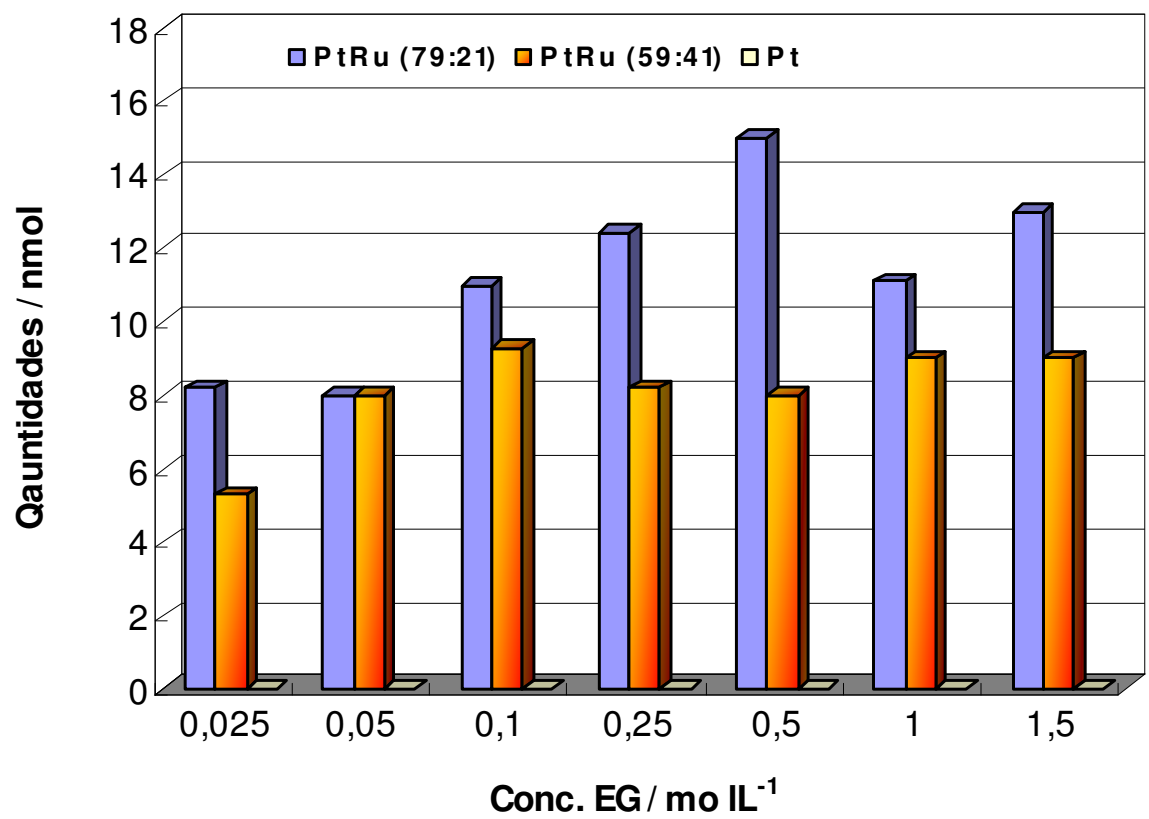

Figura 24 - Quantidades em nmol normalizadas por $\mathrm{cm}^{2}$ de área real de Acido glicólico após a eletrólise de 20 min para diferentes concentrações de $\mathrm{EG}$ em 1,0 $\mathrm{M} \mathrm{HClO}_{4}$ sobre eletrodos de Pt e $\mathrm{Pt}: \mathrm{Ru} . \mathrm{E}=0,50$ V. $\mathrm{T}=25^{\circ} \mathrm{C}$. Erro $<5 \%$. 
As diferenças nas quantidades do ácido para os eletrodos de PtRu podem ser explicadas por um mecanismo promotor do Ru atuando como doador de oxigênio. O Ru tem a capacidade de dissociar a molécula de água em baixos potenciais formando espécies oxigenadas [34]; e a formação de produtos como o $\mathrm{CO}_{2}$ e os ácidos carboxílicos depende dessas espécies oxigenadas na superfície do eletrodo [44]. A rota mais provável para a formação do ácido seria pela adsorção do glicolaldeído e posterior oxidação pelas espécies oxigenadas formadas (10).

$$
\left(\mathrm{HOH}_{2} \mathrm{C}-\mathrm{CHO}\right)_{\mathrm{ad}}+\mathrm{Ru}-\mathrm{OH} \longrightarrow \mathrm{HOH}_{2} \mathrm{C}-\mathrm{COOH}+2 \mathrm{H}^{+}+2 \mathrm{e}^{-}
$$

3.4.1 Estimativa das porcentagens de glicolaldeído e $\mathrm{CO}_{2}$ formados

As quantidades de ácido glicólico medidas por cromatografia líquida resultaram sempre menores do que o esperado para quantidade de carga medida. Os estudos de infravermelho mostraram que para uma concentração $1,0 \mathrm{M}$ de etileno glicol em PtRu (70:30) forma-se dez vezes mais ácido do que $\mathrm{CO}_{2}$ (Figura 20). Para essa concentração de etileno glicol em $\operatorname{PtRu}\left(79: 21, A_{\text {at. }}=81 \mathrm{~cm}^{2}\right)$, a quantidade de carga correspondente à formação de $11 \times 10^{-9} \mathrm{nmols} \mathrm{cm}^{-2}$ de ácido glicólico é de 0,32 C, sendo a carga total observada nesse experimento 1,13 C. Se a quantidade de $\mathrm{CO}_{2}$ formada fosse $1,1 \times 10^{-9}$ mols $\mathrm{cm}^{-2}$, a carga correspondente seria 0,086 C. Assim, a diferença entre a carga total e a carga proveniente da formação de $\mathrm{CO}_{2}$ e ácido glicólico corresponderia ao glicolaldeído $(1,13-0,32-0,086=0,724$ C). Portanto, $28 \%$ da carga seria utilizada para formar ácido glicólico, $8 \%$ para 
formar $\mathrm{CO}_{2}$ e $64 \%$ para formar glicolaldeído, sendo este último o produto principal da oxidação.

\subsection{Provável esquema de reação}

As informações coletadas ao longo deste trabalho para a eletrooxidação de etileno glicol nos eletrodos de Pt e Pt:Ru fornecem dados para as seguintes vias de reação: (a) o primeiro caminho seria a adsorção e conseqüente dissociação da molécula de etileno glicol formando $\mathrm{CO}_{\mathrm{ad}}$ e outras espécies adsorvidas contendo hidrogênio e, posteriormente, a oxidação dos adsorbatos a $\mathrm{CO}_{2}$; b) a oxidação de etileno glicol a glicolaldeído, podendo esta espécie se adsorver e dissociar formando CO como principal intermediário que é posteriormente oxidado a $\mathrm{CO}_{2}$; e c) o glicolaldeído formado pode sofrer uma oxidação parcial produzindo ácido glicólico. As vias de reação propostas são resumidas no esquema reacional abaixo:

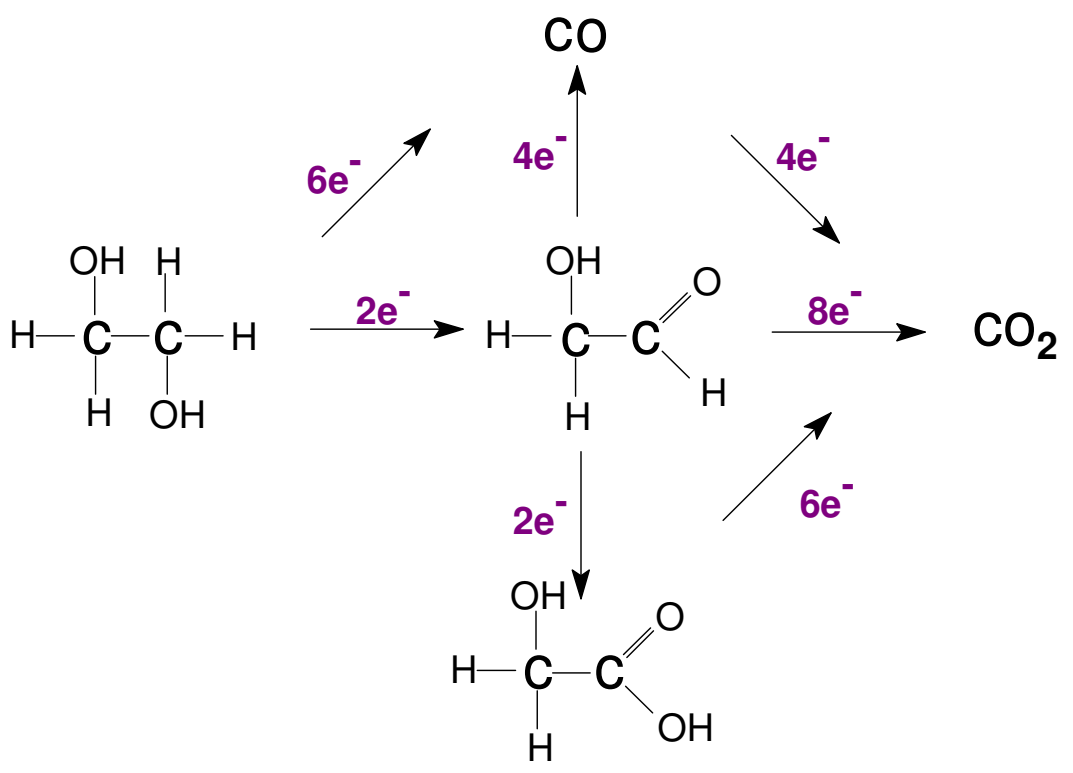

Figura 25 - Esquema proposto para a eletrooxidação de etileno glicol sobre eletrodos de Pt e PtRu. 


\subsection{Eletrooxidação dos produtos parciais de oxidação do etileno glicol em eletrodos de Pt e PtRu}

Conforme os resultados de espectroscopia de infravermelho e cromatografia líquida de alta eficiência, $\mathrm{CO}_{2}$, glicolaldeído e ácido glicólico são produtos de reação formados durante a eletrooxidação de etileno glicol. Os produtos de oxidação parcial podem difundir para o seio da solução ou adsorver-se na superfície do eletrodo oxidando para outros produtos.

Para estudar o comportamento desses produtos durante a oxidação do álcool, cada um deles foi estudado separadamente. A Figura 26 apresenta a resposta de corrente durante a eletrooxidação do glicolaldeído $(0,1 \mathrm{M})$ e do ácido glicólico $(0,1$ M) em um eletrodo de Pt:Ru (72:28).

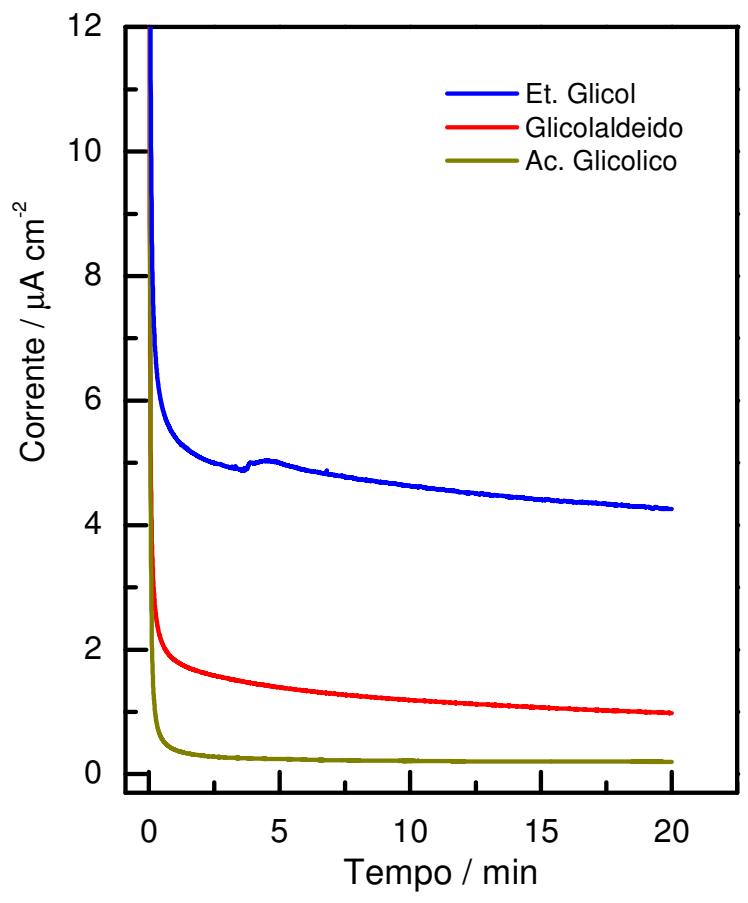

Figura 26 - Curvas corrente vs tempo para a oxidação do etileno glicol $(0,1 \mathrm{M})$ e dos seus produtos parciais de oxidação $(0,1 \mathrm{M}) . \mathrm{E}=0,50 \mathrm{~V} . \mathrm{T}=25^{\circ} \mathrm{C}$. 
Observa-se que todas as substâncias analisadas apresentam uma baixa eficiência de corrente quando comparadas ao o álcool. A corrente gerada pela oxidação do etileno glicol é cerca de quatro vezes maior quando comparada à corrente gerada pelo aldeído e vinte duas vezes maior quando comparada ao ácido.

Para melhor compreender e identificar os adsorbatos e os produtos de oxidação do aldeído e do ácido, foram realizados experimentos utilizando as técnicas eletroquímicas convencionais, além da técnica de espectroscopia de infravermelho in situ e cromatografia líquida de alta eficiência (CLAE).

\subsubsection{Eletrooxidação de Glicolaldeído em eletrodos de Pt e PtRu}

O glicolaldeído é considerado um açúcar simples contendo em sua estrutura molecular um grupamento carbonila $(-\mathrm{C}=\mathrm{O})$ e na outra extremidade um grupo hidroxila $(-\mathrm{OH})$. Este aldeído pode ser formado pela simples desprotonação da molécula de etileno glicol. A eletrooxidação de glicolaldeído tem sido estudada [45], mas pouco ainda se sabe sobre seus produtos de oxidação e principalmente sobre a natureza dos seus adsorbatos.

A Figura 27 apresenta um voltamograma para a eletrooxidação de $0,1 \mathrm{M}$ de glicolaldeído em eletrodo de platina policristalina. Podem ser observadas três regiões: A primeira delas (I) se inicia a $0,75 \mathrm{~V}$, atingindo um máximo a potenciais próximos de 0,85; a segunda (II) inicia-se a potenciais próximos a 1,0 V e a terceira região (III) é observada na varredura de retorno, e se inicia a um potencial próximo de $0,85 \mathrm{~V}$. Esta nova ativação está relacionada à recuperação da atividade catalítica após a redução dos óxidos de Pt. 


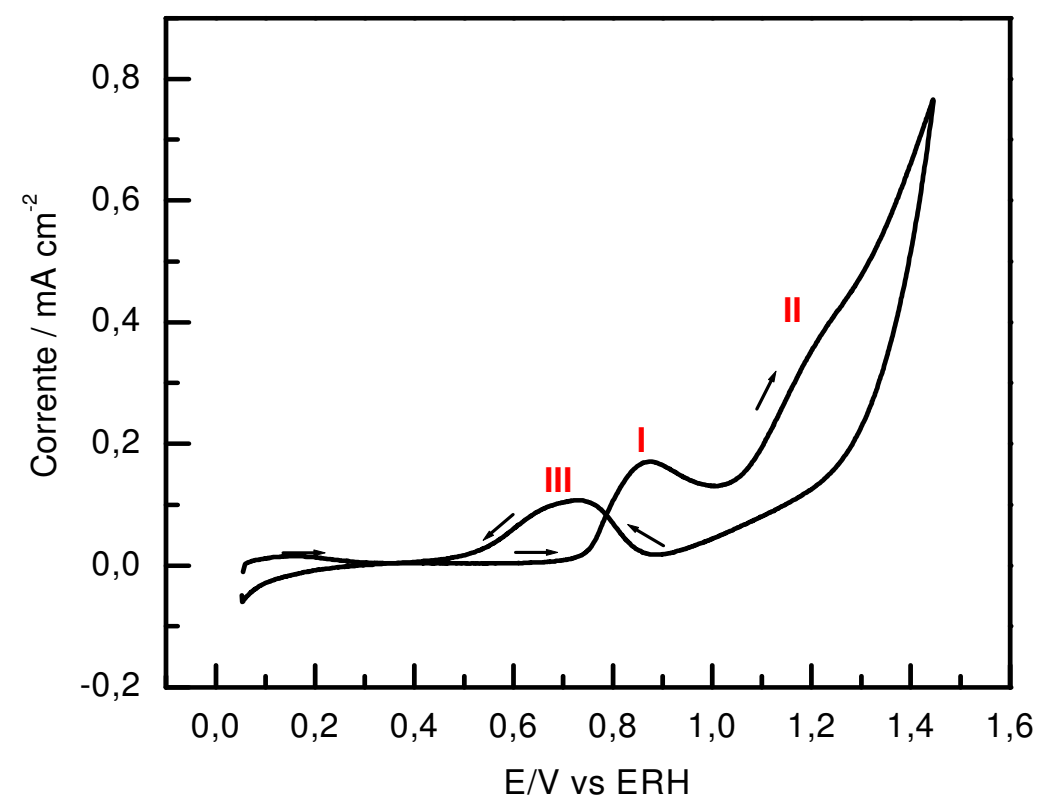

Figura 27 - Curva corrente vs potencial a $0,01 \mathrm{Vs}^{-1}$ para $0,1 \mathrm{M}$ $\mathrm{C}_{2} \mathrm{H}_{4} \mathrm{O}_{2}+0,1 \mathrm{M} \mathrm{HClO}_{4}$ em Pt. $\mathrm{E}_{\mathrm{ad}}=0,05 \mathrm{~V} . \mathrm{T}=25^{\circ} \mathrm{C}( \pm 1)$.

3.6.2 Análise dos produtos formados durante a adsorção e oxidação do glicolaldeído

Ao oxidar-se, a molécula de glicolaldeído pode gerar dióxido de carbono como produto total de oxidação ou outros produtos de oxidação parcial.

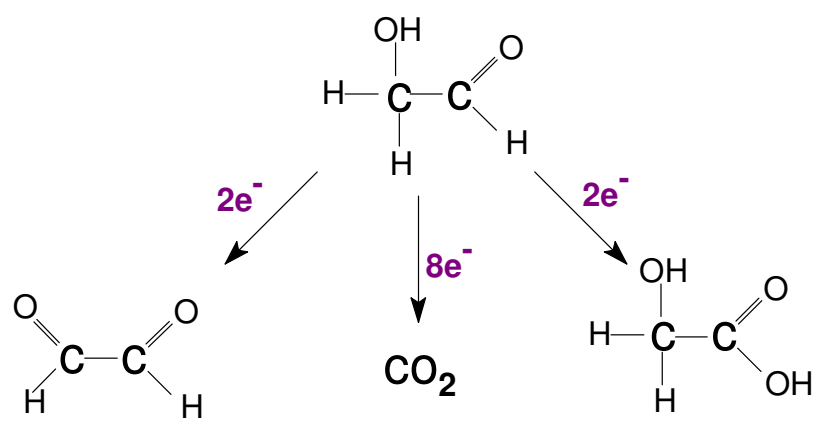

Ac. glicólico 
Para identificar os produtos gerados durante a oxidação do glicolaldeído foram realizados experimentos de espectroscopia de infravermelho. No primeiro deles, o glicolaldeído $(0,1 \mathrm{M})$ foi adsorvido a um potencial de $0,05 \mathrm{~V}$ e em seguida foram realizados saltos de potencial de $0,05 \mathrm{~V}$ entre 0,05 e 1,2 V. Os espectros coletados são apresentados na Figura 28. Na tabela 3 é apresenta atribuição de bandas para os ácidos carboxílicos.

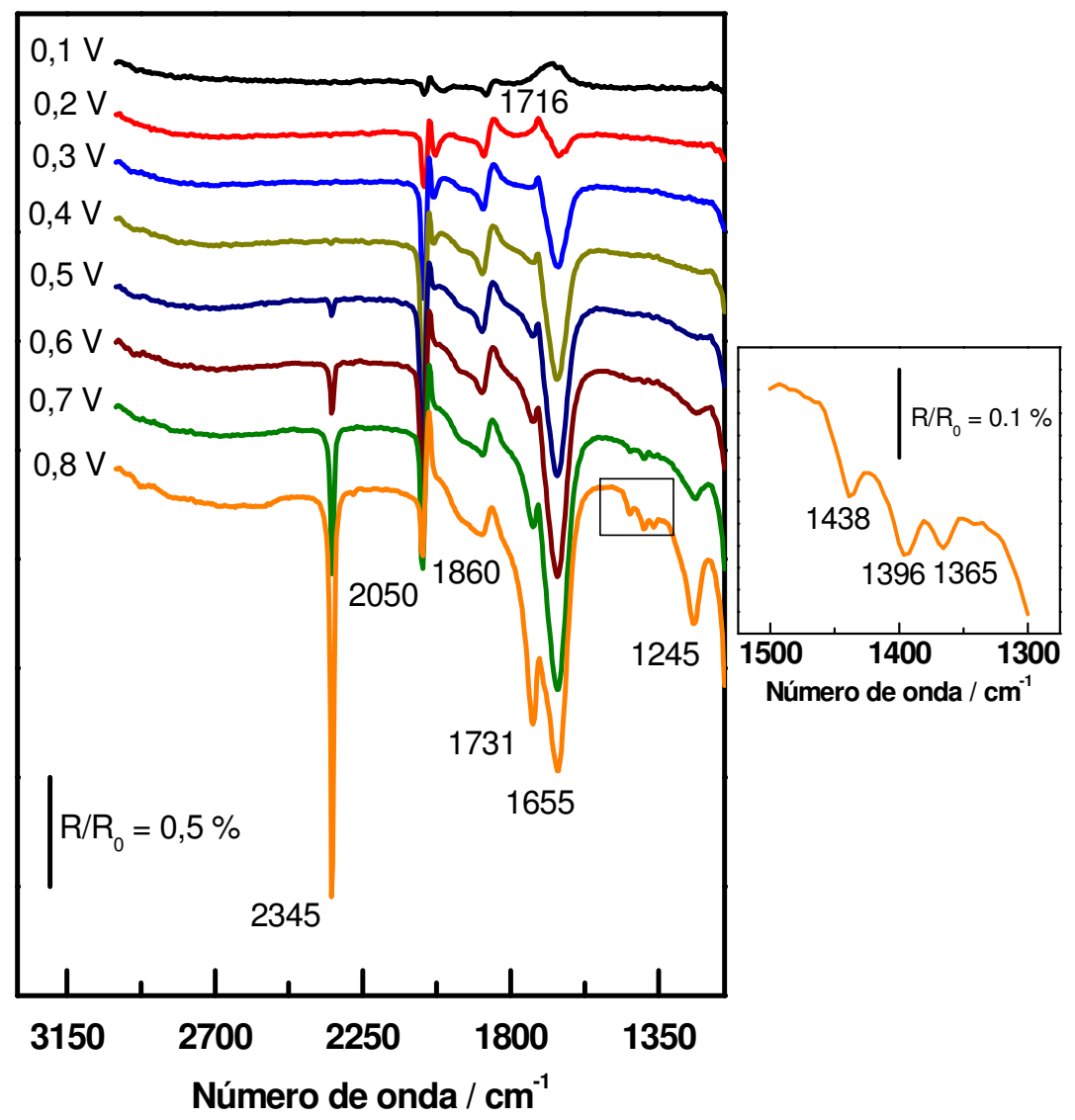

Figura 28 - Espectros de infravermelho para a oxidação $0,1 \mathrm{M}$ glicolaldeído em 0,1 $\mathrm{M} \mathrm{HClO}_{4}$. Eletrodo de Pt. $E_{\mathrm{ad}}=0,05 \mathrm{~V}$. Resolução: $8,0 \mathrm{~cm}^{-1}$. $\mathrm{T}=25^{\circ} \mathrm{C}$. 
Tabela 3 - Atribuição das freqüências para o ácido carboxílico.

\begin{tabular}{|c|l|}
\hline $\begin{array}{c}\text { Freqüência } \\
\left(\mathrm{cm}^{-1}\right)\end{array}$ & \multicolumn{1}{|c|}{ Atribuição } \\
\hline 1245 & Estiramento $\mathrm{C}-\mathrm{OH}$ \\
\hline 1365 & Deformação $-\mathrm{OH}$ def. \\
\hline 1396 & Estiramento $-\mathrm{C}=\mathrm{O}+$ deformação $-\mathrm{OH}$ ou estiramento $\mathrm{CO}_{2}^{-}$ \\
\hline 1438 & Deformação $-\mathrm{CH}$ \\
\hline 1731 & Estiramento $-\mathrm{C}=\mathrm{O}$ \\
\hline
\end{tabular}

As bandas observadas podem ser atribuídas às seguintes espécies: A um potencial de $0,50 \mathrm{~V}$, pode-se ver a $2345 \mathrm{~cm}^{-1}$ a banda característica de $\mathrm{CO}_{2}$. As bandas em $2050 \mathrm{~cm}^{-1}$ e $1860 \mathrm{~cm}^{-1}$ são atribuídas respectivamente ao $\mathrm{CO}_{\mathrm{ad}}$ na forma linear e ao $\mathrm{CO}_{\mathrm{ad}}$ na forma ponte. Nota-se um forte caráter bipolar em ambas as bandas, indicando que no potencial de referência o aldeído se dissocia.

A banda positiva situada em $1716 \mathrm{~cm}^{-1}$ é atribuída ao estiramento simétrico do grupo $\mathrm{C}=\mathrm{O}$ do glicolaldeído consumido na camada fina. A banda em $1655 \mathrm{~cm}^{-1}$ é atribuída à deformação $\mathrm{O}-\mathrm{H}$ da água não compensada. $\mathrm{O}$ conjunto de bandas nas regiões de $1731 \mathrm{~cm}^{-1}, 1438 \mathrm{~cm}^{-1}$ e $1396 \mathrm{~cm}^{-1}, 1365 \mathrm{~cm}^{-1}$ e $1245 \mathrm{~cm}^{-1}$ indica a formação de um ácido carboxílico, provavelmente o ácido glicólico [37-39].

\subsubsection{Estudos das espécies fortemente adsorvidas do glicolaldeído}

Outro ponto abordado foi a determinação da natureza dos adsorbatos provenientes da dissociação parcial do glicolaldeído na superfície do catalisador. Para estudar as espécies formadas, foi utilizada a célula da Figura 2 e um sistema de troca de solução [27, 44], semelhante ao já mostrado para o etileno glicol. 
O glicolaldeído $(0,02 \mathrm{M})$ foi adsorvido a um potencial de 0,05 V por um período de $10 \mathrm{~min}$ e, em seguida, realizada a troca de solução pela do eletrólito suporte. Após a troca da solução, foram realizados saltos de potencial de $0,05 \mathrm{~V}$ entre $0,05 \mathrm{~V}$ e $1,45 \mathrm{~V}$ para oxidar os adsorbatos. Durante toda a fase experimental, a atmosfera da célula foi controlada para evitar a oxidação prematura dos adsorbatos. Os espectros obtidos em função do potencial aplicado ao eletrodo são apresentados na Figura 29 e na Tabela 4, a atribuição correspondente de bandas.

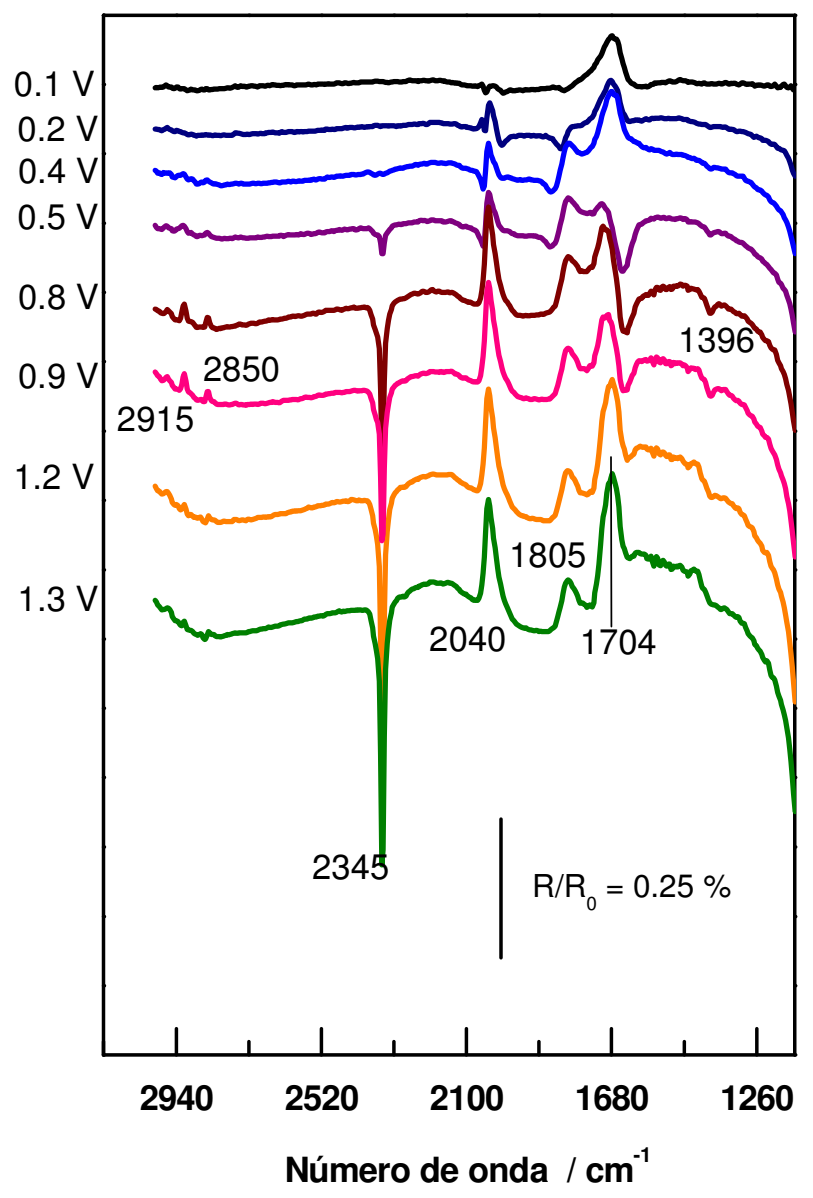

Figura 29 - Espectros de infravermelho para a oxidação das espécies adsorvidas de glicolaldeído sobre eletrodo de $\mathrm{Pt}$ policristalina. $\mathrm{E}_{\mathrm{ad}}=0,05 \mathrm{~V}$. Resolução: $8,0 \mathrm{~cm}^{-1}$. $\mathrm{T}=25 \stackrel{\circ}{\mathrm{C}}$. $\mathrm{E}_{\text {ref. }}=0,05 \mathrm{~V}$. 
Tabela 4 - Atribuição das freqüências para as bandas dos adsorbatos do glicolaldeído.

\begin{tabular}{|c|l|}
\hline $\begin{array}{c}\text { Freqüência } \\
\left(\mathrm{cm}^{-1}\right)\end{array}$ & \multicolumn{1}{|c|}{ Atribuição } \\
\hline $2915-2850$ & Estiramento simétrico e assimétrico $\mathrm{CH}_{2}$ \\
\hline $2040-1805$ & Estiramento $\mathrm{CO}_{\mathrm{L}}$ e $\mathrm{CO}_{\mathrm{B}}$ \\
\hline 1704 & Estiramento do grupo carbonila $-\mathrm{C}=\mathrm{O}$ \\
\hline 1396 & $\begin{array}{l}\text { Estiramento }-\mathrm{C}-\mathrm{O}+\text { deformação }-\mathrm{OH} \text { ou estiramento } \\
\text { simétrico }-\mathrm{CO}_{2}^{-}\end{array}$ \\
\hline
\end{tabular}

Os espectros de infravermelho dos adsorbatos do glicolaldeído no eletrodo de Pt fornecem informações necessárias para se propor dois outros adsorbatos além do monóxido de carbono para a adsorção dissociativa do glicolaldeído. Esses adsorbatos teriam em sua estrutura molecular o grupo $\mathrm{CH}_{2}$ e grupo $\mathrm{C}=\mathrm{O}$. Abaixo são ilustrados os adsorbatos propostos.

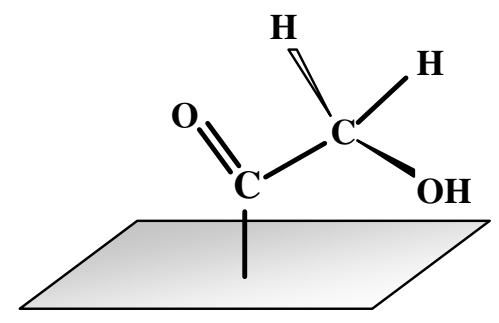

(I)

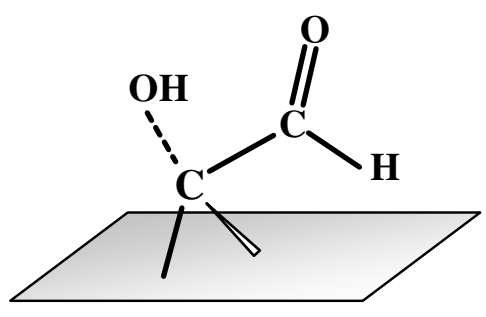

(II)

Figura 30 - Adsorbatos postulados para a adsorção não dissociativa do glicolaldeído em eletrodos de Pt policristalina. 
No primeiro (I) a liberdade de rotação da ligação C-C permitiria observar os modos simétrico e assimétrico do grupo $-\mathrm{CH}_{2}$. O arranjo geométrico forneceria também a interação do feixe de infravermelho com o grupo carbonila $\left(1704 \mathrm{~cm}^{-1}\right)$ Outro adsorbato (II) que poderia apresentar o estiramento da ligação do grupo carbonila ativo à radiação infravermelha estaria ligado a dois sítios de Pt.

Além da banda em $2345 \mathrm{~cm}^{-1}$, que indica a formação de $\mathrm{CO}_{2}$, observa-se uma banda situada na região de $1396 \mathrm{~cm}^{-1}$. A mesma banda foi observada para a oxidação dos adsorbatos do etileno glicol. A banda em $1396 \mathrm{~cm}^{-1}$ pode ser atribuída ao estiramento simétrico da ligação $\mathrm{CO}_{2}^{-}$do glicolato.

3.6.4 Estudo das espécies formadas na oxidação de glicolaldeído em eletrodos de PtRu

A eletrooxidação do glicolaldeído também foi estudada em eletrodos de Pt:Ru. A Figura 31 traz os espectros coletados para a oxidação de $0,1 \mathrm{M}$ de glicolaldeído no eletrodo de Pt:Ru (80:20). Os resultados obtidos mostram o forte caráter bipolar da banda de CO localizada em $2040 \mathrm{~cm}^{-1}$ da mesma forma que foi observado para o eletrodo de Pt (Figura 28). A 0,45 V percebe-se a banda de $\mathrm{CO}_{2}$, no entanto, ela surge a um potencial mais baixo do que o observado para o eletrodo de Pt. A um potencial de 0,60 na região de $1735 \mathrm{~cm}^{-1}$ nota-se a forte banda atribuída ao estiramento $\mathrm{C}=\mathrm{O}$ do grupo carbonila do ácido carboxílico formado. 


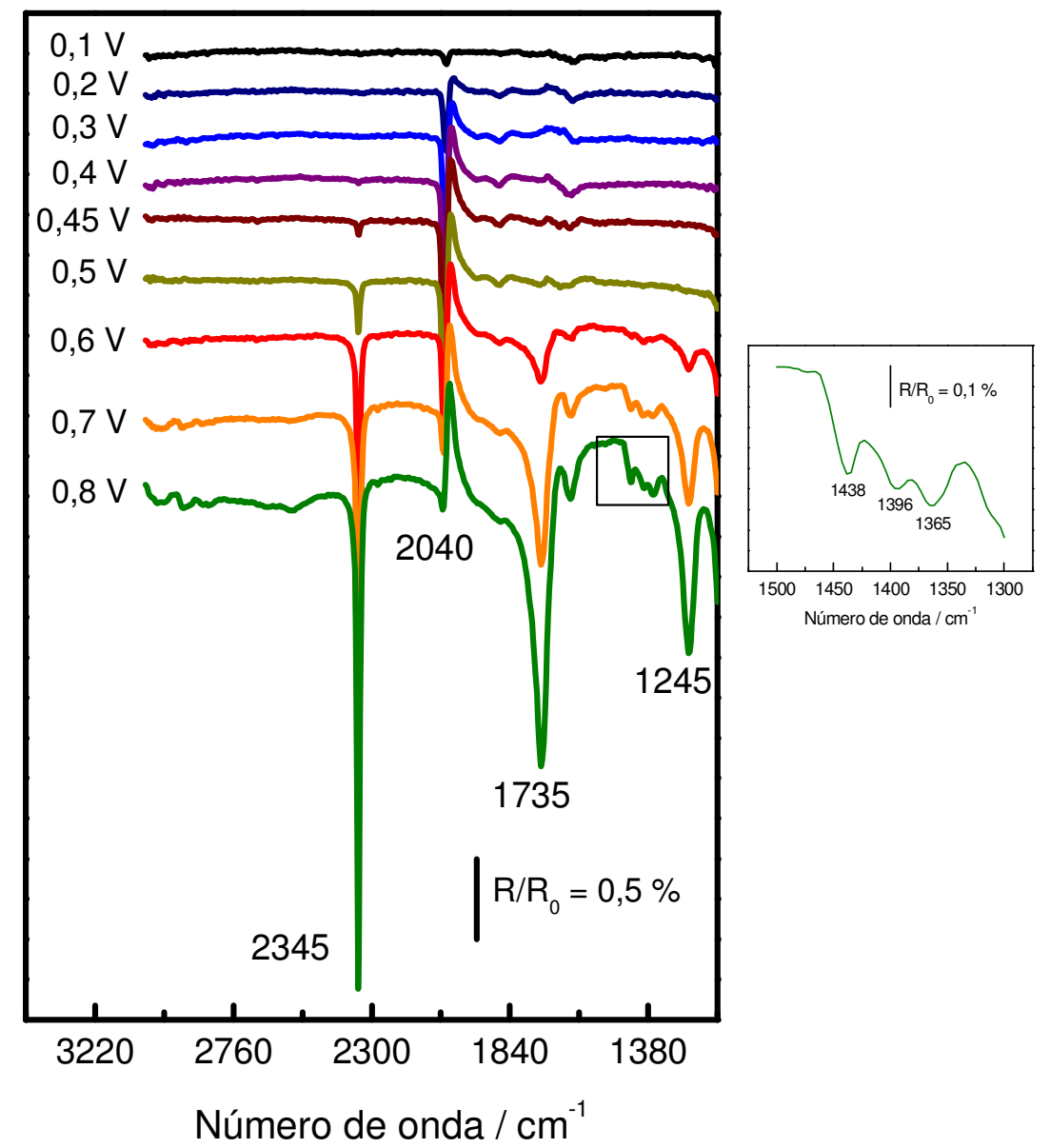

Figura 31 - Espectros de infravermelho para a eletrooxidação de glicolaldeído em função do potencial na liga de Pt:Ru (80:20).

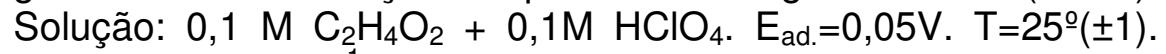
Resolução: $8,0 \mathrm{~cm}^{-1}$.

No intervalo de freqüência compreendido entre $1500 \mathrm{~cm}^{-1}$ e $1300 \mathrm{~cm}^{-1}$, observase três bandas de baixa intensidade situadas em $1438 \mathrm{~cm}^{-1}, 1396 \mathrm{~cm}^{-1}$ e $1365 \mathrm{~cm}^{-1}$, todas elas atribuídas à formação de um ácido carboxílico (vide tabela 3). Para confirmar se a banda em $1396 \mathrm{~cm}^{-1}$ é oriunda de uma espécie adsorvida, experimentos utilizando a luz polarizada-s, foram executados durante o salto de 
potencial. O resultado obtido para a oxidação de $0,1 \mathrm{M}$ de glicolaldeído no potencial e 0,80 para os dois tipos de luzes utilizadas pode ser observado na Figura 32.

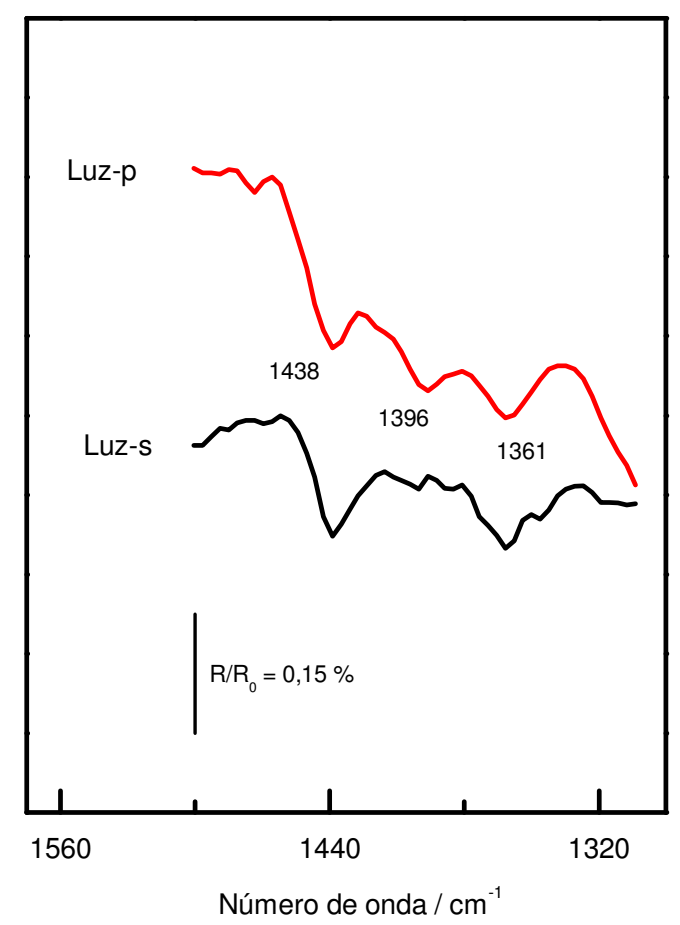

Figura 32 - Espectros de infravermelho para eletrooxidação de $\mathrm{C}_{2} \mathrm{H}_{4} \mathrm{O}_{2}$ a 0,80 V para Pt:Ru (70:30). Luz polarizada-p e luz polarizada-s. Resolução: $8,0 \mathrm{~cm}^{-1}$. $T=25^{\circ}( \pm 1)$.

Comparando os dois espectros, percebe-se que as bandas em $1438 \mathrm{~cm}^{-1}, 1361$ $\mathrm{cm}^{-1}$ estão presentes em ambos, porém, a banda situada em $1396 \mathrm{~cm}^{-1}$ não aparece no espectro coletado com a luz polarizada-s confirmando a existência de uma espécie adsorvida, possivelmente, o etileno glicolato.

As intensidades da banda de CO linear $\left(2040 \mathrm{~cm}^{-1}\right)$ e da banda de $\mathrm{CO}_{2}(2345$ $\mathrm{cm}^{-1}$ ) obtidas em função do potencial para a oxidação de $0,1 \mathrm{M}$ de glicolaldeído também foram analisadas. Devido ao caráter bipolar da banda de $\mathrm{CO}$ em ambos os tipos de eletrodo, os espectros coletados precisaram ser reprocessados para se 
obter uma banda absoluta de $\mathrm{CO}$. $\mathrm{A}$ banda de $\mathrm{CO}_{2}$ foi tomando como referência à banda de $\mathrm{CO}_{2}$ máxima obtida pela oxidação de uma monocamada de $\mathrm{CO}$ adsorvido (vide parte experimental). A Figura 33 mostra os valores obtidos para $\mathrm{CO}$ e $\mathrm{CO}_{2}$.

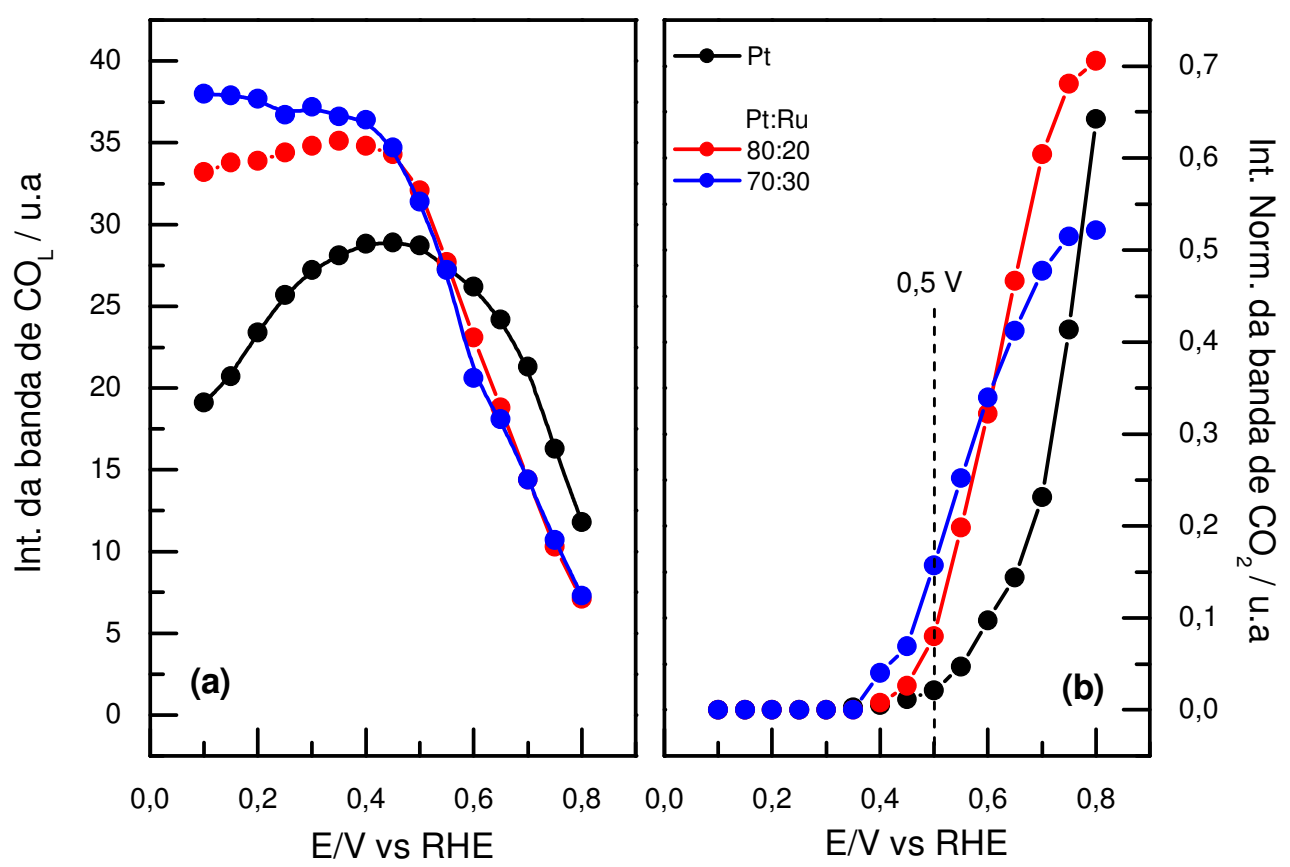

Figura 33 - Intensidade da banda de $\mathrm{CO}$ (a) e $\mathrm{CO}_{2}$ (b) vs potencial para os eletrodos de $\mathrm{Pt}$ e PtRu. Solução: $0,1 \quad \mathrm{M} \mathrm{C}_{2} \mathrm{H}_{4} \mathrm{O}_{2}+0,1 \mathrm{M} \mathrm{HClO}_{4}$. $E_{\text {ad. }}=0,05 \mathrm{~V} . \mathrm{T}=25^{\circ}( \pm 1)$

O perfil dos gráficos é bastante semelhante ao obtido para a eletrooxidação do etileno glicol. A intensidade integrada da banda de $\mathrm{CO}$ linear é maior para os eletrodos que contém Ru (Figura 33-(a)). Neste caso, a intensidade da banda chega rapidamente a um valor máximo a $0,10 \mathrm{~V}$. Em $\mathrm{PtRu}$, a banda de $\mathrm{CO}$ chega a ser quase duas vezes maior do que em Pt. A intensidade da banda de CO começa a diminuir a potenciais próximos de $0,45 \mathrm{~V}$ para os eletrodos de $\mathrm{Pt}: \mathrm{Ru}(70: 30)$ e de 0,55 V para o eletrodo de Pt. Esses potenciais coincidem com a formação de $\mathrm{CO}_{2}$ 
observada na Figura 33-(b). Note-se que os valores da intensidade da banda de $\mathrm{CO}_{2}$ é de 0,02 u.a para a Pt e de 0,15 u.a para o eletrodo de PtRu (70:30).

Os resultados obtidos com a técnica de infravermelho in situ indicam a formação de outros produtos de reação provenientes de reações paralelas que ocorrem durante o processo de adsorção da molécula de glicolaldeído. Durante a eletrooxidação do glicolaldeído, as bandas de carbonila em $1735 \mathrm{~cm}^{-1}$ e a banda do estiramento $\mathrm{C}-\mathrm{OH}$ em $1245 \mathrm{~cm}^{-1} 1$ indicam a formação de ácido glicólico.

No entanto, outros ácidos carboxílicos como o ácido glioxílico e o ácido oxálico possuem freqüências de estiramentos da ligação $\mathrm{C}-\mathrm{OH}$ na mesma região ou próximas a ela [12, 13, 29, 46]. Para identificar e quantificar com precisão os produtos solúveis formados durante a eletrooxidação do glicolaldeído nos eletrodos de Pt e PtRu, foi utilizada a técnica de cromatografia líquida de alta eficiência (CLAE).

3.6.5 Análise dos produtos solúveis da oxidação de glicolaldeído em Pt por cromatografia líquida de alta eficiência.

Nos experimentos com o eletrodo de Pt, o glicolaldeído $(0,1 \mathrm{M})$ foi adsorvido a um potencial de $0,05 \mathrm{~V}$ e posteriormente foram realizados saltos de potencial entre $0,50 \mathrm{~V}$ a $0,90 \mathrm{~V}$. Este procedimento foi utilizado para monitorar os produtos solúveis como o ácido carboxílico observado nos experimentos de infravermelho (Figuras 28 e 31). Os resultados obtidos são apresentados na Figura 34. 

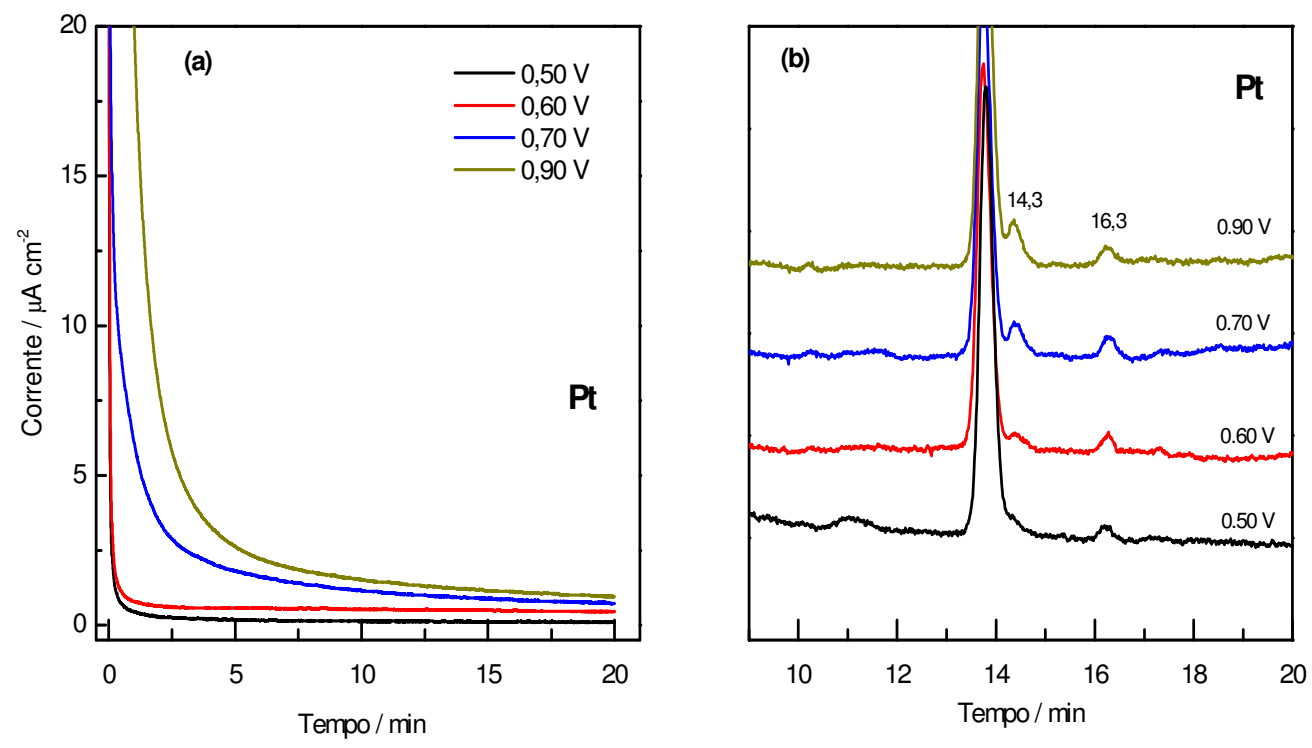

Figura 34 - Curvas corrente versus tempo (a) e cromatogramas (b) obtidos após a eletrooxidação de glicolaldeído $0,10 \mathrm{M} \mathrm{C}_{2} \mathrm{H}_{4} \mathrm{O}_{2}+1,0 \mathrm{M} \mathrm{HClO}_{4}$ em eletrodo de Pt em diferentes potenciais. $E_{a d}=0,05 \mathrm{~V} . T=25^{\circ} \mathrm{C}$. Detector: diodo $(220 \mathrm{~nm})$.

Observa-se nos primeiros minutos após o salto de potencial (Figura 34-(a)), uma queda rápida nos valores da corrente. Os resultados da análise por cromatografia são apresentados na Figura 34-(b). O pico maior observado a 13,7 min é atribuído ao glicolaldeído. O pico em 16,3 min existe devido a impurezas do reagente (Figura 22). O pico próximo a 14,3 min refere-se ao ácido glicólico; notese, que o pico sofre variação com a mudança de potencial. Nenhum outro produto com quantidades mensuráveis foi observado durante as medidas de cromatografia.

Como pode ser observado nos cromatogramas da Figura 34-(b), nos potenciais de $0,50 \vee$ e 0,60 $\vee$ o sinal correspondente ao ácido glicólico não possui uma intensidade satisfatória para sua quantificação.

As quantidades de ácido glicólico a $0,70 \vee$ e $0,90 \mathrm{~V}$ foram calculadas a partir de uma curva de calibração preparada a partir de soluções padrão da substância 
pura. $\mathrm{O} \mathrm{CO}_{2}$ foi estimado a partir da carga total. Os resultados são apresentados na Figura 35. Como pode ser visto, as quantidades de ácido glicólico aumentam com o potencial aplicado; por outro lado, $\mathrm{O}_{\mathrm{CO}_{2}}$ só aparece como produto secundário a potenciais próximos de 0,90 V.

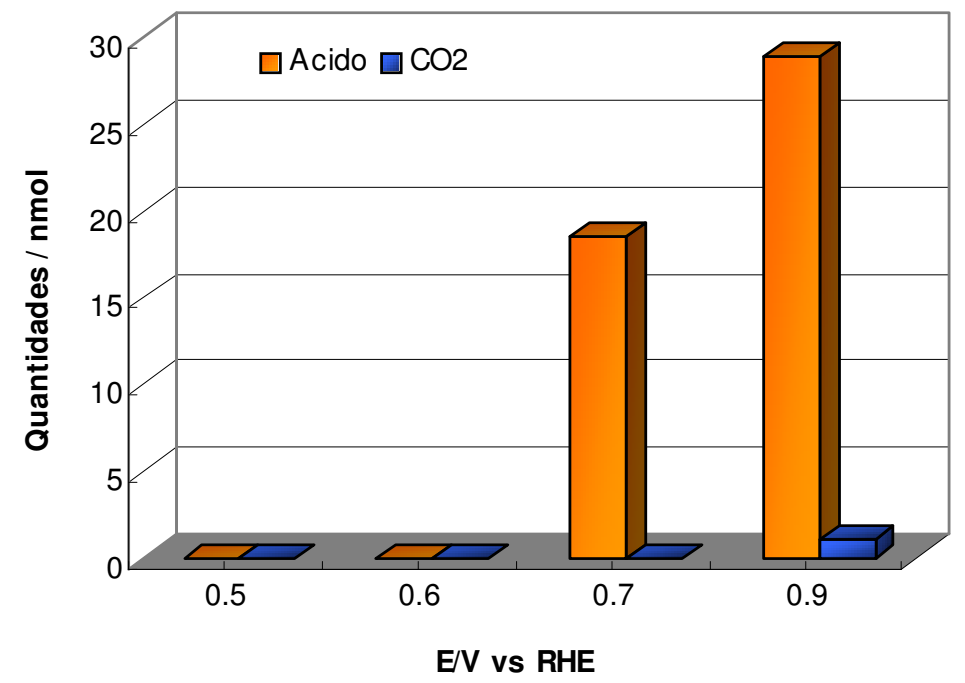

Figura 35 - Quantidades em nmol de ácido glicólico e $\mathrm{CO}_{2}$ após a eletrólise de 20 min para $0,1 \mathrm{C}_{2} \mathrm{H}_{4} \mathrm{O}_{2}+1,0 \mathrm{M} \mathrm{HClO}_{4}$ sobre eletrodos de Pt. $\mathrm{T}=25^{\circ} \mathrm{C}$.

3.6.6 Análise por cromatografia líquida dos produtos formados durante a eletrooxidação do glicolaldeído em eletrodos de PtRu

Para estudar o efeito do Ru nas vias de reação do glicolaldeído, foi preparado um eletrodo PtRu com uma concentração de Ru próxima do máximo observado para a eletrooxidação do etileno glicol (Figura 21). O eletrodepósito analisado por EDX apresenta uma composição de $72 \%$ em Pt e $28 \%$ em Ru. 
Para a realização da eletrólise, o glicolaldeído foi adsorvido a um potencial de $0,05 \mathrm{~V}$ e, em seguida, realizado um salto de potencial primeiramente a $0,50 \mathrm{~V}$ e posteriormente em um novo experimento a $0,70 \mathrm{~V}$. Os resultados de corrente e os cromatogramas obtidos das amostras coletadas ao final da eletrólise de 20 min são apresentadas na Figura 36.
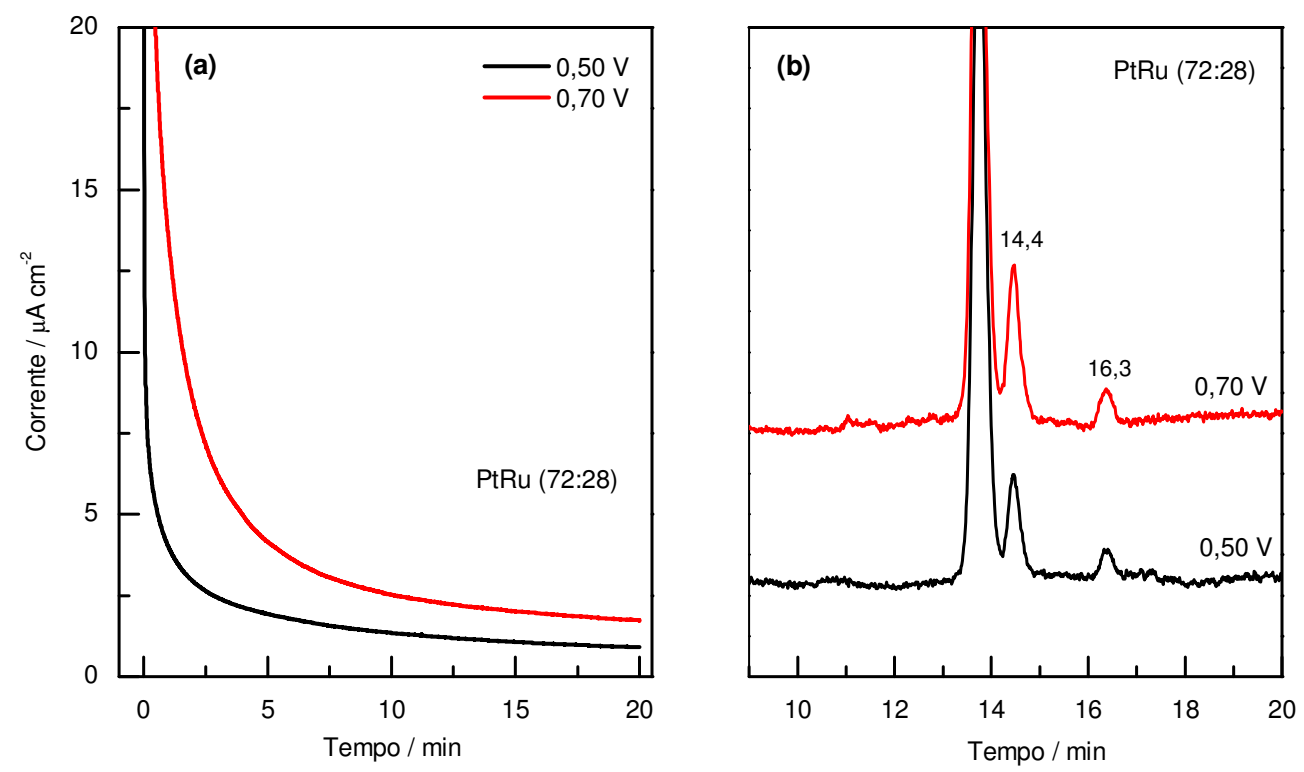

Figura 36 - Curvas corrente versus tempo (a) e cromatogramas (b) obtidos após a eletrooxidação de $0,10 \mathrm{M}$ glicolaldeído em $\mathrm{HClO}_{4}(1,0 \mathrm{M})$ em eletrodo de $\mathrm{Pt}: \mathrm{Ru}$ (72:28). $E_{a d}=0,05 \mathrm{~V} . T=25^{\circ} \mathrm{C}$. Detector: diodo $(220 \mathrm{~nm})$.

Os cromatogramas (Figura 36-(b)) apresentam os mesmos picos observados durante a eletrólise do glicolaldeído no eletrodo de Pt: o forte pico em 13,6 min corresponde ao glicolaldeído $(0,10 \mathrm{M})$ contido na solução; a 14,4 min observa-se o pico atribuído ao ácido glicólico formado durante a oxidação do aldeído, e mais uma vez nota-se o aumento do sinal do ácido com o potencial aplicado. Nenhum outro sinal correspondente à formação de outro produto de oxidação foi detectado. $\mathrm{O} \mathrm{CO}_{2}$ 
foi calculado indiretamente através da carga gerada durante a eletrólise. Os resultados obtidos são apresentados na Figura 37.

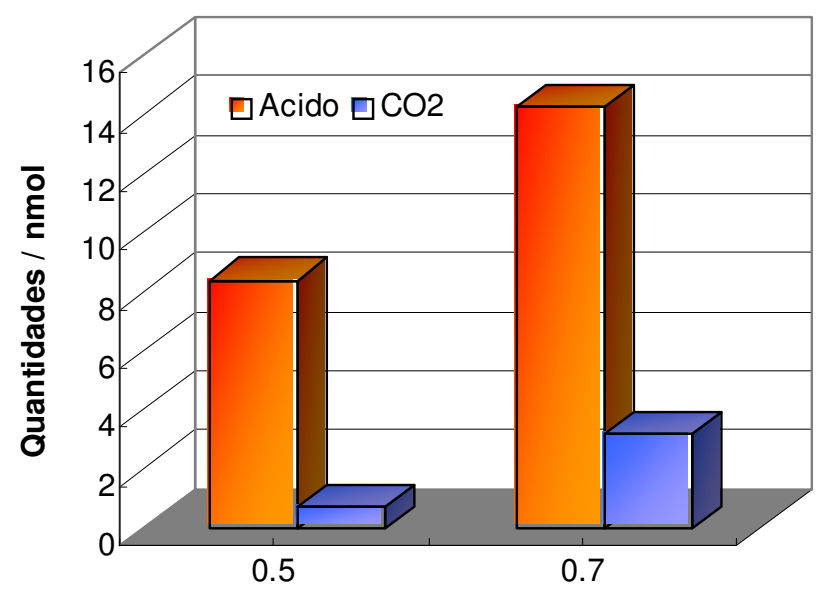

E/V vs RHE

Figura 37 - Quantidades normalizadas pela área real em nmol de ácido glicólico e $\mathrm{CO}_{2}$ após a eletrólise de 20 min para $0,1 \quad \mathrm{C}_{2} \mathrm{H}_{4} \mathrm{O}_{2}+1,0 \mathrm{M} \mathrm{HClO}$ sobre eletrodos de PtRu (72:28) em diferentes potenciais.

Observa-se, portanto, que para o eletrodo de PtRu, o ácido glicólico é o produto principal na eletrooxidação do glicolaldeído. A quantidade do ácido a $0,50 \mathrm{~V}$ é oito vezes maior do que os valores de $\mathrm{CO}_{2}$ no mesmo potencial. $\mathrm{A}$ um potencial de 0,70 V, uma maior quantidade de ácido é observada, mas, quando comparada no mesmo potencial com os valores obtidos no eletrodo de $\mathrm{Pt}$, a diferença não significativa.

As quantidades de $\mathrm{CO}_{2}$ também sofrem um significativo aumento, note que os valores obtidos no eletrodo de Pt (Figura 35) são praticamente desprezíveis chegando a valores quase nulos mesmo a altos potenciais. Contudo, no eletrodo de PtRu a formação de $\mathrm{CO}_{2}$ possui certa expressividade, principalmente a um potencial 
de 0,70 V. Esses resultados demonstram que o Ru está facilitando ambas as vias: a formação de $\mathrm{CO}_{2}$ (10 e 11) e a formação de ácido glicólico (12).

$$
\begin{aligned}
& \mathrm{HOH}_{2} \mathrm{C}-\mathrm{CHO} \longrightarrow 2 \mathrm{Pt}-\mathrm{CO}_{a d}+4 \mathrm{H}^{+}+4 \mathrm{e}^{-} \\
& 2 \mathrm{Pt}-\mathrm{CO}+2 \mathrm{Ru}-\mathrm{OH} \longrightarrow \quad 2 \mathrm{CO}_{2}+4 \mathrm{H}^{+}+2 \mathrm{Pt}+2 \mathrm{Ru}+4 \mathrm{e}^{-} \\
& \mathrm{HOH}_{2} \mathrm{C}-\mathrm{CHO}+\mathrm{Ru}-\mathrm{OH} \longrightarrow \mathrm{HOH}_{2} \mathrm{C}-\mathrm{COOH}+2 \mathrm{H}^{+}+2 \mathrm{e}^{-}
\end{aligned}
$$

3.6.7 Provável esquema de reação para a oxidação de glicolaldeído

As informações coletadas ao longo deste trabalho para a eletrooxidação de glicolaldeído nos eletrodos de Pt e PtRu fornecem dados para as seguintes vias de reação: (a) o primeiro caminho seria a adsorção e conseqüente dissociação da molécula de etileno glicol formando $\mathrm{CO}_{\mathrm{ad}}$ e outras espécies adsorvidas contendo hidrogênio e b) a oxidação de glicolaldeído a ácido glicólico, sendo este o produto principal de oxidação. Os resultados aqui propostos são resumidos no esquema reacional abaixo:

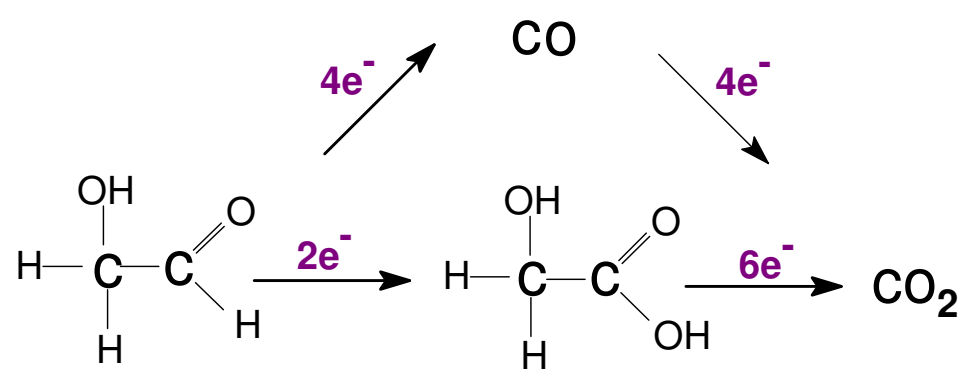

Figura 38 - Esquema proposto para a eletrooxidação de glicolaldeído sobre eletrodos de Pt e PtRu. 


\subsection{Eletrooxidação de ácido glicólico em eletrodos de platina policristalina e PtRu}

Durante os experimentos com o etileno glicol e o glicolaldeído, o ácido glicólico apareceu como produto parcial de oxidação. No caso do etileno glicol, o ácido seria um produto terciário de oxidação, sendo a principal fonte geradora o glicolaldeído formado. Ao ser formado, o ácido glicólico pode difundir para o interior da solução ou se adsorver e oxidar a outros produtos como o ácido glioxílico. Abaixo é mostrado um esquema de reação dos produtos que podem ser formados durante a oxidação do ácido glicólico.

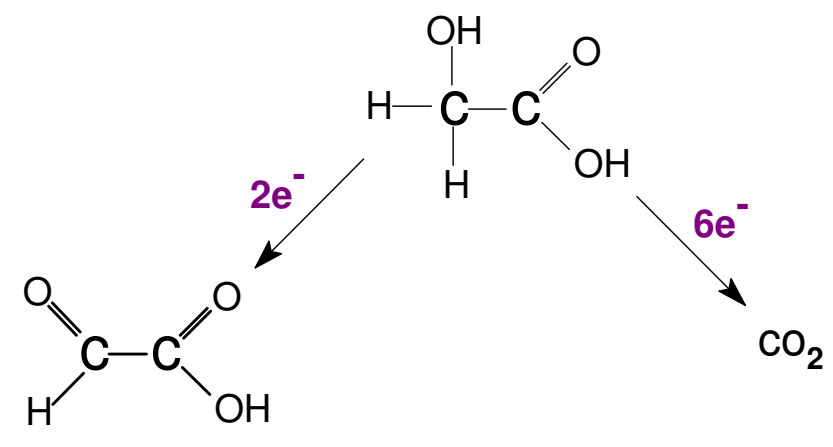

Ac. glioxílico

3.7.1 Eletrooxidação de ácido glicólico em eletrodos de Pt

Na Figura 39 tem-se o voltamograma cíclico para a oxidação de 0,1M de ácido glicólico sobre um eletrodo de Pt em meio de $\mathrm{HCLO}_{4}(0,1 \mathrm{M})$. A curva apresenta características muito diferentes quando comparada aos voltamogramas cíclicos 
obtidos para o etileno glicol (Figura 4) e o glicolaldeído (Figura 27): a região de adsorção de hidrogênio (compreendida entre 0,05V e 0,30V) é nitidamente visível.

No entanto, a partir de $0,30 \mathrm{~V}$ pode ser observado um lento aumento na corrente até um potencial de $0,75 \mathrm{~V}$. A partir de $0,75 \mathrm{~V}$, a corrente aumenta mais rapidamente formando um pico de baixa intensidade a 0,80 V. A partir de 0,95 V observa-se um grande aumento de atividade.

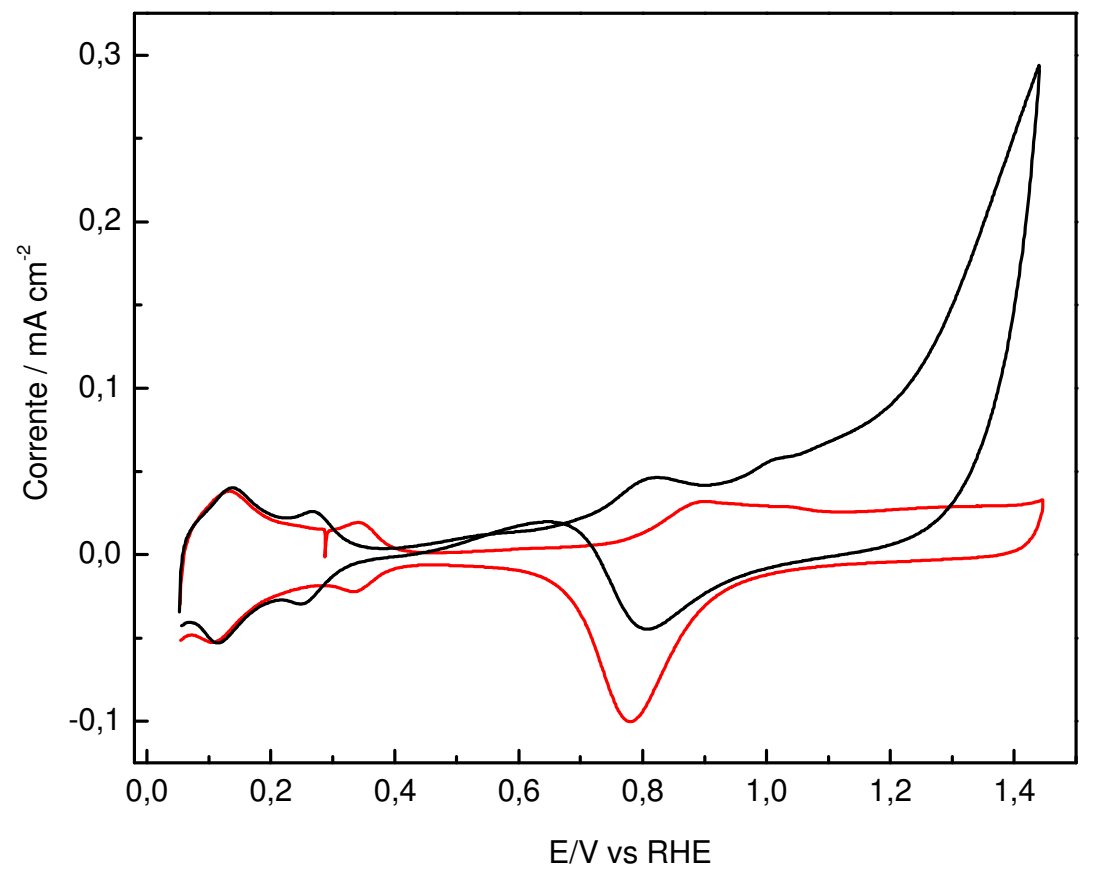

Figura 39 - Voltamograma cíclico para a oxidação de ácido glicólico $(0,1 \mathrm{M})$ em meio de $\mathrm{HClO}_{4}(0,1 \mathrm{M})$ em eletrodo de $\mathrm{Pt} . \mathrm{V}=0,01 \mathrm{Vs}^{-1}$. $\mathrm{T}=25 \stackrel{\circ}{\circ} \mathrm{C}$.

Os resultados de voltametria cíclica permitem afirmar, a princípio, que a potenciais baixos o ácido glicólico possuí uma baixa atividade em relação ao eletrodo de Pt. Contudo, foram realizados experimentos de espectroscopia de infravermelho para monitorar a dependência quanto ao potencial, da formação de adsorbatos e produtos de oxidação. 
3.7.2 Estudo dos produtos de oxidação do ácido glicólico por espectroscopia de infravermelho

A Figura 40 apresenta os espectros coletados em ácido glicólico $(0,1 \mathrm{M})$ sobre um eletrodo de Pt.

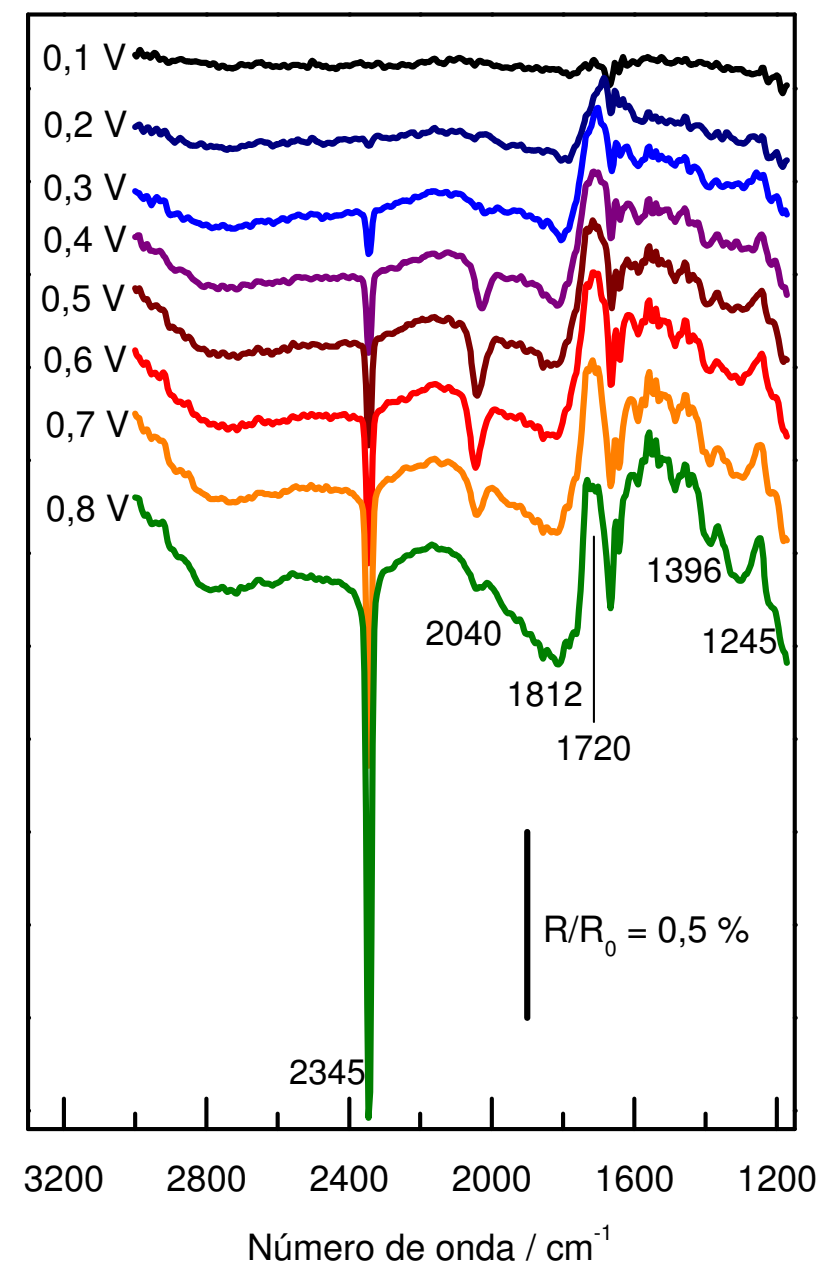

Figura 40 - Espectros de infravermelho para a eletrooxidação de ácido glicólico em função do potencial em Pt. Solução: 0,1 $\mathrm{M} \mathrm{C}_{2} \mathrm{H}_{4} \mathrm{O}_{3}+0,1 \mathrm{M}$ $\mathrm{HClO}_{4} . \mathrm{E}_{\mathrm{ad} .}=0,05 \mathrm{~V} . \mathrm{T}=25 \circ( \pm 1)$. Resolução: $8,0 \mathrm{~cm}^{-1} . \mathrm{E}_{\text {ref. }}=0,05 \mathrm{~V}$.

As intensas bandas positivas a partir de $0,30 \mathrm{~V}$ localizadas em $1720 \mathrm{~cm}^{-1} \mathrm{e}$ $1245 \mathrm{~cm}^{-1}$ pertencem respectivamente ao estiramento $\mathrm{C}=\mathrm{O}$ da carbonila e ao estiramento $\mathrm{C}-\mathrm{OH}$ do grupo carboxila do ácido glicólico. O caráter positivo de ambas 
as bandas indica o consumo do ácido glicólico presente na camada fina entre a janela prismática e o eletrodo de trabalho. Assim como na eletrooxidação de etileno glicol e glicolaldeído, observa-se a partir de $0,20 \mathrm{~V}$ a banda situada em $1396 \mathrm{~cm}^{-1}$, indicando a formação possível de etileno glicolato.

Um fato interessante é a formação de $\mathrm{CO}_{2}$ a potenciais abaixo de $0,40 \mathrm{~V}$. Esta situação não foi observada para as outras substâncias estudadas neste trabalho. Tanto o etileno glicol (Figura 5) como o glicolaldeído (Figura 28) formam $\mathrm{CO}_{2}$ em eletrodos de Pt a potenciais de 0,50 V. Para melhor compreender esse efeito, as intensidades da banda de $\mathrm{CO}\left\llcorner\right.$ e $\mathrm{CO}_{2}$ foram integradas em função do potencial. Os resultados são apresentados na Figura 41.

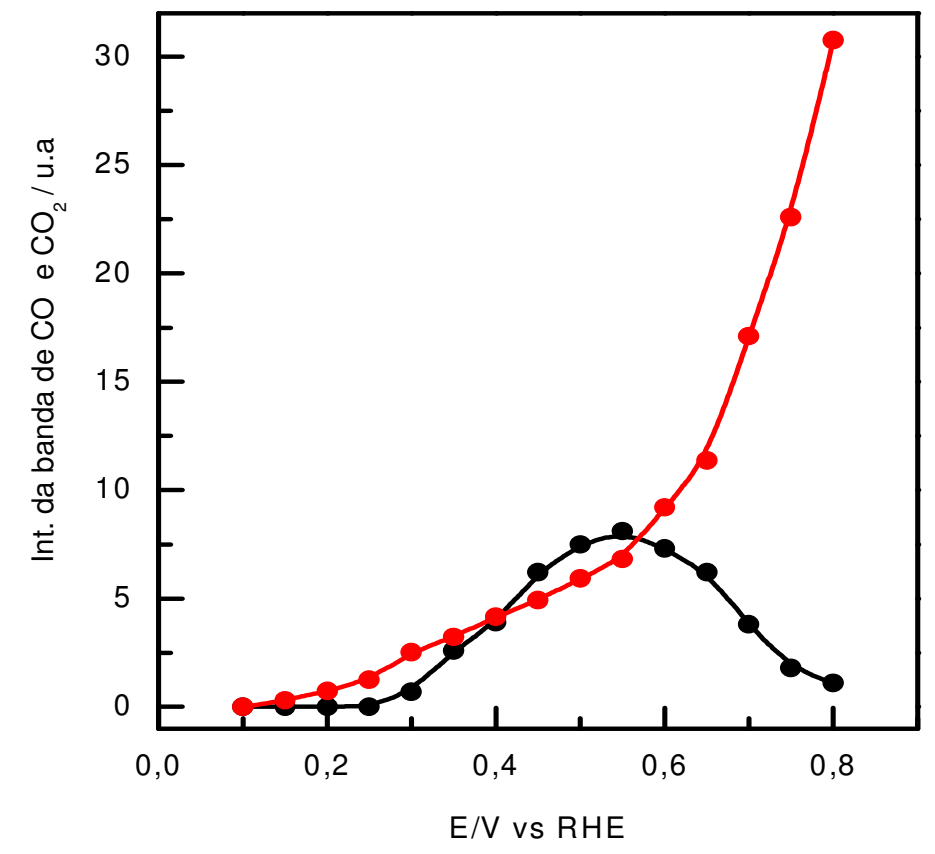

Figura 41 - Intensidade da banda de $\mathrm{CO}$ e $\mathrm{CO}_{2}$ vs potencial para o eletrodo de Pt. Solução: $0,1 \mathrm{M} \mathrm{C}_{2} \mathrm{H}_{4} \mathrm{O}_{3}+0,1 \mathrm{M} \mathrm{HClO}$. $E_{\text {ad. }}=0,05 \mathrm{~V} . T=25^{\circ}( \pm 1)$.

A banda de $\mathrm{CO}_{\mathrm{L}}$ aumenta com o potencial a partir de $0,30 \mathrm{~V}$ até atingir um máximo de intensidade a $0,55 \mathrm{~V}$. Os resultados sugerem duas possibilidades para a 
formação de $\mathrm{CO}_{2}$ em baixos potenciais: Para oxidar o $\mathrm{CO}_{\mathrm{ad}}$ a $\mathrm{CO}_{2}$ é necessária a presença de água dissociada na superfície do catalisador (mecanismo de LangmuirHinshelwood) o que só pode ocorrer a potenciais acima de $0,35 \mathrm{~V}$ em eletrodos de Pt policristalina. A outra possibilidade é a decarboxilação do ácido glicólico, deixando um resíduo carbonáceo $\mathrm{CH}_{2} \mathrm{OH}$ adsorvido.

Um resultado semelhante foi obtido em eletrodos de PtRu (Figura 42), onde a formação de $\mathrm{CO}_{2}$ começa a $0,20 \mathrm{~V}$. Por outro lado, comparando os espectros em $\mathrm{Pt}$ com os espectros em PtRu, observa-se que a formação de $\mathrm{CO}_{\llcorner}$surge a potenciais mais baixos na presença de $\mathrm{Ru}$.

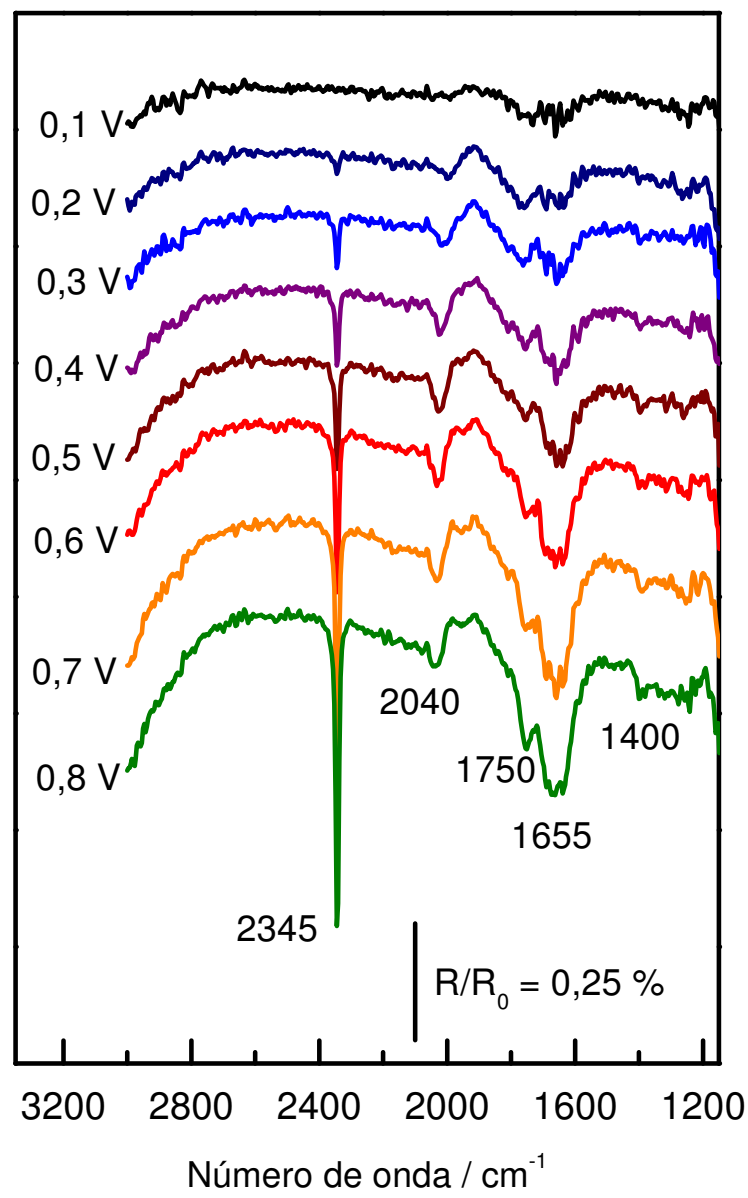

Figura 42 - Espectros de infravermelho para eletrooxidação de ácido glicólico em função do potencial em Pt:Ru (80:20). Solução: $1,0 \mathrm{M} \mathrm{C}_{2} \mathrm{H}_{4} \mathrm{O}_{3}+0,1 \mathrm{M} \mathrm{HClO}_{4}$. $\mathrm{E}_{\mathrm{ad}}=0,05 \mathrm{~V}$. $\mathrm{T}=25^{\circ}( \pm 1)$. Resolução: $8,0 \mathrm{~cm}^{-1}$. 
3.7.3 Estudo dos produtos de oxidação do ácido glicólico por cromatografia líquida.

Foram realizados experimentos de cromatografia líquida para identificar e quantificar outros produtos de reação. Para os experimentos de cromatografia foi preparado um eletrodo com uma quantidade de Ru próxima de $28 \%$ em $\mathrm{Ru}$. No experimento, o ácido glicólico $(0,10 \mathrm{M})$ foi adsorvido a um potencial de $0,05 \mathrm{~V}$ e, realizando-se posteriormente dois saltos de potencial, o primeiro a $0,50 \mathrm{~V}$ e, em um segundo experimento, a 0,70 V por 20 min. Após a eletrólise, uma alíquota da solução de trabalho foi coletada para a análise cromatográfica. Os resultados podem ser visualizados na Figura 43.
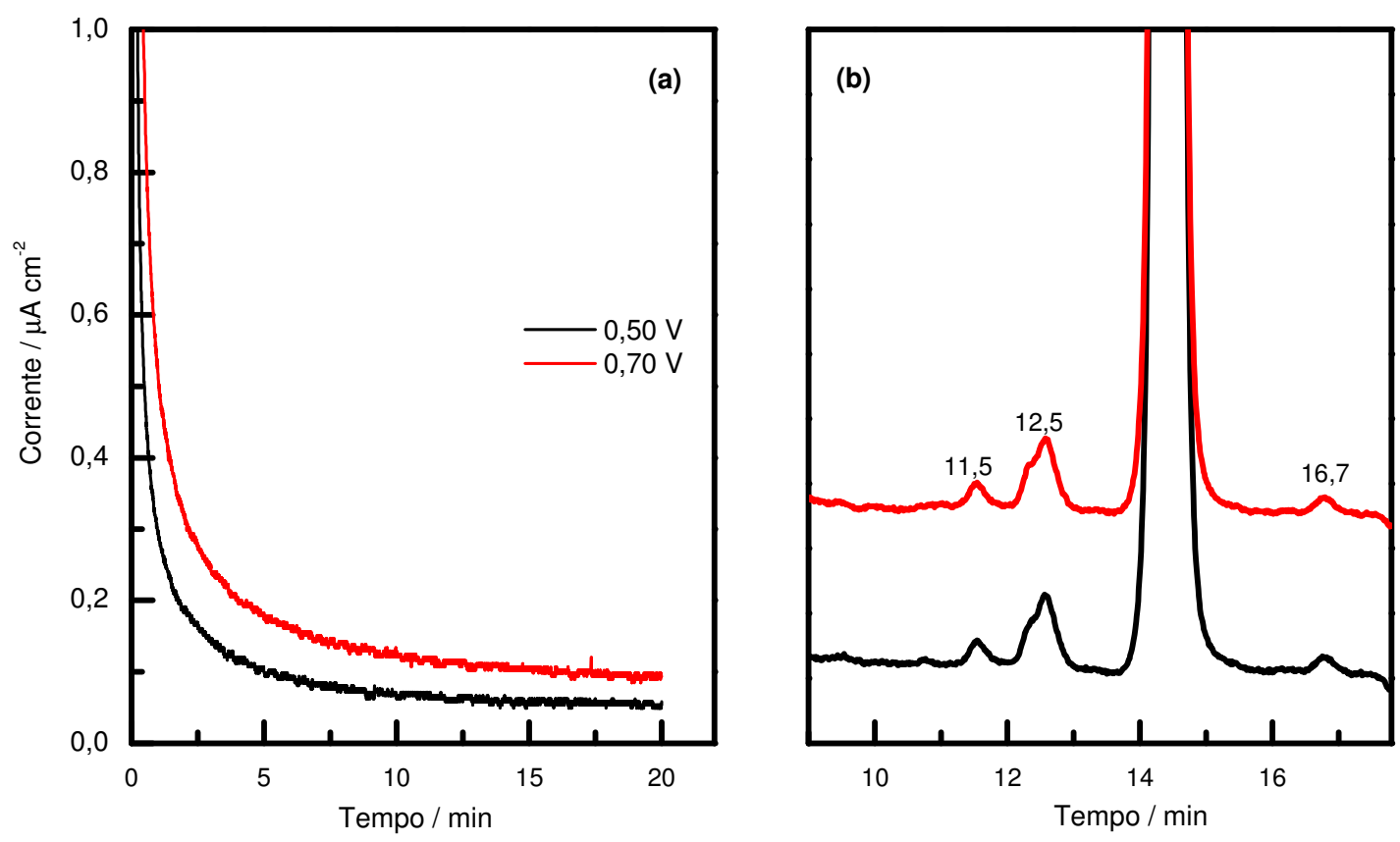

Figura 43 - Curvas corrente versus tempo (a) e cromatogramas (b) obtidos após a eletrooxidação de $0,10 \mathrm{M} \mathrm{C}_{2} \mathrm{H}_{4} \mathrm{O}_{3}+1,0 \mathrm{M} \mathrm{HClO}_{4}$ em eletrodo de Pt:Ru (83:17). $\mathrm{E}_{\mathrm{ad}}=$ $0,05 \mathrm{~V} . \mathrm{T}=25^{\circ} \mathrm{C}$. Detector: diodo $(220 \mathrm{~nm})$. 
Os resultados de corrente medidos durante a eletrólise (Figura 43-(a)) confirmam a baixa atividade de corrente já observada em experimentos anteriores (Figura 26), mesmo a potenciais mais altos. Os valores medidos a 0,50 $\mathrm{V}$ chegam a estar próximos ao zero de corrente. Os cromatogramas (Figura 43-(b)) obtidos após 20 min de eletrólise apresentaram quatro picos visíveis localizados a 11,5 min, 12,5 $\min , 14,4 \min$ e $16,7 \mathrm{~min}$. O intenso pico a $14,4 \mathrm{~min}$ e o pico situado a $14,7 \mathrm{~min}$ estão relacionados com o ácido glicólico presente na solução. O pico situado a 11,5 min está relacionado à formação de ácido glioxílico e neste caso, a função álcool presente na molécula do ácido estaria se oxidando e formando um grupo carbonila perdendo dois átomos de hidrogênio (14).

$\mathrm{HOH}_{2} \mathrm{C}-\mathrm{COOH} \stackrel{\mathrm{Pt}}{\longrightarrow} \mathrm{OHC}-\mathrm{COOH}+2 \mathrm{H}^{+}+2 \mathrm{e}^{-}$

O pico situado a 12,5 min não pertence a nenhum dos produtos analisados anteriormente por cromatografia líquida (Figura 22). Uma possibilidade é que ele seja referente à formação de um dímero do ácido glicólico [47, 48]. Neste caso, duas moléculas do ácido reagiriam entre si através dos átomos de hidrogênio da função $\mathrm{OH}$ do grupo carboxila formando pontes de hidrogênio e assim gerando uma única molécula .

3.7.4 Provável esquema de reação para a oxidação de ácido glicólico em eletrodos de Pt e PtRu

As informações coletadas durante a eletrooxidação do ácido glicólico nos eletrodos de Pt e PtRu fornecem dados para as seguintes vias de reação: (a) a decarboxilação da molécula pela quebra da dupla ligação $\mathrm{C}-\mathrm{C}$ e liberação de $\mathrm{CO}_{2} \mathrm{O}$ 
primeiro caminho seria a adsorção e conseqüente dissociação da molécula de etileno glicol formando $\mathrm{CO}_{\mathrm{ad}}$ triplamente coordenado e espécies do tipo Pt- $\mathrm{COOH}$ e, posteriormente, a oxidação dos adsorbatos a $\mathrm{CO}_{2} ;$ b) a oxidação do ácido glicólico a ácido glioxílico e c) A formação de dímeros do ácido. Os resultados aqui propostos são resumidos no esquema reacional abaixo:

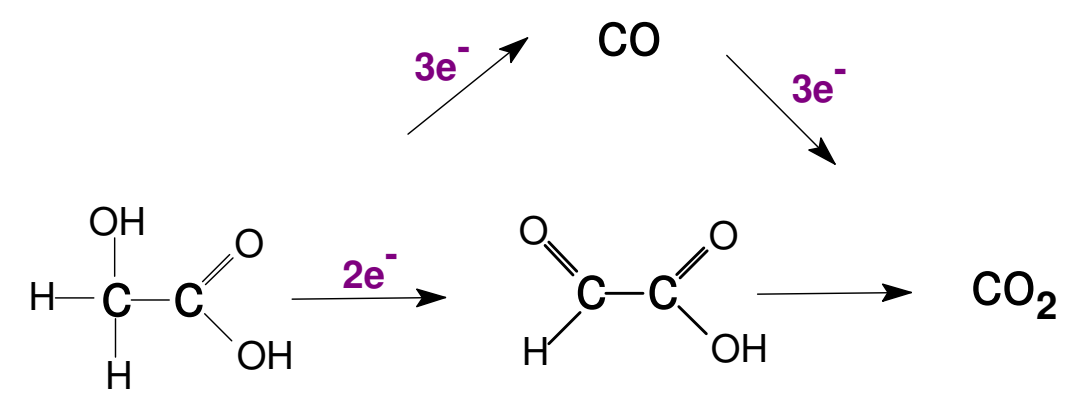

Figura 44 - Esquema proposto para a eletrooxidação de ácido glicólico sobre eletrodos de Pt e Pt:Ru. 


\subsection{CONCLUSÕES}

Com base nas informações obtidas por técnicas eletroquímicas e através da análise dos espectros de infravermelho, espectroscopia eletroquímica de massa diferencial e dos dados de cromatografia líquida de alta eficiência, pode-se chegar às seguintes conclusões para a eletrooxidação do etileno glicol e de seus produtos parciais de oxidação durante a sua oxidação sobre a superfície dos eletrodos de Pt e PtRu:

Os eletrodos Pt policristalina apresentam uma atividade muito baixa para a oxidação de etileno glicol. Após $20 \mathrm{~min}$ a $0,5 \mathrm{~V}$, observa-se uma densidade de corrente de $0,2 \mu \mathrm{A} \mathrm{cm} \mathrm{cm}^{-2}$. A oxidação para $\mathrm{CO}_{2}$ ocorre apenas a partir de $0,50 \mathrm{~V}$, e para ácido glicólico a partir de $0,70 \mathrm{~V}$. A baixos potenciais, o produto principal é o glicolaldeído, formado em pequenas quantidades já a partir de 0,05 V.

A reação de oxidação de etileno glicol é catalisada pelas ligas e eletrodepósitos de PtRu. A atividade desse catalisador depende do conteúdo de Ru, e observa-se uma corrente máxima de aproximadamente de $11 \mu \mathrm{A} \mathrm{cm}^{-2}$ para uma porcentagem de Ru próxima de 30\%. Além disso, o PtRu dissocia com maior facilidade a ligação C-C, maiores quantidades de $\mathrm{CO}_{\mathrm{ad}}$ são encontradas nesse eletrodo do que na Pt pura, e é formado cinco vezes mais $\mathrm{CO}_{2}$ e dez vezes mais ácido glicólico.

O aumento da quantidade de glicolaldeído em PtRu indica que a liga também favorece a quebra da ligação $\mathrm{CH}$. Sabendo-se que o $\mathrm{Ru}$ puro não catalisa a adsorção dissociativa de etileno glicol e a quantidade de sítios de Pt é menor nas 
ligas do que na platina pura, os efeitos observados se devem possivelmente à modificação eletrônica da platina produzida pelo Ru.

Apesar de o aldeído não ter sido medido quantitativamente neste trabalho, é possível estabelecer que o produto majoritário da reação seja o glicolaldeído. Esta observação está baseada nos valores de ácido glicólico obtidos por cromatografia e na relação de ácido glicólico/ $\mathrm{CO}_{2}$ dos espectros de infravermelho. O glicolaldeído apresenta baixas correntes em Pt policristalina. A sua oxidação é catalisada por PtRu e forma majoritariamente ácido glicólico e pequenas quantidades de $\mathrm{CO}_{2}$.

De todas as substâncias estudadas, o ácido glicólico é o único que forma $\mathrm{CO}_{2}$ já potenciais de $0,20 \mathrm{~V}$, tanto em Pt como PtRu. Esta reação estaria facilitada pela presença do grupo álcool na molécula, já que outros ácidos carboxílicos, como por exemplo o ácido acético, sofrem decarboxilação oxidativa em potenciais acima de $1,5 \mathrm{~V}$

Assim, os esquemas de reação propostos sugerem vias de oxidação do etileno glicol, formando as substâncias analisadas neste trabalho. Os valores de corrente observados no máximo da curva j versus $\theta_{\mathrm{Ru}}$ estão abaixo daqueles obtidos para outros álcoois semelhantes, como metanol e etanol, o que não diminui a importância do etileno glicol, pois este pode ser utilizado em dispositivos que requeiram baixa energia. Além disso, o conhecimento dessas vias paralelas de oxidação do etileno glicol auxilia na compreensão de mecanismos de outros possíveis candidatos a combustíveis. 


\subsection{PERSPECTIVAS FUTURAS}

Os resultados deste trabalho indicam que a ruptura da ligação $C-C$ e a conseqüente formação de produtos parciais de oxidação como o glicolaldeído e o ácido glicólico são responsáveis pelo baixo rendimento energético do álcool nos eletrodos de Pt e PtRu. Como a inserção de átomos de Ru favoreceu à ruptura da ligação $\mathrm{C}-\mathrm{C}$ durante os experimentos nos eletrodos de $\mathrm{PtRu}$, outros metais doadores de oxigênio tais como: $\mathrm{S}$, Se, $\mathrm{Cd}$ e Mo poderiam ser testados como alternativas ao uso de Ru. Idealmente, o elemento em questão não deveria inibir a adsorção do etileno glicol.

Para uma melhor caracterização do mecanismo de reação, seria relevante estudar a eletrooxidação do etileno glicol e de seus produtos de oxidação parcial em eletrodos monocristalinos de Pt e modificando a superfície com os metais propostos no parágrafo acima, ou ainda, analisar o efeito da temperatura na reação de oxidação do etileno glicol e de seus produtos parciais de oxidação. 


\subsection{REFERÊNCIAS}

1. BATISTA, E.A.; HOSTER, H.; IWASITA, T. Analysis of FTIRS and thermal effects during methanol oxidation on UHV-clenead PtRu alloys. Journal Electroanalytical Chemistry. v. 554-555, 2003.

2.DALBAY, N.; KADIRGAN, F. Electrolytically co-deposited platinum-palladium electrodes and their electrocatalytic activity for ethylene glycol oxidation: a synergistic effect. Electrochimica Acta, v. 36, n. 2, p. 353-356, 1991.

3.MENDEZ, E.; RODRIGUEZ, J.L.; ARÉVALO, M.C.; PASTOR,E. Comparative study of ethanol and acetaldehyde reactives and rhodium electrodes in acidic media. Langmuir, 18, p. 763-772, 2002.

4. COLMATI, F.; ANTOLINI, E.; GONZÁLEZ, E.R.; Effect of temperature on the mechanism of ethanol oxidation on carbon supported $\mathrm{Pt}$, PtRu and $\mathrm{Pt}_{3} \mathrm{Sn}$ electrocatalysts. Journal of Power Sources, v. 157, p. 98-103, 2006.

5. LAMY, C.; BELGSIR, E.M; LÉGER, J-M. Electrocatalytic oxidation of aliphatic alcohols: Application to the direct alcohol fuel cell (DAFC). Journal Applied Elecrochemistry, v.31, p. 799-809, 2001.

6. CHRISTENSEN, P.A; HAMMET, A. The oxidation of ethylene glycol at platinum electrode in acid and base. An in situ FTIR study. Journal Electroanalytical Chemistry, v. 260, p. 347-359, 1989.

7. CHANG, S.-C.; HO, Y.; WEAVER, J. M. Applications of Real-Time FTIR spectroscopy to the elucidation of complex electroorganic pathways: Electrooxidation of ethylene glycol on gold, platinum, and nickel in alkaline solution. Journal American Chemical Society., v.113, p. 9506-9513, 1991.

8. URETA-ZAÑARTU, M.S.; YÁÑEZ, C.; PÁEZ, M.; REYES, G. Electrocatalytic oxidation of ethylene glycol in $0.5 \mathrm{M} \mathrm{H}_{2} \mathrm{SO}_{4}$ and $0.5 \mathrm{M} \mathrm{NaOH}$ solutions at bimetallic deposited electrode. Journal Electroanalytical Chemistry, v. 405, p. 159-167, 1996.

9. KELAIDOPOULOU, A; ABELIDOU, E.; PAPOUTSIS, A. ; POLYCHRONIADIS, E.K.; KOKKINIDIS, G. Electrooxidation of ethylene glycol on Pt-based catalysts dispersed in polyaniline. Journal of Applied Electrochemistry, v.28, p. 1101-1106, 1998. 
10. LEBEDEVA, N.P; KRYUKOVA, G.N.; TSYBULYA, S.V.; SALANOV, A. N.; SAVINOVA, E. R. Effects of microstructure in ethylene glycol oxidation on graphite supported platinum electrodes. Electrochimica Acta, v.44, p. 1431-1440, 1998.

11. KARDINGAN, F.; BEDEN, B; LAMY, C. Electrocatalytic oxidation of ethylene glycol. Part I. Behaviour of platinum ad-atom electrodes in acid medium. Journal Electroanalytical Chemistry, v. 136, p. 119-138, 1982.

12. XUDONG, J.; CHANG, S.-C.; WEAVER, M. J. Electrooxidation of ethylene glycol on Bismuth-modified Pt (111). Journal Chemical Society Faraday Trans, v. 89, n. 2, p. 223-228, 1993.

13. DAILEY, A.; SHIN, J.; KORZENIEWSKI, C. Ethylene glycol electrochemical oxidation at platinum probed by ion chromatography and infrared spectroscopy. Electrochimica Acta, v. 44, p. 1147-1152, 1998.

14. CHERSTIOUK, O. V.; SAVINOVA, E.R.; KOZHANOVA, L.A.; PARMON, V. N. Electrocatalytic oxidation of ethylene glycol on dispersed Pt: Determination of the reaction products. Reaction Kinetics Catalysis Letters, v. 69, n. 2, p. 331-338, 2000.

15. DE LIMA, R.B.; PAGANIN, V.; IWASITA, T.; VIELSTICH, W. On the electrocatalysis ethylene glycol oxidation. Electrochimica Acta, v. 49, p. 85-91, 2005.

16. NETO, A.O.; VASCONCELOS, T.R.R.; DA SILVA, R.W.R.V.; LINARDI, M.; SPINACÉ, E.V. Electro-oxidation of ethylene glycol on $\mathrm{PtRu} / \mathrm{C}$ and $\mathrm{PtSn} / \mathrm{C}$ electrocatalysts prepared by alcohol-reduction process. Journal of Applied Electrochemistry, v. 35, p. 193-198, 2005.

17. WANG, H.; ZHAO, Y.; JUSYS, Z.; BEHM, R.J. Ethylene Glycol on carbon supported $\mathrm{Pt}$, $\mathrm{PtRu}$ and $\mathrm{Pt}_{3} \mathrm{Sn}$ catalysts - A comparative DEMS study. Journal power sources, v. 155, p. 33-46, 2006.

18. PELED, E.; LIVSHITS,V.; DUVDEVANI, T. High-power direct ethylene glycol fuel cell (DEGFC) base don nanoporous próton-conducting membrane (NP-PCM). Journal of Power Sources, v.106, p. 245-248, 2002.

19. LIMA, Roberto Batista de. Estudo da eletroxidação de etileno glicol em ligas de Pt:Ru eletrodepositadas e em eletrodos de alta área superficial suportados em carbono. 2003. 51 f. Dissertação (Mestrado em Físico-Química) - Instituto de Química de São Carlos, Universidade de São Paulo, São Carlos, 2003.

20. SOUZA, José Pio ludice; Eletrooxidação de metanol e etanol sobre eletrodepósitos de Pt, Rh, Pt-Ru e Pt:Rh. Um estudo de eletrocatálise usando as técnicas de FTIR in-situ e DEMS on-line. 2000. $159 \mathrm{f}$. Tese (Doutorado em Físico-Química) - Instituto de Química de São Carlos, Universidade de São Paulo, São Carlos, 2000. 
21. IWASITA, T; NART, F.C. "In-situ Fourier transform infrared spectroscopy: A tool to characterize the metal-electrolyte interface at a molecular level" in "Advances in electrochemical science and engineering". H. Gerischer, Ch.Tobias, v.4, Verlag Chemie, 1995, p. 124 - 216

22. LAMY, C. Electrocatalytic oxidation of organic compounds on noble metals in aqueos solution. Electrochimica Acta, v. 29, n. 11, p. 1581-1588, 1984.

23. BATISTA, E.A.; IWASITA, T.; VIELSTICH, W. Mechanism of stationary bulk CO oxidation on Pt (111) electrodes. Journal Physical Chemical B, v. 108, p. 1421614222, 2004.

24. VILLEGAS, I; WEAVER, M. Carbon monoxide adlayer structures on platinum (111) electrodes: a synergy between in-situ scanining tunneling microscopy and infrared spectroscopy. Journal Chemical Physical, v. 101, p. 1648-1660, 1994.

25. XIA, X.; IWASITA, T. Adsorption of water at Pt (111) electrode in $\mathrm{HClO}_{4}$ solutions. The potential of zero charge. Journal of Electroanalitycal Chemistry, v. 411, p. 95-102, 1996.

26. SOCRATES, G. Infrared and Ramam Characteristic Group Frequencies. 3 ed. John Wiley and Sons Ltda, 2001, 347 p.

27. IWASITA, T.; PASTOR, E. A DEMS and FTir Spectroscopic investigation of adsorbed ethanol on polycrystalline platinum. Electrochimica Acta, v. 39, n. 4, p. 531-537, 1994.

28. WING, L.; LEUNG, H.; WEAVER, M. J. Influence of adsorbed carbon monoxide on the electrocatalytic oxidation of simple organic molecules at platinum and palladium electrodes in acid solution: A survey using real-time FTir spectroscopy. Estados Unidos, Langmuir, v. 6, p. 323-333, 1990.

29. CHANG, S-C.; WEAVER, M.J. Coverage-depend dipole coupling for carbon monoxide adsorbed at ordered platinum (111) aqueus interface: structural and electrochemical implications. Journal Chemical Physical , v. 92, p. 4582-4594, 1990.

31. CHU, D.; GILMAN, S. Methanol electro-oxidation on unsupported PtRu alloys at different temperatures. Journal of the Electrochemical Society, vol 143, p. 16851690, 1996.

32. IWASITA, T.; HOSTER, H.; JOHN-ANACKER, A.; LIN, W.F.; VIELSTICH, W. Methanol oxidation on PtRu electrodes. Influence of surface structure and Pt-Ru atom distribution. Langmuir, v. 16, p. 522-529, 2000.

33. LIN, W.F.; IWASITA, T.; VIELSTICH, W. Catalysis of CO electrooxidation at Pt, $\mathrm{Ru}$, and PtRu alloy. An in-situ FTIR study. Journal of Physical Chemistry B, v. 103, p. 3250-3257, 1999. 
34. WATANABE, M.; MOTOO, S. Electrocatalysis by ad-atoms. Part II: Enhancement of the oxidation of methanol on platinum by ruthenium ad-atoms. Journal of Electroanalytical Chemistry, v. 60, p. 267-273, 1975.

35. KRAUSA, M.; VIESLTICH, W. Study of the electrocatalytic influence of Pt/Ru and $\mathrm{Ru}$ on the oxidation of residues of small organic molecules. Journal of Electroanalytical Chemistry, v. 379, p. 307-314, 1994.

36. McBREEN, J.; MUKERJEE, S. In-situ X-ray absorption studies of a Pt-Ru electrocatalyst. Estados Unidos, Journal of the Electrochemical Society, v. 142, p. 3399-3404, 1995.

37. CAMARA, G.A; IWASITA, T. Parallel pathways of ethanol oxidation: The effect of ethanol concentration. Journal of electroanalitical Chemistry, v. 578, p. 315-321, 2005.

38.CABANISS, S.E.; LEENHEER, J.A.; McVEY, I.F. Aqueous infrared carboxylate absorbances: aliphatic di-acids. Spectrochimica Acta Part A, v. 54, p. 449-458, 1998.

39. BERNÁ, A.; RODES, A.; FELIU, J. An in situ infrared and electrochemical study of oxalic acid adsorption at stepped platinum single crystal electrodes in the [0 11 1] zone. Electrochimica Acta, v. 49, p. 1257-1269, 2004.

40. IWASITA, T.; HOSTER, H.; JOHN-ANACKER, A.; LIN, W.F.; VIELSTICH, W. Methanol oxidation on PtRu electrodes. Influence of surface structure and $\mathrm{Pt}-\mathrm{Ru}$ atom distribution. Langmuir, v. 16, p. 522-529, 2000.

41. LEUNG, L.W.H.; WEAVER, M. J. Influence of adsorbed carbon monoxide of the electrocatalytic oxidation of simple organic molecules at platinum and palladium electrodes in acidc solution: A survey using real-time FTIR spectroscopy. Langmuir, v.6, p. 323-333, 1990.

42. OTA, K.-I.; NAKAGAWA, Y.; TAKAHASHI, M. Reaction products of anodic oxidation of methanol in sulfuric acid solution. Journal of Electroanalytical Chemistry, v. 179, p. 179-186, 1984.

43. BATISTA, Elisete. As reações de eletrooxidação de metanol e monóxido de carbono: Novos aspectos e novas interpretações. 2005. $136 \mathrm{f}$. Tese (Doutorado em Físico-Química) - Instituto de Química de São Carlos, Universidade de São Paulo, São Carlos, 2005.

44. CAMARA, G.A.; DE LIMA, R.B.; IWASITA, T. Catalysis of ethanol electrooxidation: The influence of catalyst composition. Electrochemistry Communications, v. 6, p. 812-815, 2004.

45. SHIBATA, M.; FURUYA, N. Selective oxidation of the aldehyde functional group in the glycolaldehyde molecule at $\mathrm{Pt}$ electrodes modified by ad-atoms. Electrochimica acta, v. 39, n. 11/12, p. 1877-1880, 1994. 
46. WIELAND, B.; LANCASTER, J.P.; HOAGLUND, C. S.; HOLOTA, P.; TORNQUIST, W. J. Electrochemical and infrared spectroscopic quantitative detremination of the platinum-catalyzed ethylene glycol oxidation mechanism at $\mathrm{CO}$ adsorption potentials. Langmuir, v. 12, p. 2594-2601, 1996.

47. KASSIMI, EL-B.; ARCHIBONG, E.F.; THAKKAR, A.J. Hydrogen bonding in the glycolic acid dimmer. Journal of Molecular structure (Theochem), v. 591, p. 189197, 2002.

48. THAKKAR, A.J.; KASSIMI, EL-B. N; ARCHIBONG, Hu, S. Hydrogen-bonded complexes of glycolic acid with on and two water molecules. Chemical Physics Letters, v.387, p. 142-148, 2004. 
